\title{
A Review on Surface Stress-Based Miniaturized Piezoresistive SU-8 Polymeric Cantilever Sensors
}

\author{
Ribu Mathew ${ }^{1}$ A. Ravi Sankar ${ }^{1}$
}

Received: 3 November 2017/ Accepted: 2 January 2018/Published online: 2 February 2018

(C) The Author(s) 2018. This article is an open access publication

\section{Highlights}

- A critical review on the design, fabrication, and performance aspects of surface stress-based piezoresistive SU-8 polymeric cantilever sensors is presented.

- Specifics of evolution of surface stress-based piezoresistive cantilever sensors from solid-state semiconductor materials to SU-8 polymers are detailed.

- The interdependence of the material selection, geometrical design parameters, and fabrication process of cantilever sensors is explained.

- Challenges which limit the use of SU-8 cantilevers as a universal sensing platform are presented with potential solutions.

\begin{abstract}
In the last decade, microelectromechanical systems (MEMS) SU-8 polymeric cantilevers with piezoresistive readout combined with the advances in molecular recognition techniques have found versatile applications, especially in the field of chemical and biological sensing. Compared to conventional solid-state semiconductor-based piezoresistive cantilever sensors, SU-8 polymeric cantilevers have advantages in terms of better sensitivity along with reduced material and fabrication cost. In recent times, numerous researchers have investigated their potential as a sensing platform due to high performance-to-cost ratio of SU-8 polymer-based cantilever sensors. In this article, we critically review the design, fabrication, and performance aspects of surface stress-based piezoresistive SU-8 polymeric cantilever sensors. The evolution of surface stress-
\end{abstract}

A. Ravi Sankar

a.ravishan@gmail.com

Ribu Mathew

ribumathew88@gmail.com

1 School of Electronics Engineering (SENSE), Vellore Institute of Technology (VIT) Chennai, Chennai, Tamil Nadu 600127, India

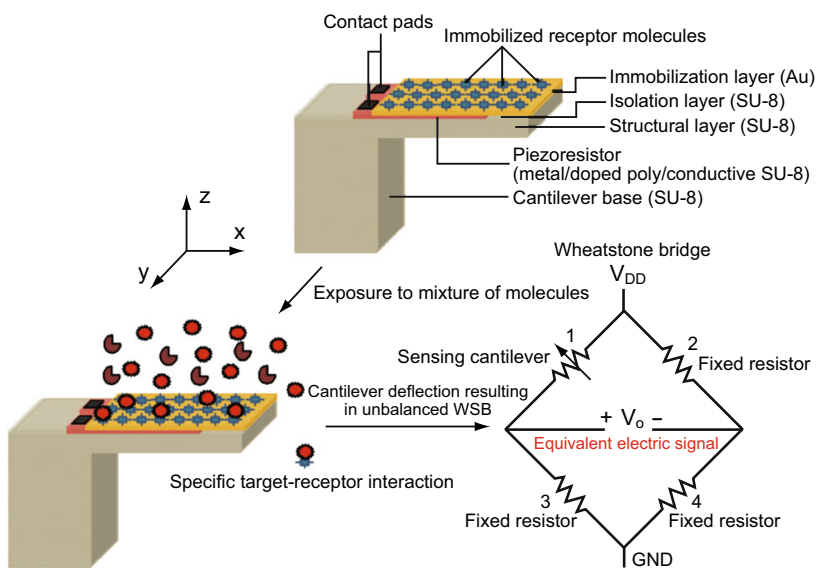

based piezoresistive cantilever sensors from solid-state semiconductor materials to polymers, especially SU-8 polymer, is discussed in detail. Theoretical principles of surface stress generation and their application in cantilever sensing technology are also devised. Variants of SU-8 polymeric cantilevers with different composition of materials in cantilever stacks are explained. Furthermore, the interdependence of the material selection, geometrical design parameters, and fabrication process of piezoresistive 
SU-8 polymeric cantilever sensors and their cumulative impact on the sensor response are also explained in detail. In addition to the design-, fabrication-, and performancerelated factors, this article also describes various challenges in engineering SU-8 polymeric cantilevers as a universal sensing platform such as temperature and moisture vulnerability. This review article would serve as a guideline for researchers to understand specifics and functionality of surface stress-based piezoresistive SU-8 cantilever sensors.

Keywords SU-8 polymer - Surface stress - Biological sensor · Cantilever · Chemical sensor · Piezoresistor . Immobilization

\section{Introduction}

Over the years, rapid progress made in micro-/nanoelectromechanical systems (MEMS/NEMS) technology has enabled researchers to develop novel investigation and diagnostic tools, especially in applications related to in situ chemical and biological sensing. This continuous development in the field of MEMS/NEMS has been propelled by the advancements in nano-science and micro-/nano-fabrication technologies [1-11]. MEMS-/NEMS-based cantilever platform sensors have been demonstrated as feasible alternative solutions to the conventional assaying tools due to their advantages of compactness, better sensitivity, lower detection limits, cost-effectiveness, and real-time operation [12]. Typical applications of micro-/nano-cantilever platform-based sensors for chemical and biological sensing include detection of explosives [13], pesticides [14], cancer tissues [15], antibodies [16], heavy metal [17], glucose [18], DNA [19], RNA [20], proteins [21], and viruses [22].

In cantilever-based chemical and biological sensors, target molecules are assayed by converting the mechanical deformation of cantilever platforms into an equivalent electrical signal. In this regard, receptor molecules which have affinity toward target molecules are immobilized on the sensor surface. When exposed to target molecules, target-receptor interactions take place on a sensor surface. These target-receptor interactions induce changes in cantilever characteristics that are in the form of either cantilever displacement (static mode) or change in its resonant frequency (dynamic mode). The aforementioned changes in cantilever characteristics are used to assay the type and quantity of target molecules. Although dynamic mode of measurement depicts higher resolution than static mode, it suffers from fluid damping effects that severely affect sensor sensitivity. In static mode, the measuring cantilever is typically placed in a micro-fluidic chamber with inlet and outlet valves designed in such a way that the fluid flow is laminar, reducing any noise from turbulence. Mechanical stability of the measuring cantilever especially against environmental vibrational noise is ensured by carefully designing the cantilever platform with a high value of resonant frequency. In addition, specific immobilization protocol and proper cleaning techniques reduce cross-sensitivity and biological noise floor. In static mode of operation, conversion of target-receptor interaction-induced deflection of the cantilever platform into an equivalent electrical signal is performed either by optical [23] or by electrical readout methods like piezoelectric [24], piezoresistive [25], and capacitive [26] techniques. Typically, in optics-based readout mechanisms, cantilever deflection is measured with a laser source that is incident on the cantilever surface and a position detector assembly that calibrates the cantilever deflection in terms of shift in laser spot from the initial position. Further, integrated optical readout on waveguides for cantilever sensors is also an alternative option [27]. Such opto-mechanical systems depict high resolution. However, in general optics-based readout methods suffer from limitations due to bulkiness of measurement setup, continuous need for realignment and recalibration, ineffectiveness in opaque medium, complexity in multiplexing, etc. Among the electrical readout techniques, piezoresistive readout is a highly preferred choice due to its advantages like compactness, better scalability, larger dynamic range, possibility of multiplexed operation, independence of operational medium, label-free detection, flexibility of on-chip or off-chip signal processing circuitry, compatibility with integrated circuit (IC) fabrication process flow, to cite a few. The aforementioned factors play a critical role in developing selfsensing, compact, and multi-functional sensors, especially for point-of-care testing (PoCT) and micro-total analysis systems ( $\mu \mathrm{TAS})$.

The micro-cantilever platforms were first utilized as atomic force microscopes (AFMs) for surface imaging applications. The potential application of micro-cantilevers as chemical sensors was first demonstrated by the group led by Prof. Thundat. Since then, in the past two decades, micro-cantilevers have been highly explored as mechanical sensing platforms for assaying various chemical and biological analytes. Initial AFMs were micro-machined on solid-state semiconductors. However, over the years, micro-cantilever-based sensors have been realized with different materials like semiconductor [28-35], metal [36], ceramic [37], plastic/polymer [38, 39], etc. The prime impetus for this endeavor by researchers to find an alternative material for semiconductor was mainly due to the limitation of semiconductor-based devices in terms of their 
fabrication cost. Among the polymers, SU-8-based piezoresistive cantilever sensors have been demonstrated to have better performance-to-cost ratio than their semiconductor counterparts.

In recent years, reviews on the development and overall performance characterization of cantilevers as sensing platforms have been reported [40-46]. Articles with insights into specific design aspects like enhancement of signal-to-noise ratio (SNR) by improving magnitude of surface stress [47], different immobilization protocols [48-50] are also available. In addition, treatise encompasses examples where researchers have devised the advancements made in polymer micro-machining [51] and polymer MEMS [52]. However, only a handful of researchers $[53,54]$ have focused on the development- and performance-related aspects of MEMS piezoresistive polymeric cantilevers, especially SU-8 polymer-based sensors. Not only there is a dearth of an article that focuses on the development of SU-8 polymeric piezoresistive cantilever surface stress sensors from their solid-state semiconductor counterparts, but also that provides in-depth specifics of the phenomenon of surface stress generation, details the rationale behind the shift from solid-state semiconductors to polymeric cantilevers, and performs critical examination of variants of SU-8 polymeric piezoresistive cantilevers based on material, design, and fabrication aspects.

In this review article, we critically examine the developments in SU-8 polymer-based piezoresistive cantilever sensors. Primary focus of this review is to provide comprehensive information on the development of piezoresistive SU-8 cantilever sensors with a focus on the design-, fabrication-, and performance-related aspects. Organization of this article is as follows: Sect. 2 details device configuration and working principle of piezoresistive SU-8 polymeric cantilever sensors. Due to their high surface-tovolume ratio, micro-cantilever platforms respond to changes in their own characteristics like mass and spring constant, and thereby to forces even in the range of a few $\mathrm{pN}$. Therefore, cantilever platforms have been extensively explored as mechanical sensing platforms. The cantilever platform-based sensors can be operated in either mass or end point deflection mode. Specifics of basic sensing modes of cantilever sensors are summarized in Sect. 3. Binding of chemical and biological analytes on the cantilever surface induces change in surface stress. Although surface stress-based sensors have found versatile applications, there is no clear understanding on the phenomenon of surface stress generation when target and receptor interact on a surface. The origin, type, and magnitude of surface stress generated due to different target-receptor interactions on cantilever surfaces along with different theoretical and experimental data related to surface stress are detailed in Sect. 4. Due to its origin from AFM, the initial piezoresistive cantilever platform surface stress sensors were based on solid-state semiconductors. The evolution of polymeric cantilevers from their semiconductor counterparts is summarized in Sect. 5. In the last two decades, the piezoresistive element in SU-8 piezoresistive cantilever sensors has been realized with different materials. Specifics of variants of piezoresistive SU-8 polymeric cantilevers which include their classification, structural details, and functional features are explained in Sect. 6. Variants of piezoresistive SU-8 cantilever sensor differ in geometrical design as well as fabrication aspects. The fabrication details of different classes of piezoresistive SU-8 polymeric cantilever sensors covering the fabrication process involved in the same are summarized in Sect. 7. Soon after its inception, SU-8 piezoresistive cantilever sensors have been used as an investigation and detection tool for assaying versatile chemical and biological entities. Typical applications of SU-8 polymeric cantilevers as chemical and biological sensors are summarized in Sect. 8. Finally, in Sect. 9, we discuss the challenges, possible solutions, and future perspectives of SU-8 polymer-based piezoresistive cantilever sensors as the next-generation sensing tool.

\section{Generic Device Details and Working Principle}

To accomplish specific detection of target molecules in a given sample, cantilever-based sensors are operated in either static or dynamic mode. In the dynamic mode, cantilever measures the change in its mass when targetreceptor interactions take place on its surface, whereas in the static mode, the addenda of target molecules are assayed by measuring the net cantilever deflection. More specifics of both the sensing modes and the rationale why static mode sensing is preferred over dynamic sensing method will be explained in the later sections of the article.

In static mode, SU-8 polymer-based piezoresistive cantilever sensors constitute mainly three components: a mechanical platform, a transduction element, and functional layers. Typical top and cross-sectional views of a piezoresistive SU-8 polymeric cantilever sensor are shown in Fig. 1. The sensor consists of the following layers (from the top): (1) an immobilization layer, (2) an isolation layer, (3) a piezoresistive layer, and (4) a structural layer. For illustration, we have considered a composite slender rectangular cantilever with a U-shaped piezoresistor confined near the central base region of the cantilever. It may be noted that the coverage of piezoresistor on the cantilever and the cantilever platform geometry may vary depending on the piezoresistor material (metal, doped polysilicon, or doped polymer), desired nominal resistance, fabrication 

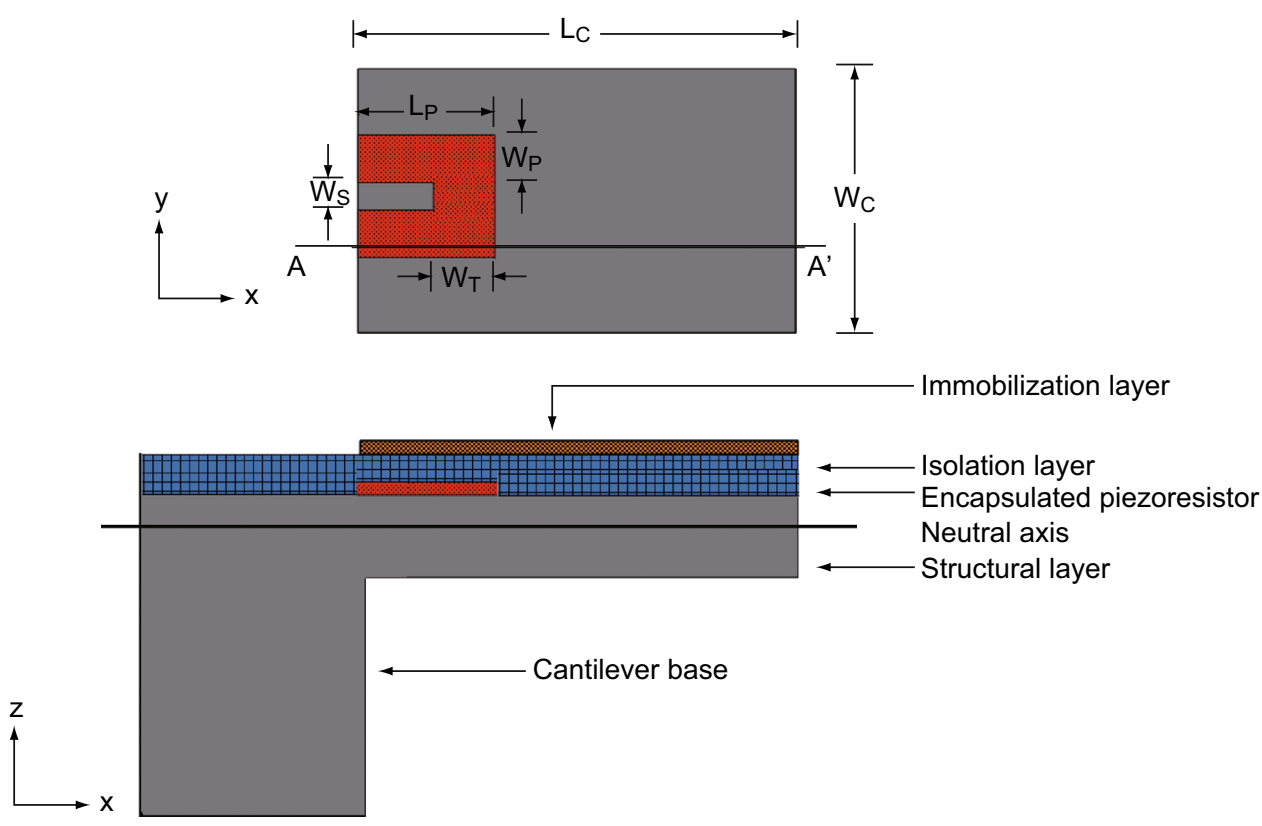

Fig. 1 A top view (without the immobilization and isolation layers) and a cross-sectional view (across AA') of a composite piezoresistive polymeric micro-cantilever sensor. Symbols $L_{\mathrm{C}}$ and $W_{\mathrm{C}}$ represent the cantilever length and width, respectively, whereas the symbols $L_{\mathrm{P}}, W_{\mathrm{P}}, W_{\mathrm{T}}$, and $W_{\mathrm{S}}$ depict the piezoresistor length, leg width, transverse leg width, and leg space between two piezoresistor strips, respectively

processes used to realize the sensor, and a specific application.

When the geometrical features of SU-8 polymeric cantilever sensors (with metal/doped polysilicon/doped composite SU-8 piezoresistors) are compared with solid-state semiconductor cantilevers especially silicon cantilevers with either diffused or ion-implanted piezoresistors reported in the literature the following observations are made: (1) Typically, SU-8 polymeric cantilevers are either threeor four-layered structures (depending on the presence of gold immobilization layer), whereas silicon-based cantilevers are two-layered (without gold) or three-layered (with gold) structures; (2) in SU-8 polymeric cantilevers, the piezoresistor is realized by deposition techniques or spin coating, whereas in silicon cantilevers the piezoresistor is either a diffused or ion-implanted resistor; and (3) in SU-8 polymeric cantilevers, the surface is immobilized by either alkanethiol protocol (gold immobilization layer) or direct chemical modification of SU-8, whereas in silicon cantilevers typically alkanethiol immobilization protocol for gold surface or siloxane immobilization protocol on silicon dioxide surface is performed. On comparing the performance characteristics, both classes depict similar electrical sensitivity with geometrical optimization. Both sensor classes have their characteristic features governed by constituent material set and realization techniques. For instance, silicon cantilever sensors are based on traditional fabrication techniques and can easily be integrated with onchip signal processing based on CMOS technology. In recent years, continuous improvement in the performance of silicon cantilever sensors has been reported by innovative engineering techniques [55-65]. Silicon cantilevers depict excellent stability against moisture and have better thermal stability. On the other hand, SU-8 polymeric cantilevers show a relatively high performance-to-cost ratio due to low material and fabrication cost. It may be noted that SU-8 polymeric cantilevers show vulnerability toward moisture and temperature variations. However, by controlling the process parameters during sensor realization and by careful sensor module design the vulnerability toward moisture and temperature effects can be reduced as discussed in the later section of this article. Thus, despite various limitations in recent years, there has been much focus on developing SU-8 polymeric cantilever micro-devices for chemical and biological sensing applications.

Structural layer of the cantilever forms the mechanical platform which not only provides mechanical stability to the sensor, but also acts as a stress collector. To perform the electromechanical transduction of structural deformation of the cantilever into an equivalent electrical signal, a piezoresistive layer is deposited atop or doped in the structural layer. Functional layers of the sensor include an isolation layer and an immobilization layer. For reliable operation of the sensor in liquid medium, the piezoresistor is encapsulated by an isolation layer, whereas the cantilever surface is grafted or immobilized with receptors that have high affinity toward the target molecules. Target-receptor interactions on the cantilever surface result in 
redistribution of energy states on the cantilever surface which is translated into a net cantilever deflection. Even though immobilization of receptors can be performed on the isolation layer, to improve the magnitude of surface stress generated on the cantilever platform, a separate immobilization layer is preferred [50].

In general, SU-8 piezoresistive cantilever sensors are realized using micro-fabrication techniques of spin coating, deposition, photolithography, and etching. At the circuit level, to reduce cross talk and improve signal-to-noise ratio (SNR), piezoresistive SU-8 cantilevers are connected in a Wheatstone bridge (WSB) configuration. A few representative figures of SU-8 cantilevers, image of sensor device chips at wafer level and a close-up view of sensor module of piezoresistive SU-8 cantilevers connected in a WSB configuration are depicted pictorially in Figs. 2, 3, and 4, respectively. Scanning electron microscope images of an SU-8 rectangular cantilever platform, cantilever arrays, and side view of a single cantilever are shown in Fig. 2. Images of an array of batch-fabricated device chips and individual constituent sensor modules of piezoresistive SU-8 cantilevers are shown in Fig. 3. Here, each device chip comprises of four carbon black (CB)-doped SU-8 polymeric cantilevers. An image of SU-8 polymeric cantilever sensor with serpentine-shaped gold piezoresistor is shown in Fig. 4. Typically, serpentine shape of piezoresistors is chosen when metal piezoresistors are used. The rationale behind the premise is to increase the nominal resistance of the piezoresistor. The graphic also represents a WSB-based circuitry, where the measuring cantilever forms one arm of the bridge. Other resistors are formed by the reference cantilever and on-chip resistors.

Detailed functionality of piezoresistive readout-based SU-8 polymeric cantilever chemical/biological sensors is depicted in Fig. 5. The immobilization layer is chemically modified and immobilized with receptor molecules that have high affinity toward target molecules. Immobilization of receptor molecules is performed using techniques like incubation of cantilever arrays in micro-capillaries, microcontact printing, and inkjet delivery. It is ensured that the immobilization of receptors is only in one surface of the cantilever face on either the top or the bottom. This selective immobilization process ensures generation of differential surface stress. The piezoresistor is typically placed on the region (with respect to neutral plane) where the immobilization surface is present for maximizing electrical sensitivity. When exposed to mixture of molecules, specific target-receptor interactions/bindings result in differential surface stress-induced cantilever bending. The target-receptor bindings result in the generation of either a compressive surface stress or a tensile surface stress leading to either a downward or an upward cantilever bending, respectively. Under mechanical loading, the nominal resistance of the piezoresistor $(R)$ placed inside the cantilever stack changes, resulting in either an increase $(+\Delta R)$ or a decrease $(-\Delta R)$ in its value. When the piezoresistive cantilever is placed in one arm of a balanced WSB, with change in its nominal resistance value there is a voltage in the WSB output. The voltage signal is equivalent to the net surface stress generated on the cantilever surface due to target-receptor interactions. A graphical representation of the cantilevers connected in a WSB configuration depicting target-receptor interactions is shown in Fig. 6.

The conversion of target-receptor interactions into an equivalent electrical signal is also possible either by using only the piezoresistive cantilever or by connecting the piezoresistive cantilever along with a fixed resistor in a voltage divider (half-bridge) configuration driven by an excitation source. Although the aforementioned methods are relatively simple to implement, a WSB configurationbased readout method offers advantage in terms of reduced thermal drift sensitivity and nullifying the initial drift in sensor output [70]. Further, it has been found that the temperature drift compensation of a WSB can be improved
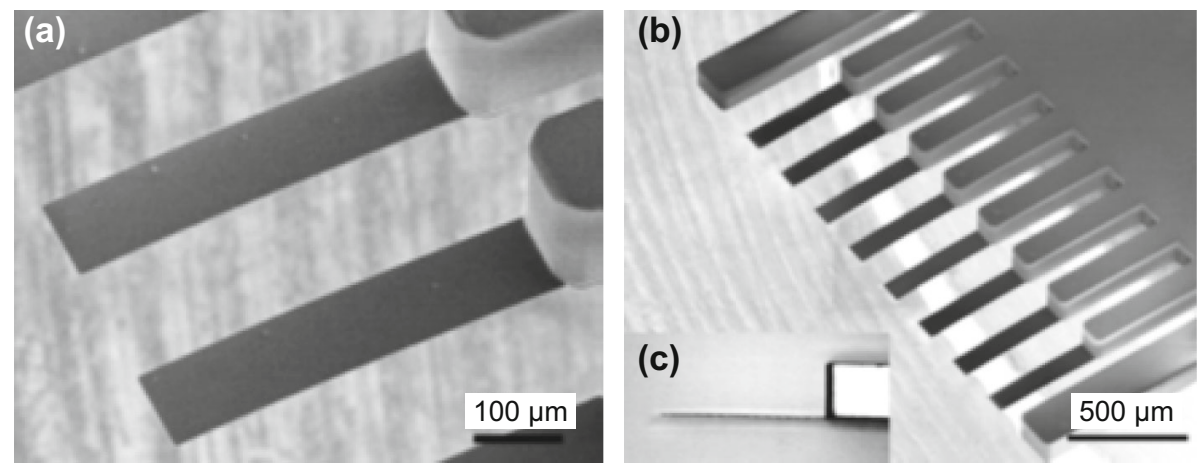

Fig. 2 Images of SU-8 cantilever sensor arrays: a, b dimensions $\left(L_{\mathrm{C}} \times W_{\mathrm{C}} \times T_{\mathrm{C}}\right)=300 \times 100 \times 2 \mu \mathrm{m}^{3}$, and $\mathbf{c}$ side view of a SU-8 cantilever. Adopted from Ref. [66]. Copyright (2010) IOP Publishing 


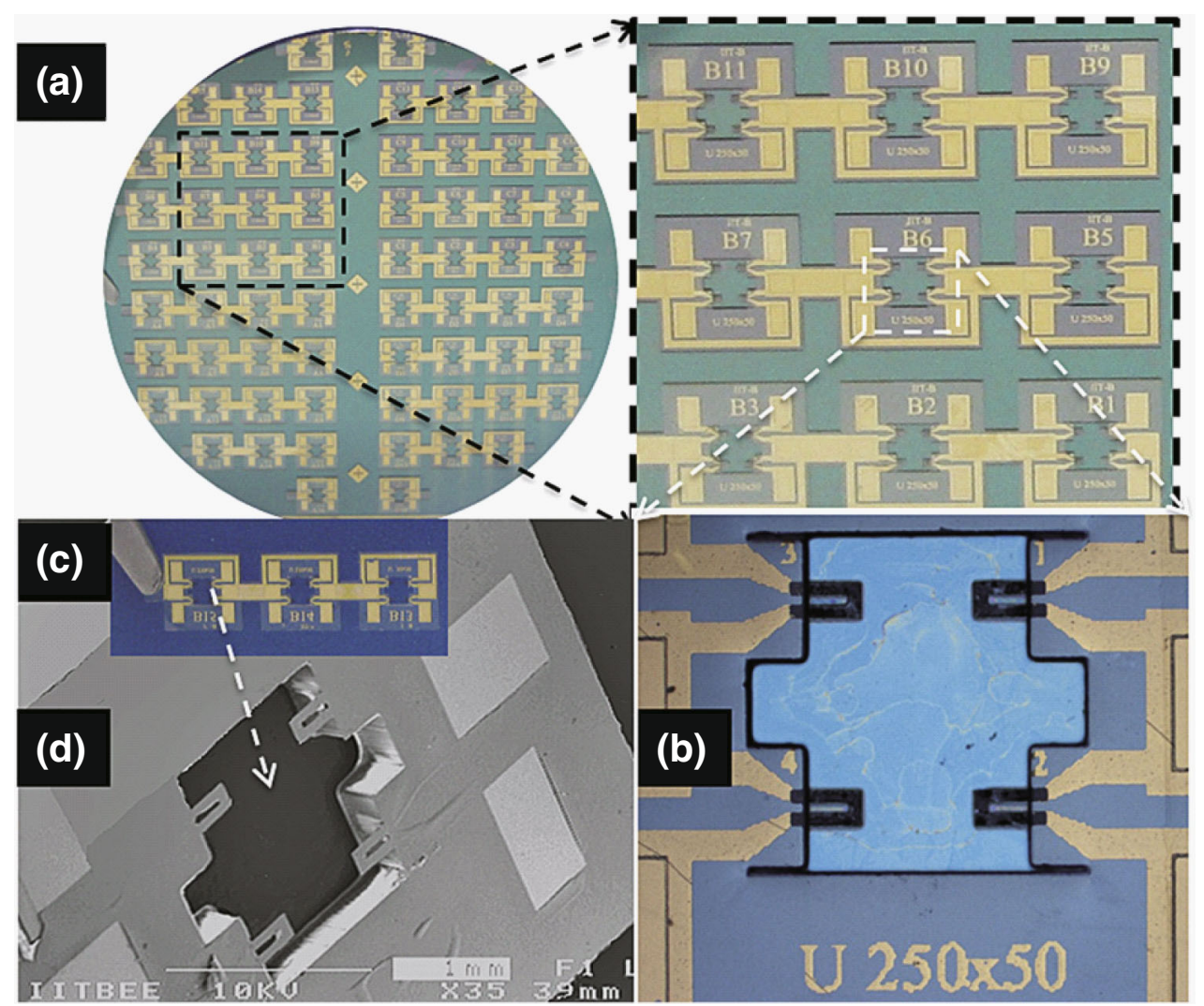

Fig. 3 Piezoresistive SU-8 cantilever sensors: a an image of processed silicon wafer with a zoom-in view of the sensor device arrays attached to the wafer before release. $\mathbf{b}$ An image of one of the device chips in the array with four rectangular cantilevers. c Array of sensor device chips after the release, and $\mathbf{d}$ one of the device chips. Adopted from Ref. [67]. Copyright (2011) IOP Publishing
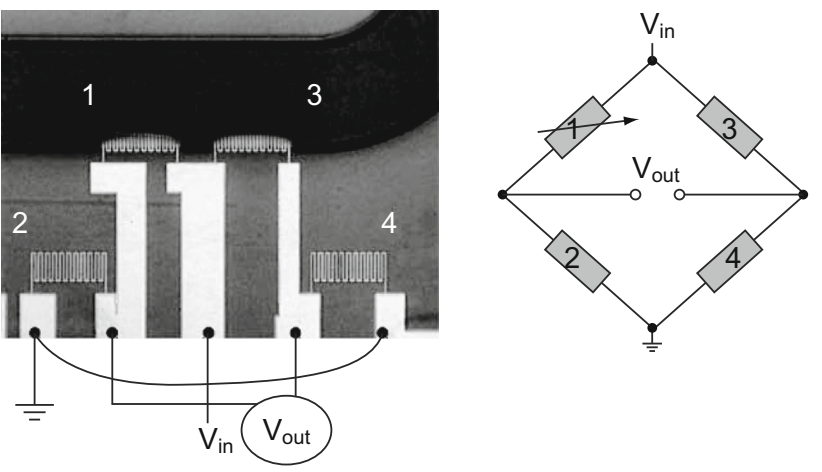

Fig. 4 Optical image of a serpentine Au piezoresistor-based SU-8 polymeric cantilever connected in a Wheatstone bridge (WSB) configuration. Adopted from Ref. [68]. Copyright (2005) Elsevier B.V.

by a factor of more than two orders of magnitude when a thermally symmetric design is used instead of a conventional WSB configuration. Additional feedback resistors can also be used for temperature compensation. WSB is excited by either a voltage source or a current source with its magnitude limited by power dissipation of the sensor.
Typically, output signal from the WSB is conditioned (amplified) using an instrumentation amplifier (INA). Apart from WSB measurement, other measurement techniques have been also reported. For instance, it has been reported that through current excitation of half-bridges, insensitivity against thermoelectric and stray noise can be obtained with a measurement resolution of parts per million (ppm) [71]. Further, the differential amplifier-based measurement instead of WSB has been also reported in the literature [72].

At the system level, typically for detecting the target molecules especially in the case of biological sensing applications, the cantilevers are placed in a micro-fluidic channel comprising an inlet valve, a channel and an outlet valve as shown in Fig. 7. In chemical sensing systems, the cantilevers are housed in a gas chamber with inlet and outlet valves through which mixture of gas samples are pumped for detection.

A typical time response plot of a piezoresistive cantilever sensor depicting various stages of generation of surface stress upon target-receptor interactions as a function of change in voltage is shown in Fig. 8. This particular example depicts the variation in sensor output voltage 


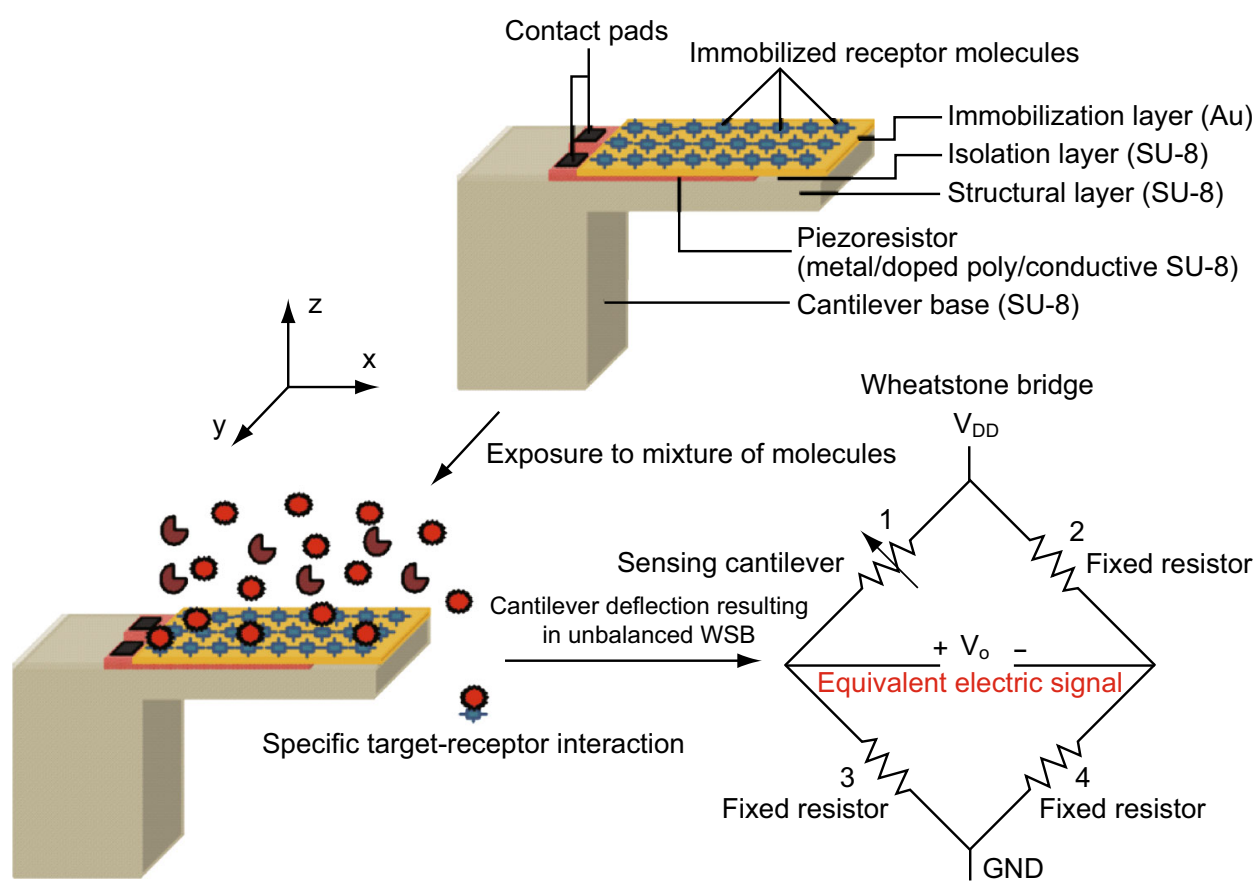

Fig. 5 Working principle of piezoresistive SU-8 polymeric micro-/nano-cantilever sensors for chemical/biological sensing applications

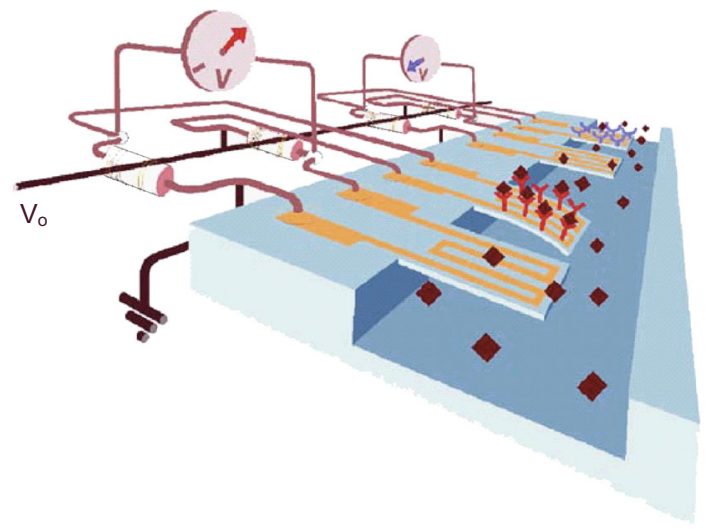

Fig. 6 Graphics of a serpentine gold (Au) piezoresistor-based cantilever depicting target-receptor interactions and connected in a Wheatstone bridge (WSB) configuration. Adopted from Ref. [69]. Copyright (2009) Elsevier Ltd.

when specific detection of mercaptohexanol molecules is performed on a gold-coated cantilever immobilized with alkanethiol protocol. There are three stages of sensor response: (1) initial stage: when a stable sensor output is observed due to coating on cantilever surface with selfassembled monolayers (SAMs) of receptors; (2) transition stage: when sensor is exposed to target molecules targetreceptor bindings take place on cantilever surface and there is a significant change in sensor terminal voltage; and (3) saturation stage: after the target-receptor pair binding is

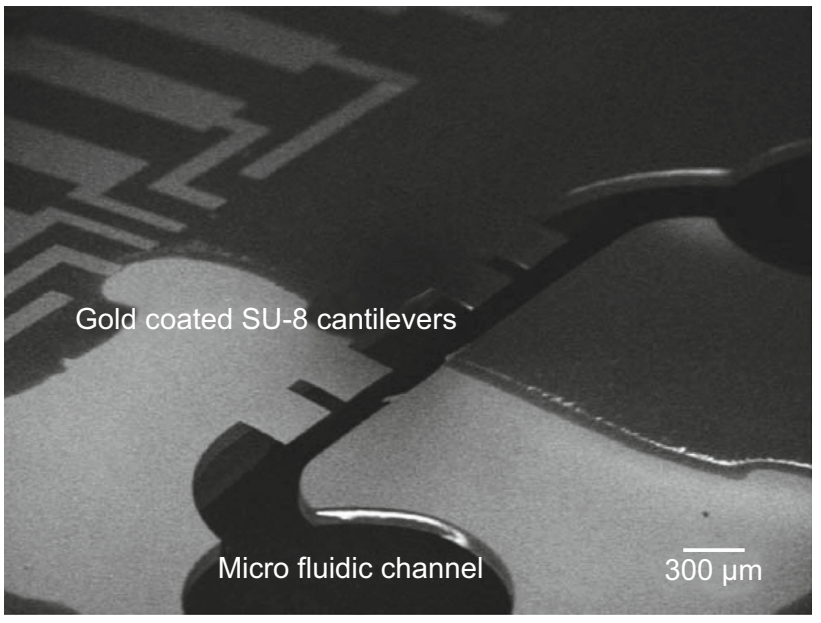

Fig. 7 Image of gold-coated SU-8 cantilevers placed in a microfluidic channel. Adopted from Ref. [68]. Copyright (2009) Elsevier Ltd.

completed and the change in surface stress saturates, the sensor output becomes constant.

\section{Sensing Modes}

Typically, cantilever sensors are used to assay a specific target molecule or different targets from a mixture of molecules. To accomplish specific target detection, one 


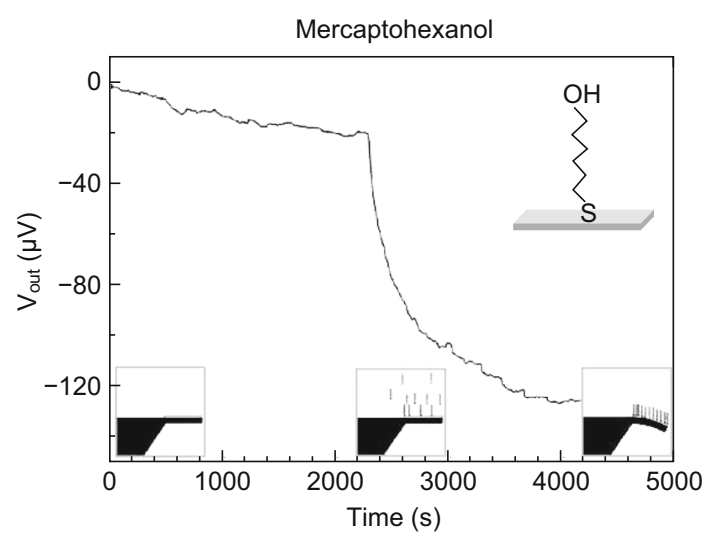

Fig. 8 Time response of a piezoresistive cantilever sensor for specific detection of mercaptohexanol. Adopted from Ref. [68]. Copyright (2005) Elsevier B.V.

side of the cantilever is chemically modified with receptors which have high affinity toward the target molecules by an immobilization or grafting process. The specific targetreceptor interactions on the cantilever surface can be assayed in terms of either cantilever deflection or change in resonant frequency. In this section, the two operational modes of cantilever sensors are detailed.

\subsection{Dynamic Mode}

In dynamic mode of operation, change in mass of the cantilever platform due to the addition of target molecules is measured in terms of change in its resonant frequency. The receptor molecules are coated on either one side or both sides of the cantilever platform. The resonant frequency $\left(f_{0}\right)$ of a cantilever platform is mathematically given by Eq. 1 [73]:

$f_{0}=\frac{1}{2 \pi} \sqrt{\frac{k}{m}}$

where the symbols $k$ and $m$ represent the flexural rigidity and mass of the cantilever platform, respectively. Resonant frequency of a cantilever is a function of its geometry and constituent material properties. When target molecules bind to the receptors on the cantilever surface, the resonant frequency of the cantilever changes as given by Eq. 2 .

$f_{0}^{*}=\frac{1}{2 \pi} \sqrt{\frac{k}{m+m^{*}}}$.

Change in the resonant frequency depends on the total mass of the target molecules given as $m^{*}=n \times m_{\mathrm{i}}$, where $n$ is the total number of target molecules and $m_{\mathrm{i}}$ is the mass of a single target molecule. Shift in the resonant frequency that gives a measure of the target molecules on the cantilever surface is given as $\Delta f=f_{0}-f_{0}^{*}$. In dynamic mode of operation, mass detection resolution as low as yoctogram $\left(10^{-24} \mathrm{~g}\right)$ has been reported in the literature [74]. Similarly, the typical value of surface stress resolution measured is in the range of $1-4 \mathrm{mN} \mathrm{m}^{-1}$ [75]. A measure of the performance of dynamic sensors is its quality factor (Q-factor), which determines the sharpness of resonance peak. Ideally, the Q-factor of a dynamic mode sensor should be infinity for maximizing the minimum detection limits. The Q-factor of a dynamic sensor is reduced mainly due to intrinsic material and extrinsic environmental damping loss [76]. Compared to solid-state semiconductor materials, the material damping loss in polymers is more, which results in reduced Q-factor. Typical values of Q-factor of SU-8 cantilever resonators when operated in air and water are approximately 28 and 1, respectively [77].

Even though high detection resolution is obtained by dynamic mode of sensing, this scheme suffers from limitations such as ineffectiveness in liquid medium due to large fluid damping losses [78], and dependence of resonant frequency shift on the position of target molecule binding site on the cantilever platform [79, 80]. For biological sensing applications, the medium of operation is predominantly liquid. When dynamic sensors are operated in fluids with high viscosity, large fluid/viscous damping results in reduced sensitivity. The positional dependence of shift in the resonant frequency of a cantilever sensor operated in dynamic mode is shown in Fig. 9. When the target-receptor interactions occur near the free end of the cantilever, there is a decrease in resonant frequency, whereas the magnitude of resonant frequency increases when target-receptor interactions takes place near the cantilever fixed end. This is due to the interplay between competing factors of the "mass" and the "flexural rigidity" of the cantilever platform in determining its resonant frequency. When target-receptor interactions occur near the free end of the cantilever, mass effect dominates, resulting in a decrease in the resonant frequency. On the other hand, when the target-receptor bindings occur near the fixed end of the cantilever, flexural rigidity dominates, resulting in a net increase in the magnitude of the resonant frequency. However, due to this dependence of resonant frequency on the position of target-receptor interaction on the cantilever, it is important that in dynamic mode, the cantilever is not fully coated with receptor molecules. This constraint on the coverage area of receptor molecules results in reduced biological sensitivity of the sensor.

\subsection{Static Mode}

In static mode of operation, the net cantilever deflection due to target-receptor interactions is measured. Receptor molecules are coated on one side of the cantilever platform. When exposed to target molecules, specific target-receptor 


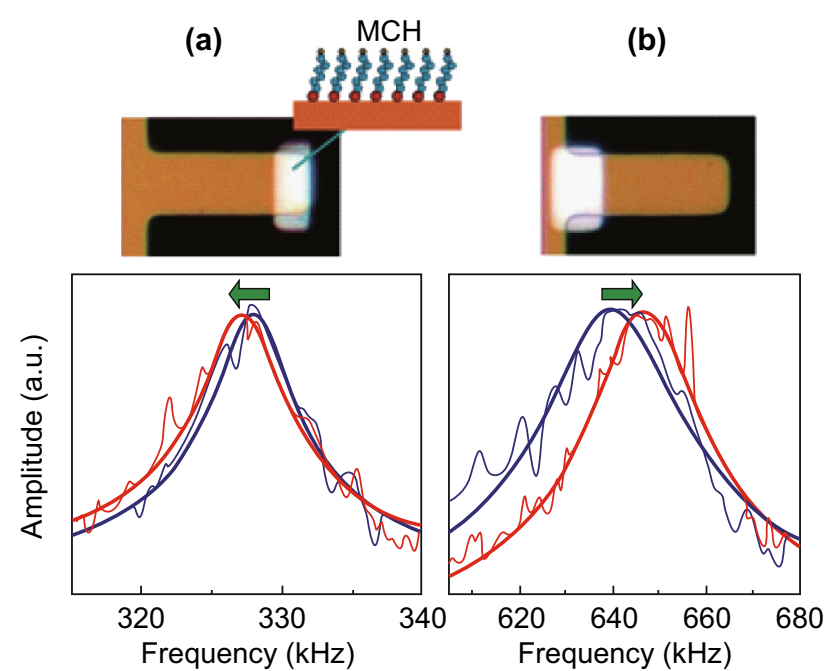

Fig. 9 Optical images of cantilevers with selectively coated gold layer coated with self-assembled monolayer (SAM) of mercaptohexanol $(\mathrm{MCH})$. Response of a cantilever operated in dynamic mode: $\mathbf{a}$ with the gold layer near the free end and $\mathbf{b}$ with the gold layer near the fixed end. The graphs represent the resonance peaks of the cantilever before (blue line) and after (red line) adsorption of $\mathrm{MCH}$. Adopted from Ref. [81]. Copyright (2009) American Chemical Society. (Color figure online)

bindings on the cantilever cause variation in the surface energy states (surface stress) of the cantilever that are nullified by a net cantilever deflection. Depending on the type of target species, the cantilever bends in either the upward or downward direction [45]. Theoretical computation of the net cantilever displacement corresponding to the difference in the magnitude of surface stress $\left(\Delta \sigma_{\mathrm{s}}\right)$ between the opposite cantilever faces was first devised by Stoney that is mathematically represented by Eq. 3 [82]:

$\Delta Z=\frac{3 L_{\mathrm{C}}^{2}(1-v)}{E t_{\mathrm{C}}^{2}} \Delta \sigma_{\mathrm{s}}$,

where $\Delta Z$ is the cantilever displacement corresponding to the surface stress difference. The symbols $L_{\mathrm{C}}, t_{\mathrm{C}}, v$, and $E$ represent the cantilever length, cantilever thickness, Poisson's ratio, and Young's modulus of the cantilever material, respectively. More accurate modeling of surface stress-based cantilever deflections considering the clamping of fixed end of the cantilever was performed by Sader [83]. Comprehensive specifics of surface stress modeling and the response of cantilever platforms under surface stress loading can be found in [84-86]. Typical magnitude of surface stress generated on the cantilever when chemical and biological molecules interact with cantilever surface is in the range of a few $\mathrm{mN} \mathrm{m}^{-1}$ to a few $\mathrm{N} \mathrm{m}^{-1}$ that induces cantilever deflection in the range of a few $\mathrm{nm}$ to $\mu \mathrm{m}$, respectively. Ultra-sensitive MEMS cantilever platforms present a viable solution to detect such minuscule forces due to their high surface-to-volume ratio. However, cantilever geometry has to be tailored by careful design (with its flexural rigidity in the range from $0.1 \mathrm{mN} \mathrm{m}^{-1}$ to $10 \mathrm{~N} \mathrm{~m}^{-1}$ ) so that the cantilever is compliant to changes in target-receptor interactions-induced surface stress. The target-receptor interactions result in either an upward or downward deflection of the cantilever. The downward cantilever bending is due to the generation of compressive stress, i.e., decrease in surface energy, whereas the upward cantilever bending is attributed to tensile stress, i.e., increase in surface energy. Using surface stress-based cantilever sensors, deflection sensitivity, minimum detectable deflection, surface stress sensitivity, and minimum detectable surface stress of $0.3 \mathrm{ppm} \mathrm{nm}^{-1}, 4 \AA$, $3 \times 10^{-4}(\mathrm{Nm})^{-1}$ and $1.4 \times 10^{-4}(\mathrm{Nm})^{-1}$, respectively, have been reported in the literature [87]. An artistic representation of specific target-receptor interactions (DNA hybridization) on cantilevers is shown in Fig. 10 [88]. Figure 10a represents two cantilevers immobilized with two different oligonucleotides or single-strand DNA (ssDNA). The subsequent phase of injection of the complementary DNA strands of oligonucleotides (in red color) is shown in Fig. 10b. Injection and hybridization processes of another set of oligonucleotides (in blue color) are represented in Fig. 10c. Schematic also depicts the downward deflection of the cantilever when DNA hybridization takes place on the cantilever surface. The downward deflection of the cantilever indicates that in this case the surface stress generated due to DNA hybridization is compressive in nature.

A comparison of dynamic and static modes of sensing using a cantilever as the mechanical platform for chemical and biological sensing applications is summarized in Table 1. Compared to static mode of operation, dynamic mode suffers from reduced sensitivity and erroneous measurement due to fluid damping effects. Sensitivity loss due to material damping is prominent, especially in polymeric cantilevers attributed to the high intrinsic material loss of polymers [42]. Even though the performance of cantilevers operated in dynamic mode can be improved by using higher modes of vibration, the reduced amplitude of oscillation makes the readout challenging. In addition, dynamic mode of measurement suffers from the limitation due to stiffness-induced shift in resonant frequency by the adsorbates apart from the mass of target molecules restricting the immobilization area which results in reduced biological sensitivity.

In this regard, static mode of measurement has advantages in terms of reduced dependency of measurement on external ambient and intrinsic material parameters, and better performance in liquid medium which is desirable for chemical and biological sensing applications. When operated in static mode with self-sensing piezoresistive readout, 


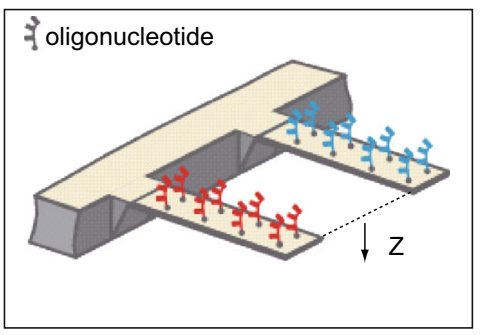

(a)

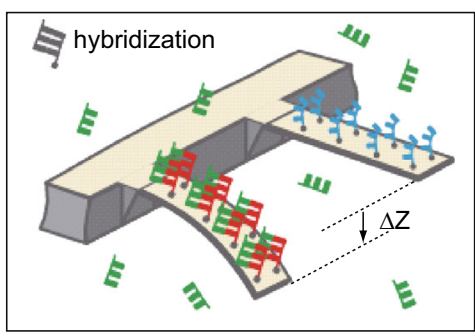

(b)

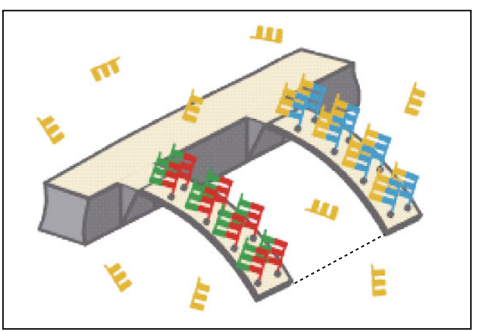

(c)

Fig. 10 Schematic representation of specific DNA hybridization process and the resultant cantilever deflection. a Oligonucleotides with different bases (red and blue) coated on top surface of the cantilevers. Both the cantilevers have net zero displacement. b Injection of matching complementary oligonucleotides of base represented in red results in a net deflection of the cantilever due to hybridization. c Injection of matching complementary oligonucleotides of base represented in blue results in hybridization-induced deflection. Figures are adopted from Ref. [88]. Copyright (2000) The American Association for the Advancement of Science. (Color figure online)

Table 1 Comparison of static and dynamic sensing modes of cantilever platforms

\begin{tabular}{|c|c|c|c|}
\hline \multirow[t]{2}{*}{ Parameters } & & \multicolumn{2}{|l|}{ Sensing modes } \\
\hline & & Dynamic & Static \\
\hline Sensing principle & & $\begin{array}{l}\text { Measurement of change in resonant frequency due to change in } \\
\text { mass and/or spring constant } \\
\text { Measurement of resonant frequency due to change in surface } \\
\text { stress }\end{array}$ & $\begin{array}{l}\text { Measurement of cantilever displacement due } \\
\text { to change in surface stress }\end{array}$ \\
\hline Features & & $\begin{array}{l}\text { Receptors are immobilized on either one side or both sides of the } \\
\text { cantilever } \\
\text { Sensitivity can be improved by operating the cantilever at higher } \\
\text { modes }\end{array}$ & $\begin{array}{l}\text { Receptors are immobilized on one side of the } \\
\text { cantilever } \\
\text { Sensitivity can be improved by incorporating } \\
\text { stress concentration regions }\end{array}$ \\
\hline Limitations & & $\begin{array}{l}\text { Erroneous due to adsorbate-induced changes in stiffness } \\
\text { Susceptible to fluid damping effect } \\
\text { Susceptible to material damping effect } \\
\text { Dependence of change in resonant frequency on position of the } \\
\text { target molecule on the cantilever }\end{array}$ & $\begin{array}{l}\text { Structural nonlinearity due to large } \\
\text { deflection of the cantilever } \\
\text { Dependence of surface stress generation on } \\
\text { immobilization protocols }\end{array}$ \\
\hline $\begin{array}{l}\text { Suitability for } \\
\text { measurement }\end{array}$ & $\begin{array}{l}\text { Liquid } \\
\text { Air }\end{array}$ & $\begin{array}{l}\text { Low } \\
\text { High }\end{array}$ & $\begin{array}{l}\text { High } \\
\text { High }\end{array}$ \\
\hline Resolution & & Mass: $10^{-24} \mathrm{~g}[74]$ & Cantilever deflection: $4 \AA$ [87] \\
\hline
\end{tabular}

the performance of cantilever can be improved by incorporating stress concentration regions [89-92]. The stress concentration regions (SCRs) act as mechanical amplifiers of stress generated due to cantilever bending, thereby improving electrical sensitivity. In addition, when operated in static mode, polymeric cantilevers depict high displacement sensitivity due to low Young's modulus of polymers which translates into higher electrical sensitivity. Therefore, compared to dynamic mode, static mode of operation is preferred for polymeric cantilever-based surface stress sensors, especially for chemical and biological sensing applications.

\section{Theory of Surface Stress}

The minuscule attractive or repulsive forces that occur on a cantilever surface due to change in its electronic energy states or charge distribution when target-receptor interactions take place on it are known as surface stress. Over the last two decades, more than 50 analytes (chemical and biological molecules) have been assayed using cantilever sensing technology [44]. A graphical representation of the versatility in the size of the analytes assayed is shown in Fig. 11. As evident, the analytes vary not only in terms of their mass, but also in their morphology. Even though surface stress-based cantilever sensors have been widely explored and studied for various applications, the origin of 
surface stress is still not clear and an in-depth understanding on its basic physics is still to be achieved. In this section, we briefly discuss about various theories proposed by researchers to comprehend the origin of surface stress.

A few researchers have carried out experimental studies to understand the origin of surface stress, and the details are tabulated in Table 2.

Even though the concept of surface stress was known from 1900s [93], its application using micro-cantilever structure for sensing was used by Thundat et al. in 1994 . Followed by this work on surface stress sensors by the researchers from Thundat et al. group, a few more research articles involving cantilevers were reported by other researchers. Yet, a clear understanding on the origin of surface stress was not reported. Therefore, a few researchers carried out systematic experimental investigation to understand the origin of surface stress. Fritz et al. [88] in the year 2000 were the first to study the origin of surface stress by investigating Watson-Crick base pairing of DNA strands using cantilevers as sensing platform. They have conducted experiments using silicon cantilever coated with gold layer (cantilever dimensions: $L_{\mathrm{C}} \times W_{\mathrm{C}} \times$ $T_{\mathrm{C}}=500 \times 100 \times 1 \mu \mathrm{m}^{3}$, pitch $=250 \mu \mathrm{m}$, spring constant $=0.02 \mathrm{~N} \mathrm{~m}^{-1}$, surface coverage: $10 \times 10^{10}$ oligonucleotides per cantilever). They observed a compressive surface stress on Au-immobilized side of a cantilever due to a DNA hybridization process. The origin of surface stress was attributed to electrostatic, steric, and hydrophobic interactions. The electrostatic and steric interactions that were attributed to charge transfer and chain packing density were found to be repulsive in nature, generating a compressive surface stress. The magnitude of compressive surface stress was reported as $5 \mathrm{mN} \mathrm{m}^{-1}$ which is equivalent to an actuating force of $300 \mathrm{pN}$. Subsequently, in the year 2001, Wu et al. [94] reported that the interdependence of configurational entropy changes and intermolecular energetics results in surface stress during DNA hybridization, where the former plays a critical role in determining the direction of cantilever bending. Experiments were conducted with V-shaped silicon nitride cantilevers (V-shaped silicon nitride cantilever coated with $\mathrm{Au}$ cantilever details: $L_{\mathrm{C}} \times W_{\mathrm{C}} \times T_{\mathrm{C}}=200 \times 20 \times 0.5$ $\mu \mathrm{m}^{3}$, Au film thickness $=25 \mathrm{~nm}$ with 5 -nm chrome for adhesion, surface density of probes: $6 \times 10^{12}$ chains $\mathrm{cm}^{-2}$ ). The group also postulated that the chain length and phosphate buffer (PB) solution concentration also play a vital role in determining cantilever bending. They reported that the immobilization of ssDNA on a cantilever surface generates a net compressive surface stress resulting in downward deflection of the cantilever. However, contrary to the results reported by Fritz et al. [88], their experiments showed that DNA hybridization resulted in tensile surface stress which relieves the compressive stress generated during immobilization process. They also concluded that since the hybridization process always generated tensile surface stress relieving the initial compressive stress, electrostatic and steric interactions are not the only cause of surface stress. The additional factor that resulted in the curvature of cantilevers was proposed as the configurational entropy.

Later in 2002, MeKendry et al. [95] demonstrated that a DNA hybridization process generates a compressive surface stress of $2.7 \mathrm{mN} \mathrm{m}^{-1}$ on Au-coated cantilevers (rectangular silicon cantilevers coated with 2-nm Ti adhesion layer and $20-\mathrm{nm} \mathrm{Au}$ layer, $L_{\mathrm{C}} \times W_{\mathrm{C}} \times$ $T_{\mathrm{C}}=500 \times 100 \times 1 \mu \mathrm{m}^{3}$, pitch $250 \mu \mathrm{m}$ and spring
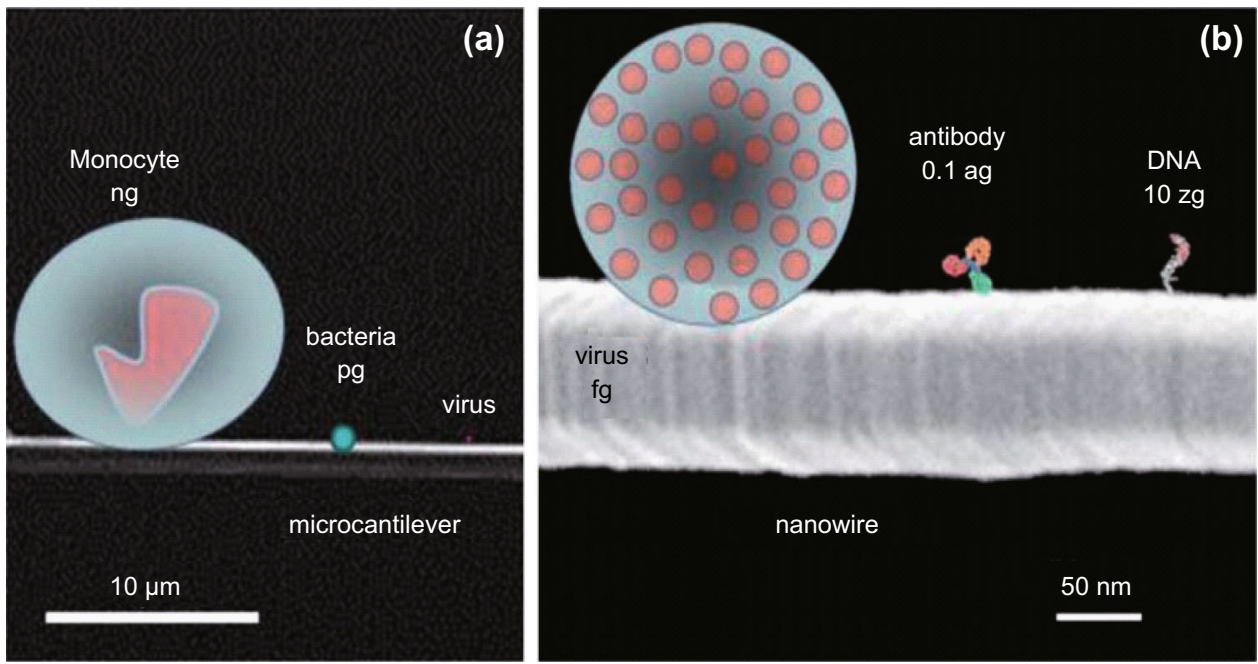

Fig. 11 Pictorial representation of different analytes with special emphasis on their size and mass. Adopted from Ref. [44]. Copyright (2012) The Royal Society of Chemistry 
Table 2 Experimental details of the origin, type, and magnitude of surface stress generated due to different target-receptor interactions on cantilever platform

\begin{tabular}{|c|c|c|c|c|c|c|}
\hline $\begin{array}{l}\text { Reference } \\
\text { numbers }\end{array}$ & Authors & \multicolumn{2}{|c|}{$\begin{array}{l}\text { Type and magnitude of surface } \\
\text { stress }\end{array}$} & Cause of surface stress & Target molecule & Readout \\
\hline$[88]$ & $\begin{array}{l}\text { Fritz et al. } \\
\quad(2000)\end{array}$ & \multicolumn{2}{|c|}{ Compressive $5 \times 10^{-3} \mathrm{~N} \mathrm{~m}^{-1}$} & $\begin{array}{l}\text { Electrostatic, steric, and } \\
\text { hydrophobic interactions }\end{array}$ & $\begin{array}{l}\text { DNA and protein A } \\
\text { immunoglobulin (IgG) } \\
\text { (protein-protein) } \\
\text { interactions }\end{array}$ & Optical \\
\hline [94] & $\begin{array}{l}\text { Wu et al. } \\
\text { (2001) }\end{array}$ & \multicolumn{2}{|c|}{$\begin{array}{l}\text { Compressive immobilization of } \\
\text { ssDNA } \\
\text { Tensile with DNA hybridization, } \\
\text { but remains net compressive }\end{array}$} & $\begin{array}{l}\text { Configurational entropy and } \\
\text { intermolecular energetics } \\
\text { (electrostatic and steric } \\
\text { interactions) }\end{array}$ & $\begin{array}{l}\text { DNA and biotin-avidin } \\
\text { (protein-ligand) } \\
\text { binding }\end{array}$ & Optical \\
\hline$[95]$ & $\begin{array}{l}\text { McKendry } \\
\text { et al. } \\
\text { (2002) }\end{array}$ & \multicolumn{2}{|c|}{$\begin{array}{l}\text { Compressive } 2.7 \times 10^{-3} \mathrm{~N} \mathrm{~m}^{-1} \\
\text { Single duplex molecule exerts a } \\
\text { compressive stress of } 1 \times 10^{12} \\
\mathrm{~N} \mathrm{~m}^{-1}\end{array}$} & Steric hindrance & DNA & Optical \\
\hline [96] & $\begin{array}{l}\text { Watari et al. } \\
\qquad(2007)\end{array}$ & \multicolumn{2}{|c|}{$\begin{array}{l}\text { For } \mathrm{pH} \geq 7.0 \\
\text { Compressive } 14.5 \pm 0.3 \times 10^{-3} \\
\quad \mathrm{~N} \mathrm{~m}^{-1} \\
\text { For } \mathrm{pH}<6.0 \\
\text { Tensile } 0.9 \pm 0.3 \times 10^{-3} \\
\mathrm{~N} \mathrm{~m}^{-1}\end{array}$} & $\begin{array}{l}\text { Electrostatic (ionic hydrogen bond } \\
\text { interactions, dipole-dipole } \\
\text { interactions, and Columbic } \\
\text { forces) }\end{array}$ & $\begin{array}{l}\text { Mercaptohexadecanoic } \\
\text { acid (MHA) and } \\
\text { hexadecanethiol (HDT) }\end{array}$ & Optical \\
\hline [97] & $\begin{array}{l}\text { Stachowiak } \\
\text { et al. } \\
\text { (2006) }\end{array}$ & \multicolumn{2}{|c|}{$\begin{array}{l}\text { Compressive } 2-32 \times 10^{-3} \\
\mathrm{~N} \mathrm{~m}^{-1}\end{array}$} & $\begin{array}{l}\text { Steric and hydrostatic hindrances, } \\
\text { osmotic and hydration forces }\end{array}$ & DNA & Optical \\
\hline [98] & $\begin{array}{l}\text { Mertens } \\
\text { et al. } \\
(2008)\end{array}$ & $\begin{array}{l}\text { RH: } 5-20 \% \\
\text { Tensile } \\
\text { RH: } \\
\text { 50-70\% } \\
\text { Compressive }\end{array}$ & $\begin{array}{l}40-70 \times 10^{-3} \\
\mathrm{~N} \mathrm{~m}^{-1} \\
150-200 \times 10^{-3} \\
\mathrm{~N} \mathrm{~m}^{-1}\end{array}$ & $\begin{array}{l}\text { Hydration forces } \\
\text { Dipole-dipole interactions } \\
\text { (Attractive): tensile } \\
\text { Steric hindrance } \\
\text { (Repulsive): compressive }\end{array}$ & DNA & Optical \\
\hline [99] & $\begin{array}{l}\text { Godin et al. } \\
\quad(2010)\end{array}$ & Compressive & $6.3 \pm 0.2 \mathrm{~N} \mathrm{~m}^{-1}$ & $\begin{array}{l}\text { Lennard-John-type interactions } \\
\text { (van der Waals and Pauli } \\
\text { exclusion): } \\
\pm 0.001-0.01 \mathrm{~N} \mathrm{~m}^{-1} \\
\text { Electrostatic interactions } \\
\text { (Coulombic interactions): } \\
0.01-0.1 \mathrm{~N} \mathrm{~m}^{-1} \text { (compressive) } \\
\text { Changes in electronics charge } \\
\text { density of Au surface: } \\
6.3 \pm 0.2 \mathrm{~N} \mathrm{~m}^{-1} \text { (compressive) }\end{array}$ & $\begin{array}{l}\text { DNA } \\
\text { Hexanethiol (C6), } \\
\text { octanethiol (C8), } \\
\text { decanethiol (C10) }\end{array}$ & - \\
\hline [100] & $\begin{array}{l}\text { Yang et al. } \\
\text { (2011) }\end{array}$ & 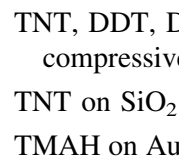 & $\begin{array}{l}\text { NT on Au surface } \\
\text { tensile } \\
\text { tensile } 0-1 \mathrm{~N} \mathrm{~m}^{-1}\end{array}$ & $\begin{array}{l}\text { Stereo effect and hydrogen bond } \\
\text { intensity }\end{array}$ & TNT, DDT, DNT, TMAH & Piezoresistive \\
\hline
\end{tabular}

constant $\left.0.02 \mathrm{~N} \mathrm{~m}^{-1}\right)$. Authors have used high-density probes $\left(1.3 \times 10^{13}\right.$ probes $\left.\mathrm{cm}^{-2}\right)$ to measure the type and magnitude of surface stress resulting from hybridization of a single molecule. Their experimental investigation showed that the hybridization of a single molecule results in a compressive stress of $1 \times 10^{-12} \mathrm{~N} \mathrm{~m}^{-1}$. They suggested that the electrostatic interactions contribute less to surface stress generation, whereas it is the high-density probes- induced physical steric crowding/steric hindrance effect on $\mathrm{Au}$ surface which plays the key role in surface stress generation. In addition, it was demonstrated that surface preparation and DNA probe arrangement on cantilever also have an important role in surface stress generation. Watari et al. [96] performed experiments by immobilizing mercaptohexadecanoic acid (MHA) and hexadecanethiol (HDT) to investigate the nature of surface stress [where the 


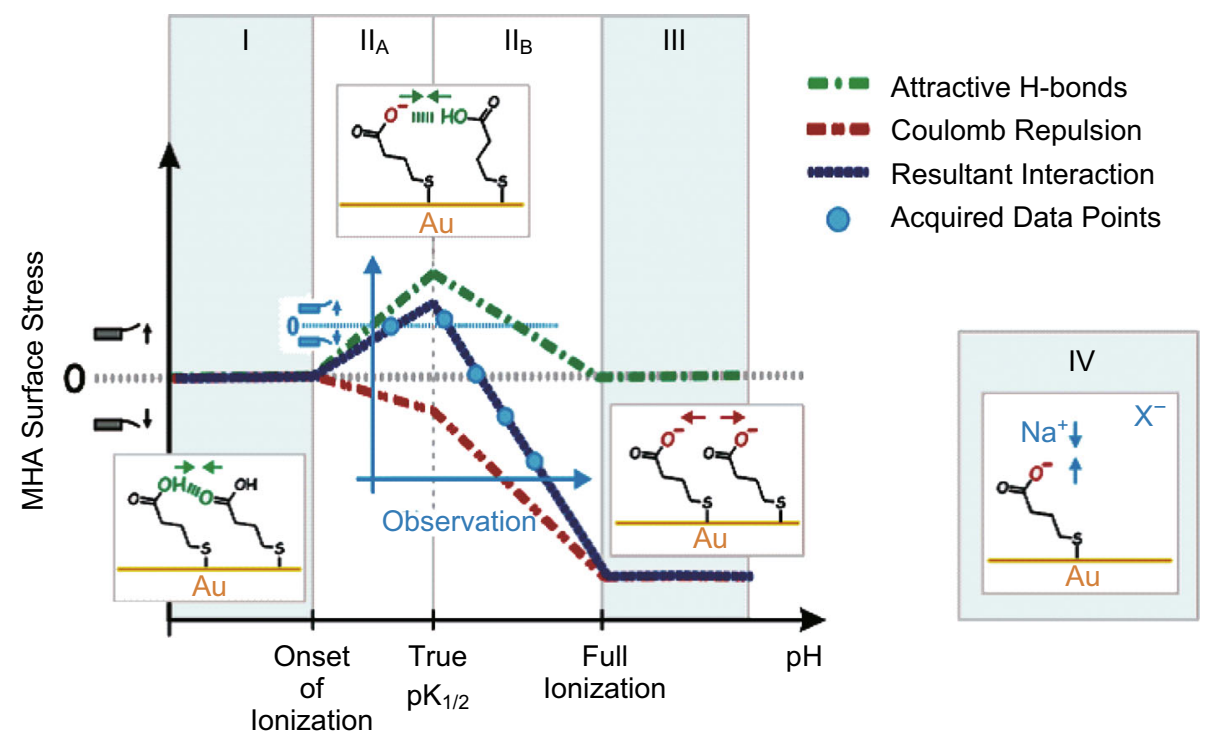

Fig. 12 Graphical representation of surface ionization state in different pH regimes. Adopted from Ref. [96]. Copyright (2007) American Chemical Society

former was immobilized on the sensing cantilevers, whereas self-assembled monolayer (SAM) of the later was grafted on reference cantilevers]. Experiments were conducted with rectangular silicon cantilevers with dimensions $L_{\mathrm{C}} \times W_{\mathrm{C}} \times T_{\mathrm{C}}=500 \times 100 \times 0.9 \mu \mathrm{m}^{3} \quad$ coated with 2-nm Ti adhesion layer and 20-nm Au layer. The group utilized variation in the acid-base properties, i.e., protonation and deprotonation of carboxylic acid-terminated MHA by controlling the $\mathrm{pH}$ of the medium. Unlike Fritz et al., who performed their experiments for a fixed $\mathrm{pH}$, Watari et al. demonstrated the importance of $\mathrm{pH}$ in governing the nature of surface stress in liquid medium. A graphical representation of the impact of $\mathrm{pH}$ variation on surface stress is shown in Fig. 12. Even though the magnitude of surface stress measured by Watari et al. was of the same order of the data published by Fritz for $\mathrm{pH}>7.0$, for $\mathrm{pH}$ 6.0, Fritz et al. reported a compressive surface stress of $2 \mathrm{mN} \mathrm{m}^{-1}$, whereas Watari et al. demonstrated a tensile surface stress of $-0.9 \pm 0.3 \mathrm{mN} \mathrm{m}^{-1}$. This discrepancy was found to be due to the difference in molecular packing and Au morphology during sample preparation. Apart from $\mathrm{pH}$, ionic strength and ionic species present in the aqueous medium were also reported to affect the generation of surface stress. The surface stress generation was proposed to be due to the electrostatic and ionic hydrogen bond interactions between the molecules, and the counter-ions and co-ions present in the medium.

Chemo-mechanics of the transduction of chemical free energy due to DNA hybridization into mechanical deflection of cantilevers was investigated by Stachowiak et al. [97] to understand the origin behind surface stress generation. They conducted experiments with silicon nitride cantilever (with paddle at the end whose dimensions are the following: $L_{\mathrm{C}} \times W_{\mathrm{C}} \times$ $T_{\mathrm{C}}=200-400 \times 30-40 \times 0.5 \mu^{3}$ coated with $5-\mathrm{nm} \mathrm{Cr}$ adhesion layer and 25-nm Au layer). The group proposed that the surface stress generation is influenced by factors like the length of DNA chain, grafting density, ionic strength of the medium, and hybridization density. Among the aforementioned factors, hybridization density was found to be the dominant factor which combined the effects of chain length and ionic strength in governing the surface stress generation. The surface stress generated due to DNA hybridization was observed to be compressive. It was reported that at a low ionic strength of medium, osmotic pressure of counter-ions prevails over intermolecular forces, whereas at high ionic strength, hydration forces dominate. Mertens et al. [98] proposed that the cause of surface stress in highly packed SAM-based DNA hybridization process is the steric and hydration forces along with steric crowding effects. Experiments were conducted with silicon cantilever coated with gold (silicon micro-cantilever with gold coating of typical dimensions: $L_{\mathrm{C}} \times W_{\mathrm{C}} \times T_{\mathrm{C}}=400 \times 100 \times 0.6 \mu^{3}$, coated with 2-nm $\mathrm{Cr}$ adhesion layer and 20-nm Au layer, resonant frequency: $\quad 5.3 \pm 0.1 \mathrm{kHz}$, and spring constant: $0.029 \pm 0.001 \mathrm{~N} \mathrm{~m}^{-1}$ ). Hydration/dehydration cyclic tests were performed to investigate the effect of $\mathrm{RH}$ on surface stress generation for immobilized ssDNA on a cantilever surface. It was demonstrated that the variation in $\mathrm{RH}$ affects not only the magnitude of surface stress, but also its type. Results depicted that for $\mathrm{RH}$ in the range from 5 to 
$20 \%$, the surface stress was tensile with its magnitude ranging from 40 to $70 \mathrm{mN} \mathrm{m}^{-1}$, whereas an increase in $\mathrm{RH}$ (50-70\%) resulted in a large compressive surface stress $\left(150-200 \mathrm{mN} \mathrm{m}^{-1}\right)$. It was proposed that the tensile and compressive surface stress generated on the cantilever is due to the attractive dipole-dipole interactions and repulsive steric hindrance, respectively. While the change in surface stress induced by ssDNA was found to be affected by various parameters, in hybridized DNA the specific Watson-Crick base binding (intermolecular interaction) mainly resulted in surface stress changes. The competing factors of hydrogen bonding (tensile stress) and steric hindrance interactions (compressive stress) were found to play a less significant role in surface stress generation.

A detailed investigation on the contribution of various factors that affect surface stress generation in Au-coated cantilevers was performed by Godin et al. [99]. They proposed that surface stress is due to three reasons: (1) Lennard-John's interactions between adsorbed molecules which can be due to either van der Waals forces (attractive) or Pauli exclusion forces (repulsive), (2) electrostatic interactions between Au-thiol bonds, and (3) changes in electronic state of the surface that results in net charge redistribution on the cantilever surface during a DNA hybridization process. However, the group reported that among the three factors, the large compressive stress generated in DNA hybridization process is largely due to the change in electronic state of the underlying $\mathrm{Au}$ immobilization surface. A pictorial representation of the immobilized gold-coated cantilever with self-assembled monolayers of receptors and modified electronic energy states is shown in Fig. 13. The redistribution of energy states of $\mathrm{Au}$ surface due to $\mathrm{Au}^{+} \mathrm{S}^{-}$bond and charge transfer from $\mathrm{Au}$ surface to $\mathrm{S}$ atom reduces the bond strength of Au surface atoms, resulting in the generation of compressive surface stress. In addition, unlike previous studies, they reported that the generation of surface stress is independent of molecular chain length. This discrepancy between the reported results in previous studies was attributed to the dependence of surface stress generation on the grain size of Au immobilization surface. More recently, Yang et al. [100] reported that the origin of surface stress is due to interface vertical effects and lateral interactions. They had carried out experiments with rectangular silicon dioxide cantilever with a thin U-shaped SCS piezoresistor, silicon dioxide insulating layer, and immobilization layer realized with thin film of $\mathrm{Au}$ (cantilever dimensions: $L_{\mathrm{C}} \times W_{\mathrm{C}} \times T_{\mathrm{C}}=90 \times 20 \times 1.0 \mu^{3}$ ). Interface vertical effects include interfacial energy change and charge redistribution, whereas van der Waals force, electrostatic Coulombic effect, intermolecular hydrogen bond intensity, and steric effects contribute to lateral interactions. However, lateral interactions were found to play a more

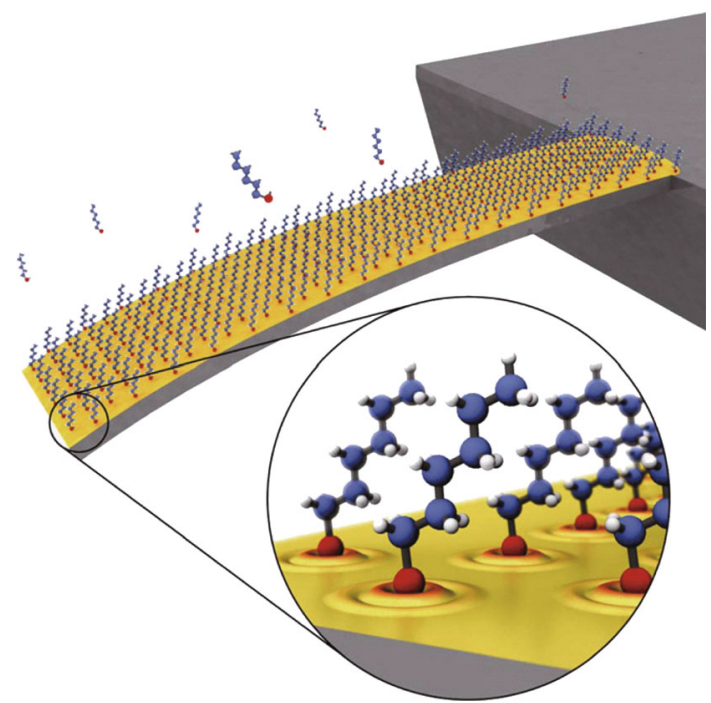

Fig. 13 Pictorial representation of alkanethiol-based self-assembled monolayers on a gold-coated cantilever platform and a zoom-in view of the redistribution of electronic states of Au immobilization layer. Adopted from Ref. [99]. Copyright (2010) IOP Publishing

significant role in generating surface stress. Among the factors which contribute to the lateral interactions, the intermolecular hydrogen bond intensity and steric interactions were reported to be dominating over the other two factors.

Thus, the reported results show that the origin of surface stress is not due to a single factor, but due to the complex interchange of energies attributed to various parameters like electrostatic interactions, steric interactions, hydrophobic interactions, configurational entropy, hydration forces, Lennard-John's interactions, changes in electronic charge density of Au layer, stereo effect, and hydrogen bond density. The temporal variation of surface stress from the initial immobilization of receptors to various stages of target-receptor interactions is a function of factors like $\mathrm{pH}, \mathrm{RH}$, temperature, receptor coverage, chain length (in case of DNA), ionic concentration of medium, characteristics of the immobilization surface, position of immobilization surface, and size of target molecules.

Active research is underway to explore the possibility of direct immobilization of receptors without the gold immobilization layer. For instance, in the case of SU-8 cantilevers, the top isolation layer realized with a thin layer of SU-8 can also act as the immobilization surface. Apart from cost reduction, direct immobilization on SU-8 polymer is seen as a possibility to reduce high-temperature process-induced thermal stress during separate Au metal deposition on SU-8. Covalent bond-based immobilization techniques on polymer surface have been reported by immobilization of functional groups like $\mathrm{CHO}, \mathrm{SH}, \mathrm{NH}_{2}$, etc. One of the techniques used to immobilize amino 
functional groups on the SU-8 polymer is aminosalinization process, which takes advantage of the opened epoxied groups of SU-8 polymer [101]. Other techniques include treatment of SU-8 with glycine [102], silane and polyethylene glycol (PEG) [103], and ceric ammonium nitride (CAN) [104, 105]. Using surface modification techniques, ssDNA probe density of $100 \mathrm{fmol} \mathrm{mm}^{-2}$ has been reported in the literature [106]. For more details regarding the various immobilization protocols, different immobilization surfaces, surface stress enhancement techniques, etc., readers may refer the literature [48-50].

As discussed earlier, covalent immobilization protocol is the most stable protocol. SU-8 cantilevers support covalent bond only when functional groups like amine, aldehyde, thiol, and carboxyl are present. Immobilization of receptors is accomplished by either a wet or a dry method. Literature encompasses examples of both the wet and dry immobilization techniques. A brief summary of wet and dry methods used for surface treatment is detailed in Table 3. Typically, wet method of surface modification has been reported, in which acid/base chemicals are used for surface modification. However, wet method of surface modification suffers from the following limitations: (1) It uses strong oxidizing/hydrolyzing agents that damage device surface apart from the immobilization region, (2) it requires repetitive steps which involves immersion, washing, and drying the surface which is time-consuming and results in surface damage or even increases chance of contamination, and (3) it requires tight control over process parameters and ambient conditions like temperature and $\mathrm{pH}$ value of the medium. Dry surface modification is performed in several ways. For instant, by exposing the surface to UV light in ammonia (environment), amine group is immobilized. Another method is by using oxygen/ammonia plasma treatment by which hydroxyl/amine groups are immobilized on SU-8 surface. However, surface modification using exposure to plasma damages the device surface, and grafting using UV light is not only timeconsuming, but also results in change in the material properties of polymer. One alternative dry immobilization technique is by using the pyrolytic dissociation of ammonia for grafting amine groups in a hotwire chemical vapor deposition (HWCVD) environment. Compared to the wet method, the dry method holds the following advantages: (1) Damage to the sensor surface and alterations to constituent material properties are negligible especially in the technique based on HWCVD due to low temperature requirement, and (2) unlike typical wet grafting methods, the use of strong chemical is avoided, thereby resulting in unaltered surface properties. Retaining the surface characteristics of devices becomes important especially when the device is reused, i.e., for device repeatability or reusability.

The covalent bonds formed especially in the case of thiol-gold are strong with a binding energy of $120 \mathrm{~kJ} \mathrm{~mol}^{-1}$ [112]. Thus, it becomes difficult to dissociate the covalent bond without additional energy. Premise presents a challenge in terms of repeatability of devices. However, when external energy is provided covalent bonds dissociate and this may be used for refreshment of cantilever surface. Typically, these refreshment techniques are based on light and temperature. In optics-based refreshment technique, light energy incident from a light source dissociates the bond, whereas in temperature-based refreshment techniques the rise in surface temperature of device typically by an integrated heater resistor results in

Table 3 Details of various dry and wet immobilization techniques with their respective application

\begin{tabular}{|c|c|c|c|}
\hline Authors and year & $\begin{array}{l}\text { Immobilization } \\
\text { method }\end{array}$ & Immobilized group/process & Application and device \\
\hline Mayer et al. (2003) [107] & Dry (plasma) & $\begin{array}{l}\text { Functionalization of amino } \\
\text { group }\end{array}$ & Protein detection \\
\hline Gao et al. (2006) [108] & Wet & $\begin{array}{l}\text { Photopolymerization } \\
\text { Surface graft polymerization }\end{array}$ & Hydrogel detection with potential SU-8 micro-channels \\
\hline Wang et al. (2007) [105] & Wet & Surface graft polymerization & $\begin{array}{l}\text { Mouse IgG detection with SU-8 micro-cantilever and } \\
\text { micro-channels }\end{array}$ \\
\hline Joishi et al. (2007) [109] & Dry & Aminosilanization & $\begin{array}{l}\text { Human immunoglobulin (HIgG) detection using SU-8 } \\
\text { micro-cantilevers }\end{array}$ \\
\hline Blagoi et al. (2008) [110] & Wet & Aminosilanization & $\begin{array}{l}\text { Goat anti-mouse antibody whole-molecule detection with } \\
\text { SU- } 8 \text { micro-wells }\end{array}$ \\
\hline Deepu et al. (2009) [102] & Wet & Carbodiimide/succinimide & Human immunoglobulin $\mathrm{G}(\mathrm{HIgG})$ detection \\
\hline Cao et al. (2011) [111] & Wet & $\begin{array}{l}\text { Covalent bonding of } \mathrm{Au} \\
\text { nanoparticles }\end{array}$ & DNA hybridization with micro-device \\
\hline
\end{tabular}


dissociation of covalent bonds. In piezoresistive readoutbased cantilever sensors, refreshment using an integrated heater becomes a more attractive option since the piezoresistor and the heater can be realized using similar steps. In addition, an integrated method provides compactness to the device, thereby reducing device footprint. The integrated heater technique uses joule heating to increase the sensor surface temperature for refreshment. Integrating a heater element can influence the detection technique and piezoresistance properties. For instance, the sensor reported for detection of TNT vapors in [113] uses the heat generated by the in-built heater resistor for deflagration of TNT vapors, resulting in enhanced heat generation and thereby cantilever bending. The resultant cantilever bending due to the heat generated by deflagration of TNT vapors is gauged by the piezoresistor. Although integrated heater-based sensor design has several advantages, it may result in variation in piezoresistor properties due to temperature coefficient of piezoresistance, irreversible plastic deformation, and thermal drift in device output. Cleaning the device surface once the bond dissociates is performed by chemical or dry methods. The extent of cleaning and surface regeneration by subsequent chemical modification determines the immobilization efficiency and therefore biological sensitivity of devices.

\section{Evolution: Solid-State Semiconductor to Polymeric Cantilevers}

Due to its origin from the matured microelectronics technology, initial MEMS cantilever sensors were based on solid-state semiconductor materials, especially silicon and its derivatives. A timeline of the evolution of cantilever platform sensors is shown in Table 4. The timeline includes representative papers of different cantilever sensors, and omission of any important references is regretted. Miniaturized cantilevers with their dimensions in microregime were first used as atomic force microscopes (AFMs) for surface imaging applications by Binning et al. [114]. The reported AFM consisted of a slender rectangular cantilever with a sharp tip at its end that allowed topological measurement of a sample surface with atomistic resolution. In 1991, Thundat et al. [115] used AFM for imaging deoxyribonucleic acid (DNA) strands at different levels of relative humidity. In the next few years, the same group explored the use of AFM in understanding both single and double strands of DNA in various external conditions [116-119]. Gimzewski et al. [120] in 1993 demonstrated a micro-cantilever-based chemical sensor to detect the catalytic conversion of hydrogen $\left(\mathrm{H}_{2}\right)$ and oxygen $\left(\mathrm{O}_{2}\right)$ into water $\left(\mathrm{H}_{2} \mathrm{O}\right)$. The sensor constituted a silicon cantilever coated with a thick layer of aluminum $(\mathrm{Al})$ metal and a thin film of platinum $(\mathrm{Pt})$ atop which the reaction takes place. This multi-morph configuration could convert the heat flux generated from the catalytic reaction into cantilever deflection due to the difference in temperature coefficient of expansion (TCE) of two layers up to $1 \mathrm{nW}$ with a response time of $1 \mathrm{~ms}$. Subsequently, in $1994 \mathrm{sev}-$ eral concurrent developments demonstrated the bimetallic configuration of a cantilever platform coated with a metal layer as a viable sensing platform. For instance, Barnes et al. developed a bilayer of silicon nitride cantilever and a thin film of aluminum atop as a calorimeter that depicted sensitivity as low as $10 \mathrm{pW}$ [121]. By the mid-1990s, MEMS-based cantilever platforms were demonstrated as physical and chemical sensors by Thundat et al. The group used micro-cantilevers with metal layers for the detection of surrounding humidity (bilayer of silicon/silicon nitride cantilevers coated with a layer of gold and/or aluminum) [122] and mercury vapors [123]. Further in the year 1995, Raiteri et al. [124] demonstrated the applicability of AFM (silicon nitride cantilevers) coated with gold/platinum metal layer in measuring electrochemically induced surface stress using optical leverage technique. These cantilever platforms exhibited ultra-high sensitivity to changes in their external environment and their own mass mainly due to their large surface-to-volume ratio. In addition, the micro-cantilevers had the inherent advantage of low spring constant and high resonant frequency, thus making them highly sensitive to external forces. Later, this arrangement of micro-cantilever platform with a metal layer was demonstrated as a viable biological sensing tool for applications like detection of protein [125] and DNA [88] by various researchers.

The initial AFMs and cantilever sensors were either optics- or resonant frequency shift readout-based systems (where, in the former technique, a laser beam is incident at the apex of the cantilever and its shift in position is measured with a photodetector, and in the latter, the shift in the resonant frequency of the cantilever is measured using a piezoelectric actuation system). Even though optics- and resonant frequency shift-based readout techniques exhibited cantilever displacement resolution in nanometer $(\mathrm{nm})$ [126] and mass detection sensitivity in picogram (pg) [127] range, their applicability was restricted to vacuum and air operational medium mainly due to the following reasons: (1) inaccurate measurement in liquid medium due to fluid damping effect, (2) ineffectiveness in opaque liquid, (3) bulkiness of measurement setup, and (4) need for continuous realignment and recalibration. To overcome the limitations of optics- and resonant frequency-based readout methods, self-sensing piezoresistive readout technique was adopted by various researchers in the mid-1990s. Piezoresistive readout was first demonstrated by Tortonese et al. in 1991 [128] in AFM cantilevers. Even though other 
Table 4 Chronological details of the evolution of micro-/nano-cantilever sensors

\begin{tabular}{|c|c|c|c|c|}
\hline Authors and year & Material set & Constituent layers & $\begin{array}{l}\text { Readout } \\
\text { technique }\end{array}$ & Comments \\
\hline $\begin{array}{l}\text { Binning et al. } \\
\text { (1986) }\end{array}$ & Cantilever Au, tip diamond & Structural layer: $\mathrm{Au}$ & $\begin{array}{c}\text { Tunneling } \\
\text { current }\end{array}$ & AFM topological measurement \\
\hline $\begin{array}{l}\text { Gimzewski et al. } \\
\text { (1993) }\end{array}$ & Cantilever $\mathrm{Si}, \mathrm{Al}+\mathrm{Pt}$ coating & Additional layer: $\mathrm{Al}+\mathrm{Pt}$ & Optical & Calorimeter-based chemical sensing \\
\hline $\begin{array}{l}\text { Thundat et al. } \\
\text { (1994) }\end{array}$ & $\begin{array}{l}\text { Cantilever } \mathrm{Si}^{\prime} \mathrm{Si}_{3} \mathrm{~N}_{4}+\mathrm{Au} / \mathrm{Al} \\
\text { coating }\end{array}$ & $\begin{array}{l}\text { Additional layer: } \mathrm{Au} / \mathrm{Al} \\
\text { Structural layer: } \mathrm{Si} / \mathrm{Si}_{3} \mathrm{~N}_{4}\end{array}$ & Optical & Humidity and mercury vapor sensing \\
\hline $\begin{array}{l}\text { Raiteri et al. } \\
\text { (1995) }\end{array}$ & Cantilever $\mathrm{Si}_{3} \mathrm{~N}_{4}+\mathrm{Au} / \mathrm{Pt}$ coating & $\begin{array}{l}\text { Structural layer: } \mathrm{Si}_{3} \mathrm{~N}_{4} \\
\text { Additional layer: } \mathrm{Au} / \mathrm{Pt}\end{array}$ & Optical & $\begin{array}{l}\text { Measurement of electrochemically } \\
\text { induced surface stress }\end{array}$ \\
\hline $\begin{array}{l}\text { Boisen et al. } \\
\text { (2000) }\end{array}$ & $\begin{array}{l}\text { Cantilever Si, piezoresistor doped } \\
\quad \mathrm{Si}\end{array}$ & $\begin{array}{l}\text { Immobilization layer: gold/ } \\
\text { polymer } \\
\text { Protective layer: } \mathrm{SiO}_{2} \\
\text { Piezoresistive layer: p-poly- } \\
\mathrm{Si} \\
\text { Isolation layer: } \mathrm{SiO}_{2} \\
\text { Structural layer: } \mathrm{Si}\end{array}$ & Piezoresistive & $\begin{array}{l}\text { Temperature, humidity, and alcohol } \\
\text { sensing }\end{array}$ \\
\hline $\begin{array}{l}\text { Thaysen et al. } \\
\text { (2002) }\end{array}$ & Cantilever SU-8, piezoresistor $\mathrm{Au}$ & $\begin{array}{l}\text { Immobilization }+ \text { isolation } \\
\text { layer: SU-8, } \\
\text { Piezoresistor layer: Au } \\
\text { Structural layer: SU-8 }\end{array}$ & Piezoresistive & Surface micro-machining \\
\hline $\begin{array}{l}\text { Rasmussen et al. } \\
\text { (2003) }\end{array}$ & $\begin{array}{l}\text { Cantilever } \mathrm{Si}_{3} \mathrm{~N}_{4} \text {, piezoresistor } \\
\text { doped polysilicon }\end{array}$ & $\begin{array}{l}\text { Immobilization layer: } \mathrm{Au} \\
\text { Isolation layer: } \mathrm{SiN}_{x} \\
\text { Piezoresistor layer: p-poly- } \\
\quad \mathrm{Si} \text {, } \\
\text { Structural layer: } \mathrm{SiN}_{x}\end{array}$ & Piezoresistive & $\begin{array}{l}\text { ssDNA sensing } \\
\text { Bulk }+ \text { surface micro-machining }\end{array}$ \\
\hline $\begin{array}{l}\text { Gammelgaard } \\
\text { et al. (2006) }\end{array}$ & $\begin{array}{l}\text { Cantilever SU-8, piezoresistor CB } \\
\text { SU-8 }\end{array}$ & $\begin{array}{l}\text { Isolation layer: SU-8 } \\
\text { Piezoresistor layer: CB SU- } \\
\quad 8 \\
\text { Structural layer: SU-8 }\end{array}$ & Piezoresistive & Surface micro-machining \\
\hline Zuo et al. (2006) & $\begin{array}{l}\text { Cantilever } \mathrm{SiO}_{2} \text {, piezoresistor } \\
\text { p-SCS }\end{array}$ & $\begin{array}{l}\text { Immobilization layer: } \mathrm{Au} \\
\text { Isolation layer: } \mathrm{SiO}_{2} \\
\text { Piezoresistor layer: p-SCS } \\
\text { Structural layer: } \mathrm{SiO}_{2}\end{array}$ & Piezoresistive & $\begin{array}{l}\text { Methyl-phosphonate sensing } \\
\text { Bulk micro-machining }\end{array}$ \\
\hline Kale et al. (2009) & $\begin{array}{l}\text { Cantilever SU-8, piezoresistor } \\
\text { p-poly-Si }\end{array}$ & $\begin{array}{l}\text { Immobilization }+ \text { isolation } \\
\text { layer: SU-8 } \\
\text { Piezoresistive layer: p-poly- } \\
\text { Si, } \\
\text { Structural layer: SU-8 }\end{array}$ & Piezoresistive & Surface micro-machining, HWCVD \\
\hline Seena et al. (2009) & $\begin{array}{l}\text { Cantilever SU-8, piezoresistor CB } \\
\text { SU-8 }\end{array}$ & $\begin{array}{l}\text { Immobilization }+ \text { isolation } \\
\text { layer: SU-8 } \\
\text { Piezoresistive layer: CB } \\
\text { SU-8 } \\
\text { Structural layer: SU-8 }\end{array}$ & Piezoresistive & Surface micro-machining \\
\hline $\begin{array}{l}\text { Reddy et al. } \\
\text { (2012) }\end{array}$ & $\begin{array}{l}\text { Cantilever SU-8, piezoresistor CB } \\
\text { SU-8 }\end{array}$ & $\begin{array}{l}\text { Immobilization }+ \text { isolation } \\
\text { layer: SU-8 } \\
\text { Piezoresistive layer: CB } \\
\text { SU-8 } \\
\text { Structural layer: SU-8 }\end{array}$ & Piezoresistive & $\begin{array}{l}\text { CO sensing } \\
\text { Surface micro-machining }\end{array}$ \\
\hline
\end{tabular}


Table 4 continued

\begin{tabular}{|c|c|c|c|c|}
\hline Authors and year & Material set & Constituent layers & $\begin{array}{l}\text { Readout } \\
\text { technique }\end{array}$ & Comments \\
\hline Patil et al. (2014) & $\begin{array}{l}\text { Cantilever SU-8, piezoresis or CB } \\
\text { SU-8 }\end{array}$ & $\begin{array}{l}\text { Immobilization }+ \text { isolation } \\
\text { layer: SU-8 } \\
\text { Piezoresistor layer: CB SU- } \\
\quad 8 \\
\text { Structural layer: SU-8 } \\
\text { Prohibition layer: } \mathrm{Au}\end{array}$ & Piezoresistive & $\begin{array}{l}\text { Soil moisture and relative humidity } \\
\quad(\mathrm{RH}) \text { sensing } \\
\text { Surface micro-machining }\end{array}$ \\
\hline
\end{tabular}

integrated readout techniques like capacitive [129], piezoelectric [130], tunneling [131], and integrated optical waveguide [132] were also implemented, piezoresistive readout demonstrated better performance. A few early illustrations of piezoresistive cantilever-based biological and chemical sensors include analysis of the dehydration of copper sulfate pentahydrate with picogram resolution [133], detection of alcohol vapor with detection limits below $10 \mathrm{ppm}$ [134], measurement of temperature, humidity and alcohol with a minimum detectable cantilever deflection of $1 \AA$ and a deflection sensitivity of $1.6 \mathrm{~nm}$ $(\mu \mathrm{W})^{-1}$ [135], investigation of surface stress due to selfassembled alkanethiol on gold surface [136]. Furthermore, to reduce the probability of non-specific detection, specific receptors, which have high affinity toward target molecules, were immobilized on the cantilever surface. The specific bindings of target molecules on the cantilever platform resulted in either a change in its mass or a variation in its surface energies that resulted in cantilever deflection.

In the past decade, various solid-state semiconductor cantilever sensors based on silicon [137-142], silicon nitride [143-146], and silicon dioxide [147-153] with integrated doped single crystalline, polysilicon, and metal piezoresistors have been demonstrated. Typically, in solidstate semiconductor-based piezoresistive cantilever sensors, the structural layer is realized with materials like silicon, silicon dioxide, or silicon nitride and the piezoresistor element is doped silicon, doped polysilicon, or gold. Even though semiconductor cantilever sensors have advantages in terms of low cost due to batch fabrication (when produced in large volume) and performance, the research and development to realize such sensors is cumbersome and limited due to the stringent requirement of clean room facilities and large initial investments for equipments. This was the impetus for researchers to find an alternative material, which could match semiconductorbased sensors in terms of performance with a reduction in material and fabrication cost.

Although various materials like metal, silicon carbide, graphene, diamond, ceramic, etc., have been used to realize
MEMS-based devices, their applicability to realize piezoresistive cantilever sensors is limited due to higher stiffness of the structure, high material cost, fabrication complexity, and incompatibility with batch fabrication. Polymers were considered as alternative materials due to their low Young's modulus, biocompatibility, and costeffectiveness in terms of both material and fabrication. Pechmann et al., in 1994, were the first to report polymeric cantilever devices based on novolak photoresist [154]. Since then, various polymers such as parylene [155], polypropylene [156], fluoropolymer [157], SU-8 [158], polyethylene terephthalate [159], polyimide [160], TOPAS $^{\circledR}$ [161], polystyrene [162], polydimethylsiloxane (PDMS) [163], and polymethyl methacrylate (PMMA) [164] have been extensively explored to realize miniaturized devices. An overview of material properties, fabrication process, and representative applications of the aforementioned polymers in MEMS are summarized in Table 5.

Various polymers were demonstrated as alternative materials to solid-state semiconductors. However, SU-8 is found to be particularly suitable for MEMS applications. Variants of SU-8 polymers are classified primarily based on their viscosity and processing time, which include commercially available SU-8 2, SU-8 5, SU-8 10, SU-8 25 , SU-8 50, SU-8 100, etc. However, new generation of SU-8 2000 series polymers are now widely used due to their better adhesion properties, improved coating, and faster processing time, especially for realizing piezoresistive SU8 cantilever sensors. SU-8 polymers have advantages such as ability to form high-aspect-ratio and mechanically stable structures, inertness to chemicals, and compliance to fabrication facilities and techniques used in conventional IC fabrication processes like photolithographic process, dry or wet etching. Photosensitivity of SU-8 polymer combined with the ability to produce sharp edges even for large thicknesses has enabled MEMS engineers to realize highaspect-ratio structures $(>20)$ by using UV lithography [192]. Furthermore, due to advantages like higher refractive index, biocompatibility, and controllability over its electric, magnetic, optical, and mechanical properties, SU- 
Table 5 Overview of various polymers with their representative fabrication process, features, and applications in MEMS

\begin{tabular}{|c|c|c|c|}
\hline Polymer & Fabrication process & Features & Applications \\
\hline Parylene & $\begin{array}{l}\text { Chemical vapor deposition } \\
\quad \text { (CVD) } \\
\text { Etching by oxygen plasma } \\
\text { Hot embossing } \\
\text { Lithography }\end{array}$ & $\begin{array}{l}\text { Young's modulus, } E \sim 5 \mathrm{GPa} \\
\text { Chemically inert } \\
\text { Low intrinsic stress and gas } \\
\text { permeability } \\
\text { Hydrophobic } \\
\text { Optically transparent } \\
\text { Vulnerable to temperature }\end{array}$ & $\begin{array}{l}\text { Electrostatic actuator [155] } \\
\text { Micro-valve [165] } \\
\text { Spring [166] } \\
\text { Electrostatic micro-peristaltic pump [167] }\end{array}$ \\
\hline Polypropylene & $\begin{array}{l}\text { Injection molding } \\
\text { Laser ablation }\end{array}$ & $\begin{array}{l}\text { Young's modulus, } E \sim 1.45 \\
\text { GPa } \\
\text { Vulnerable to oxidants } \\
\text { Thermal resistance } \\
\text { Large thermal coefficient of } \\
\text { expansion } \\
\text { Opaque }\end{array}$ & $\begin{array}{l}\text { Surface stress cantilever sensor [156] } \\
\text { Component in air-coupled piezoelectric } \\
\text { transducer [168] } \\
\text { Piezo-electret film transducer [169] }\end{array}$ \\
\hline $\begin{array}{l}\text { Fluoropolymer } \\
\text { Teflon }{ }^{\circledR} \\
\text { Polytetrafluoroethylene } \\
\text { Tefzel }^{\circledR} \\
\text { Fluoroethylenepropylene }^{\circledR}\end{array}$ & $\begin{array}{l}\text { Spin coating } \\
\text { Ion beam sputter etching } \\
\text { Magnetically controlled reactive } \\
\text { ion etching }\end{array}$ & $\begin{array}{l}\text { Young's modulus, } E \sim 1.45 \\
\text { GPa }\left(\text { Teflon }{ }^{\circledR} \text { ) }\right. \\
\text { Chemically inert } \\
\text { Hydrophobic } \\
\text { Thermally stable } \\
\text { Teflon }{ }^{\circledR} \text { smoothest surface } \\
\text { morphology }\end{array}$ & $\begin{array}{l}\text { AFM-based biochemical sensor [157] } \\
\text { Micro-tube [170] } \\
\text { Micro-fluidic channel [171] }\end{array}$ \\
\hline SU-8 & $\begin{array}{l}\text { Spin coating } \\
\text { Photolithography } \\
\text { Excimer laser patterning } \\
\text { Pyrolysis } \\
\text { Dry etching }\end{array}$ & $\begin{array}{l}\text { Young's modulus, } E \sim 5 \mathrm{GPa} \\
\text { Low molecular weight } \\
\text { Chemically inert } \\
\text { High refractive index } \\
\text { Compatibility with grayscale } \\
\text { lithography }\end{array}$ & $\begin{array}{l}\text { Optical waveguide [172] } \\
\text { Micro-needles [173] } \\
\text { Micro-resonator [174] } \\
\text { AFM cantilever [175] } \\
\text { Surface stress cantilever sensor [68] }\end{array}$ \\
\hline Polyethylene terephthalate & $\begin{array}{l}\text { Excimer laser patterning and laser } \\
\text { ablation }\end{array}$ & $\begin{array}{l}\text { Young's modulus, } E \sim 2.8 \mathrm{GPa} \\
\text { Excellent resistance to moisture } \\
\text { High impact resistance }\end{array}$ & $\begin{array}{l}\text { Cantilever biosensor [159] } \\
\text { Mechanical substrate [176] } \\
\text { Micro-pump [177] }\end{array}$ \\
\hline Polyimide & $\begin{array}{l}\text { Spin coating } \\
\text { Dry etching using oxygen or } \\
\text { fluorine plasma } \\
\text { Hot embossing } \\
\text { Lithography }\end{array}$ & $\begin{array}{l}\text { Young's modulus, } E \sim 7.5 \mathrm{GPa} \\
\text { Chemically inert } \\
\text { Stable at high temperature and } \\
\text { heat } \\
\text { Vulnerable to alkalis } \\
\text { Low susceptibility to moisture }\end{array}$ & $\begin{array}{l}\text { Scanning probe }[160] \\
\text { Tactile sensor }[178,179] \\
\text { Humidity sensor }[180] \\
\text { Micro-channels [181] }\end{array}$ \\
\hline TOPAS $^{\circledR}$ & $\begin{array}{l}\text { Spin coating } \\
\text { Nano-imprint lithography }\end{array}$ & $\begin{array}{l}\text { Young's modulus, } E \sim 3.5 \mathrm{GPa} \\
\text { High chemical inertness } \\
\text { Low susceptibility to moisture } \\
\text { Good optical transmission }\end{array}$ & $\begin{array}{l}\text { Water vapor sensor [161] } \\
\text { Optical waveguide [182] } \\
\text { Micro-fluidic devices [183] }\end{array}$ \\
\hline Polystyrene & $\begin{array}{l}\text { Injection molding } \\
\text { Solvent casting technique }\end{array}$ & $\begin{array}{l}\text { Young's modulus, } E \sim 3.0 \mathrm{GPa} \\
\text { Vulnerable to moisture } \\
\text { Optically transparent }\end{array}$ & $\begin{array}{l}\text { Surface stress sensor [162] } \\
\text { Accelerometer [184] }\end{array}$ \\
\hline PDMS & $\begin{array}{l}\text { Spin coating } \\
\text { Cast molding }\end{array}$ & $\begin{array}{l}\text { Young's modulus, } \\
\quad E \sim 0.75 \mathrm{MPa} \\
\text { Incompatible with organic } \\
\text { solvents } \\
\text { Optically transparent } \\
\text { Gas permeable }\end{array}$ & $\begin{array}{l}\text { Micro-valve [185] } \\
\text { Magnetic actuator [186] } \\
\text { Micro-pump [187] } \\
\text { Micro-channel [188] }\end{array}$ \\
\hline
\end{tabular}


Table 5 continued

\begin{tabular}{llll}
\hline Polymer & Fabrication process & Features & Applications \\
\hline PMMA & Injection molding & Young's modulus, $E \sim 3.1 \mathrm{GPa}$ & Micro-channel [189] \\
& Hot embossing & Low susceptibility to moisture & Acceleration sensor [190] \\
& Wire printing & Optically transparent & Nano-structure arrays [191] \\
& Laser ablation & & \\
\hline
\end{tabular}

8 has become the preferred polymeric material for realizing miniaturized devices. In SU-8 polymeric piezoresistive sensors, the piezoresistive element is either gold, doped polysilicon, or doped SU-8. To understand the importance of material selection in determining the $G / E$ ratio, we have detailed the typical values ( $G$ and $E$ ) of materials which are used to realize piezoresistive cantilever sensors as summarized in Table 6. It is observed that all the solid-state semiconductor-based designs have $G / E$ ratio less than the SU-8 polymer-based designs (except in the case of $\mathrm{Au}$ piezoresistor and SU-8 structural layer). The higher G/ $E$ ratio of polymer-based design (with doped polysilicon and doped SU-8) is attributed to the lower Young's modulus of SU-8 structural layer. Although doped polysilicon and $\mathrm{CB}$ SU-8 piezoresistor-based SU-8 polymeric cantilevers depict high electrical sensitivity, SU-8 polymeric cantilevers with graphene nano-platelet piezoresistors have been reported to have sensitivity in parts per billion (ppb) concentrations in ambient conditions for detecting explosive 2, 4, 6-trinitrotoluene (TNT). Compared to other combinations of piezoresistor material and SU- 8 structural layer, this ultra-sensitivity of graphene-based SU-8 polymeric cantilever is primarily due to the high gauge factor of the graphene nano-platelet piezoresistor $(G=144)$ [195].

In recent years, much focus of both industry and academia has been on developing state-of-the-art SU-8 polymeric piezoresistive cantilever sensors. Researchers have explored various possibilities at material level, device level, and fabrication process optimization for developing systems with high performance-to-cost index. Recently, Adams et al. [196] demonstrated SU-8-based polymeric cantilevers depict 19 times higher imaging in-air detection bandwidth than their conventional counterparts for similar size and mechanical characteristics. With focus on performance optimization, materials like $\mathrm{SU}-8 / \mathrm{ZnO}$ nanocomposite nano-wires have been investigated for realizing devices [197]. Highly conductive CB-doped SU-8 nanocomposite at low percolation threshold with good mechanical strength and photopattern ability has been reported for realizing cantilever sensors [198]. Process parameter optimization has been also reported in the literature. For instance, optimization of baking temperatures and release methods has been reported for maximizing the fabrication yield [199]. It has been found that baking temperature influences deformation of fabricated SU-8 device, especially SU-8 cantilevers due to the residual stress component generated within the structure. In addition, out of three releasing methods (dry method-fluorocarbon film, and wet method-Omnicoat sacrificial layer and polymethyl methacrylate sacrificial layer), wet release method using polymethyl methacrylate sacrificial layer was found to give the highest yield of $90 \%$. Using the optimized recipe, SU-8 cantilever aptasensors were demonstrated for thrombin detection.

At the system level, SU-8 cantilevers vertically allocated in micro-fluidic channel have been demonstrated with enhanced performance [200]. Conductive SU-8 nanocomposite comprising silver nanoparticles have been demonstrated to realize electronics components and interconnect on flexible substrate for sensing application [201]. The reported miniaturized electronic components and highdensity interconnects were realized using low-cost microfabrication techniques. Realization of such high-density electronic components at reduced cost compared to their semiconductor counterparts paves a way to realize homogeneous SU-8 polymeric devices and signal processing circuitry. Experimental results have been reported for developing miniaturized devices with low-cost fabrication process using SU-8 as sacrificial layer [202]. Research on the methods of immobilization has been also reported to improve the biological sensitivity without affecting the SU8 cantilever structure. Typically, harsh chemical treatment during immobilization of receptor has a detrimental impact of device structure. Recently, a vapor phase deposition of self-assembled monolayers with reduced impact on device structure has been reported [203].

The performance optimization of cantilever sensors using various innovative designs and process optimizations has been also reported. Sensor performance optimization has been carried out by careful structural optimization [204-207] and material selection [208-210]. The performance of SU-8 polymeric piezoresistive micro-cantilever sensors is determined not only by electrical sensitivity governed by material parameters of piezoresistor gauge factor and Young's modulus of structural layer, but also by geometrical factors and noises (both intrinsic and 
Table 6 Various combinations of materials for piezoresistor and structural layer with their respective G/E ratios [90, 192-195]

\begin{tabular}{lclcc}
\hline Structural layer & Young's modulus $(E)(\mathrm{GPa})$ & Piezoresistor & Gauge factor $(G)$ \\
\hline $\mathrm{Si}$ & 169 & $\mathrm{Si}$ & 140 & 0.82 \\
$\mathrm{SiO}_{2}$ & 70 & $\mathrm{Si}$ & 140 & 2.0 \\
& 70 & p-poly-Si & 20 & 0.28 \\
$\mathrm{Si}_{3} \mathrm{~N}_{4}$ & 250 & Au & 20 & $8 \times 10^{-3}$ \\
& 250 & p-poly-Si & 2 & 0.40 \\
$\mathrm{SU}-8$ & 5 & Au & 20 & $10^{-2}$ \\
& 5 & p-poly-Si & 20 & 4.0 \\
& 5 & CB SU-8 & 144 & 4.0 \\
\end{tabular}

extrinsic). Geometrical parameters include the cantilever platform and piezoresistor shape (including constituent layer dimensions) and are governed by desired electrical sensitivity and mechanical stability of the sensor from external vibrational noises. In addition, the sensor design is also governed by noise sources like thermal drift of sensor output, invalid detection due to temperature variation of cantilever surface induced by either external temperature change or joule heating of the dc-excited piezoresistor, variation in sensor output due to change in $\mathrm{pH}$ of operational medium, plastic deformation and electro-migration (in case of metal piezoresistors) due to joule heating, change in cantilever resonant frequency due to moisture absorption by SU-8 polymer, biological noise floor due to non-specific target-receptor interactions, to mention a few. Importantly, the aforementioned factors are limited by fabrication constraints.

Primary reliability issues are mainly vulnerability of SU-8 cantilevers to moisture, resist aging and temperature sensitivity. Moisture absorption not only impacts the mechanical sensitivity, but also has a detrimental impact on piezoresistor stability when polymeric cantilevers are used in organic solvents and buffer solution. Similarly, temperature susceptibility results in invalid detection, thermal drift-induced inaccuracy in sensor output characteristics, and plastic deformation. Various solutions have been devised to overcome the aforementioned limitations. Indepth investigation on understanding the atomistic physics of moisture absorption and its impact on system level of micro-/nano-epoxy-bonded systems depicts the hierarchical structure of the epoxy-bonded system is crucial for the interfacial integrity [211]. Recently, a parylene-C-coated SU-8 cantilever has been reported with reduced moisture vulnerability and better stability [212]. Seldom researchers have addressed the self-heating effect on SU-8 polymeric piezoresistive micro-cantilever sensors. However, for solid-state semiconductor piezoresistive cantilever sensors, the literature encompasses a few examples which detail the impact of self-heating and provide design solutions to overcome the inaccuracy induced due to thermal drift [213, 214]. Such solutions can be also extended to SU-8 polymeric piezoresistive cantilever sensors. More specifics on the aforementioned parameters which determine sensor performance and their dependence on fabrication techniques adopted to realize the sensor are detailed in the subsequent sections.

\section{SU-8 Polymer-Based Piezoresistive Cantilever Sensors}

SU-8 is an epoxy-acrylate-based negative-tone chemically amplified photoresist (PR) polymer which constitutes SU-8 monomers with 8 epoxy groups each forming the polymer matrix and comprising resin (SU-8 monomers), organic solvent, and photoacid generator. On exposure to light [215] or high-energy proton beam [216], SU-8 polymers undergo chemical amplifications that result in polymerization (cross-linking of monomers) due to photoacid generation. However, the complete cross-linking of monomers takes place only at elevated temperatures, which becomes essential to obtain mechanical stability. For more details on the variants of SU-8 polymers, their classification, and thermo-electromechanical characteristics readers may refer the literature $[217,218]$. SU- 8 polymers have been found versatile applications like optical waveguide [132], neural probe [172], micro-pump [219], micro-needle [173], micro-gripper [220], micro-gear [221], micro-mold [222], micro-lens array [223], micro-channel [224], AFM cantilever [175], micro-pillar [225], and micro-resonator [175]. In recent times, SU-8 polymers have also been extensively explored for realizing piezoresistive cantilevers for chemical and biological sensing. SU-8 piezoresistive cantilever sensors can be classified based on either 
geometrical features or constituent materials of the composite cantilever structure. Here, we have classified such sensors based on the piezoresistor material utilized to carry out the electromechanical transduction, as depicted in Fig. 14.

Based on the piezoresistor material, SU-8 polymeric cantilever sensors are classified into two types: hetero- and complete SU-8 polymeric cantilever sensors. While heteroSU-8 cantilevers are designed with a piezoresistor material different from the SU-8 structural layer, the piezoresistors in complete SU-8 cantilevers are realized by electrically conductive SU-8 polymer itself. Further, the hetero-SU-8 cantilever sensors are categorized as metal and doped polysilicon piezoresistor-based sensors. It may be noted that the piezoresistive material not only determines the geometrical design aspects of SU-8 cantilever sensors, but also affects the fabrication process flow to realize such sensors.

Specifics of a few reported metal, doped polysilicon, and doped SU-8 piezoresistor-based SU-8 cantilever sensors detailing their type, cantilever stack configuration, cantilever shape, piezoresistor type, electrical and mechanical parameters are summarized in Table 7. The sensors reported vary in terms of the cantilever geometry, constituent layers, and piezoresistor material. Various cantilever shapes like rectangle (slender and wide), square, $\mathrm{V}$ shape with slit, and $U$ shape have been used to realize piezoresistive SU-8 cantilever sensors. Irrespective of the piezoresistive element in SU-8 sensors, the structural layer and isolation layer are realized with SU-8 polymer. The sensors are realized with either three or four constituent layers. It may be noted that in three-layered structures, there is no separate immobilization layer and the SU-8 isolation layer itself is immobilized with receptors. However, to improve the specificity of detection, a separate $\mathrm{Au}$ immobilization layer is also incorporated by various researchers.

Lateral dimensions of the cantilever platform and thicknesses of the constituent layers are designed to meet specifications of mechanical stability, i.e., spring constant, resonant frequency, and electrical sensitivity. To ensure

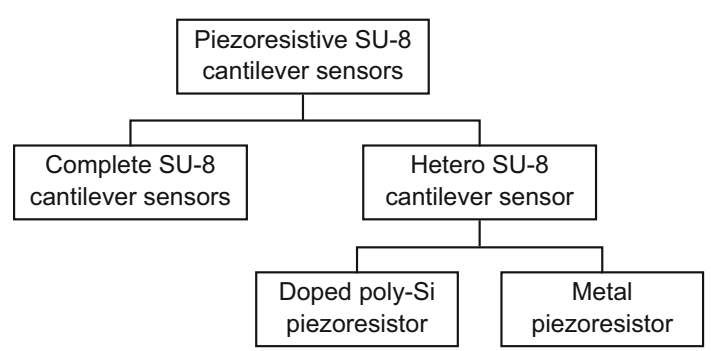

Fig. 14 Classification of SU-8 piezoresistive cantilever sensors based on the piezoresistor material stability and compliance of the cantilever, the spring constant is typically chosen in the range from $0.1 \times 10^{-3}$ to $10 \mathrm{~N} \mathrm{~m}^{-1}$, whereas to reduce the vulnerability of the sensor from external vibrational noise, the sensor is designed with resonant frequency more than $5 \mathrm{kHz}$. The lateral dimensions of the cantilever are also governed by factors like piezoresistor coverage area, sensor die size, etc. Compared to the typical thickness of solid-state semiconductor cantilevers (less than $1 \mu \mathrm{m}$ ), the thickness of SU-8 cantilevers is kept more than $1 \mu \mathrm{m}$ mainly to ensure mechanical stability of the cantilever platform. It may be noted that in all the devices mentioned, careful design is performed such that the distance between the mid-plane of piezoresistor and the neutral axis of the cantilever stack is maximum, thereby maximizing the electrical sensitivity. For instance, in most cases, the thickness of the structural layer is kept more than three times the isolation layer thickness. Even though a separate Au immobilization layer is used, its thickness is kept minimal (nm) to maximize electrical sensitivity.

Piezoresistor geometry is chosen based on the desired nominal resistance value and signal-to-noise ratio (SNR). Lower limit of nominal resistance is determined by joule heating-induced self-heating effects and electro-migration, whereas its upper limit is determined by specifications of driving current and interface circuitry. Thus, typically the value of nominal resistance of piezoresistors is kept in $\mathrm{k} \Omega$ range. In general, the piezoresistors are designed to be U-shaped to improve reliability by avoiding interconnects on the cantilever platform. Since the electrical resistivity of metals is low (in the range of $\mu \Omega-\mathrm{cm}$ ), when metal piezoresistors are designed in $U$ shape, their nominal resistance is only a few ohms, which results in large joule heating. Thus, strategically the metal piezoresistors are designed lengthier to obtain large nominal resistance. Therefore, in few cases, rather than the conventional U-shaped design, the piezoresistors are meander-shaped. However, the coverage of the piezoresistor is limited by the cantilever lateral dimensions, since lengthier cantilever platforms result in reduced mechanical stability and electrical sensitivity. On the other hand, by tailoring the electrical resistivity of the piezoresistor material and careful design, it is possible to realize U-shaped metal piezoresistors. Similarly, the width and thickness of the piezoresistor are designed to obtain a desirable nominal resistance. Thickness of metal piezoresistors has an additional constraint on noise figure, since thinner metal piezoresistors show higher electrical noise level. The need for high nominal resistance value to reduce the current density and therefore the joule heating effects is achieved by using lower supply voltages. In the case of doped polysilicon or doped SU-8 piezoresistors, the electrical resistivity is controlled by varying the dopant concentration. Thus, by 


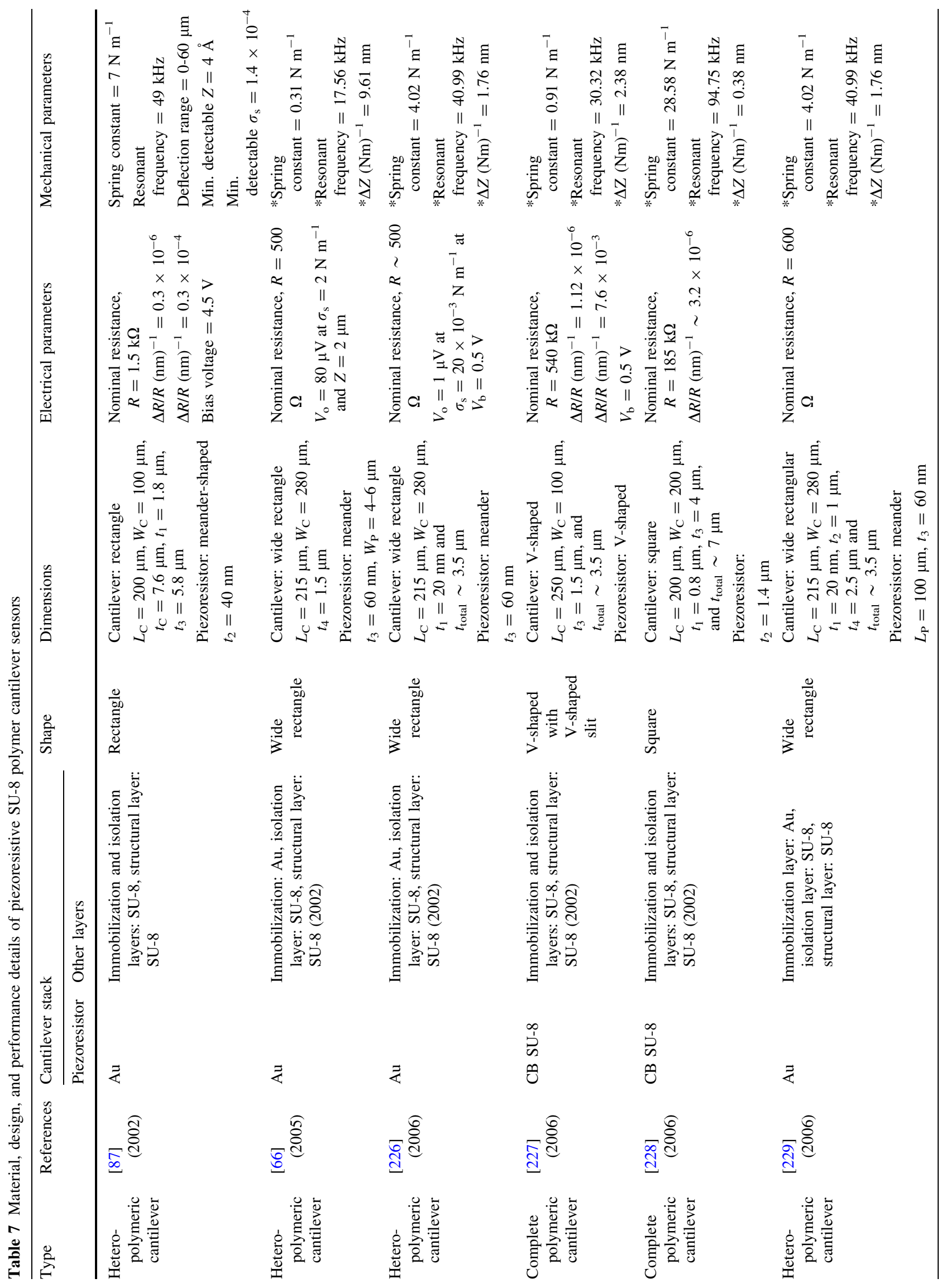




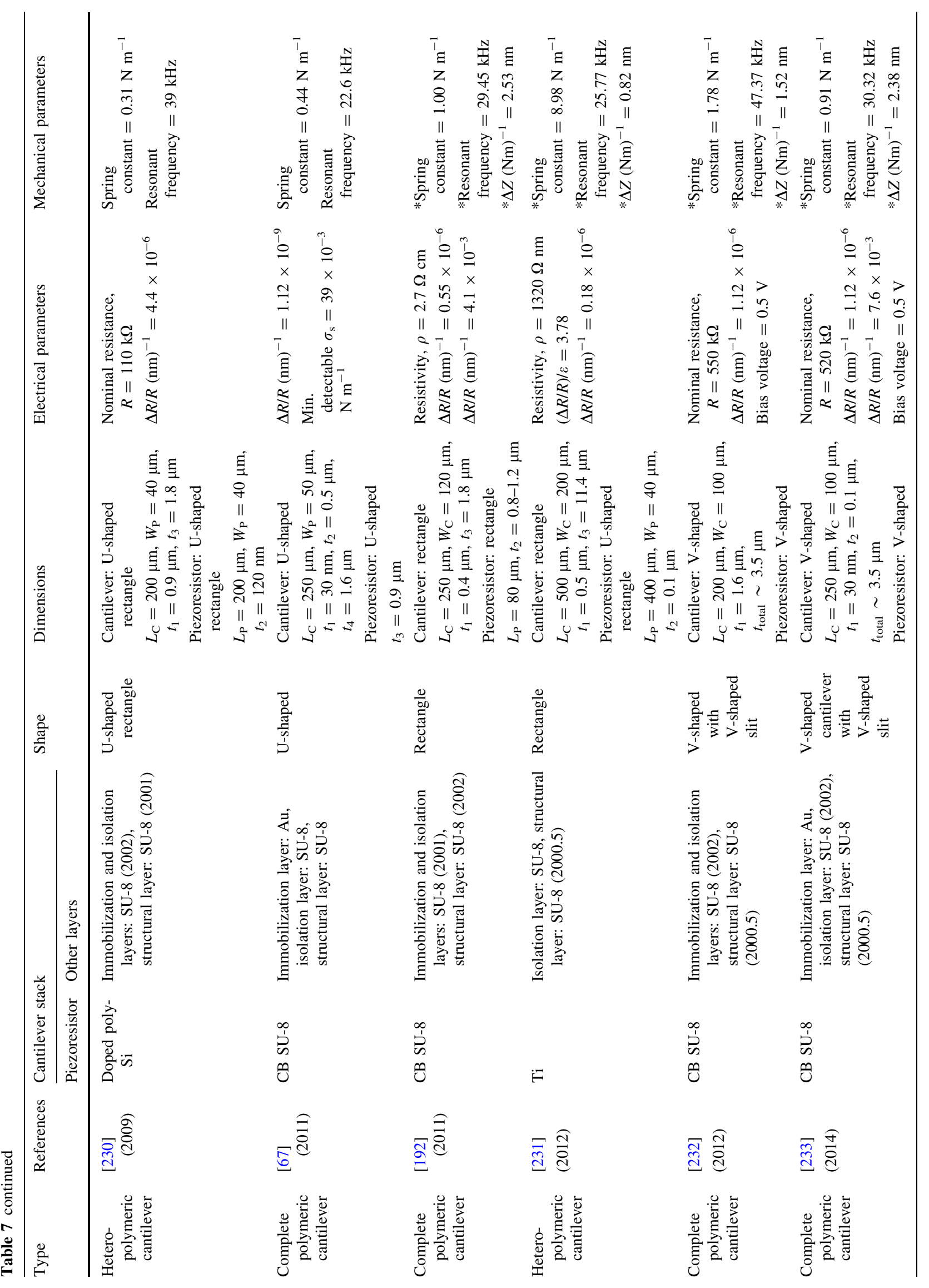




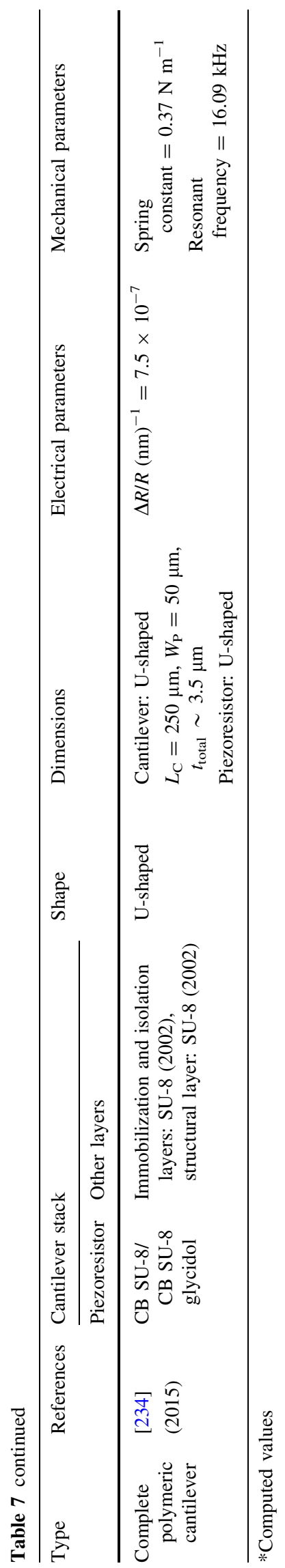

optimizing the dopant concentration and geometry of the piezoresistor, desired nominal resistance is achieved. Typical magnitude of surface stress sensitivity and deflection sensitivity of SU-8 piezoresistive cantilever sensors are in the range of a few $\times 10^{-3}(\mathrm{~N} / \mathrm{m})^{-1}$ and a few $\times 10^{-6}$ to $\times 10^{-9}(\mathrm{~nm})^{-1}$ which can detect miniscule forces of $\mathrm{pN}$ magnitude and lower.

Comprehensive specifics of the metal, doped polysilicon, and doped polymer-based SU-8 cantilever sensors are detailed in the subsequent sections.

\subsection{Hetero-SU-8 Polymeric Cantilevers}

In SU-8-based hetero-polymeric cantilever sensors, the structural and isolation layers are realized with SU-8 polymer, whereas the piezoresistor is either a metal or a semiconductor element.

\subsubsection{Cantilevers with Metal Piezoresistors}

The combination of metal piezoresistor $(\mathrm{Au})$ with SU-8 polymer structural layer was first demonstrated by Thaysen et al. in 2002 [87]. Under stress, unlike semiconductor piezoresistors in which deformation of energy bands results in change in electrical resistivity, in metal piezoresistors geometrical variations (strain) cause the resistance to change. Over the years, various metals and their alloys have been investigated for application in strain sensing which includes titanium (Ti) [231], gold (Au) [235], copper $(\mathrm{Cu})$ [236], bismuth-antimony (Bi-Sb) [237], copper-nickel $(\mathrm{Cu}-\mathrm{Ni})$ constantan alloy [238], nickel-chromium (Ni-Cr) [239], palladium-chromium (Pd-Cr) [240], platinum (Pt) [241], manganese (Mn) [242], and nickel-silver (Ni-Ag) [243].

In metal piezoresistor-based cantilever sensors, a metal resistive layer is deposited atop the SU-8 structural layer. In order to prevent direct contact between the external environment and the electrically active metal piezoresistor, a thin layer of SU-8 is coated over the metal resistive element. Metal piezoresistors have the inherent advantage of low Johnson and $1 / f$ noise [244]. Moreover, the sensitivity factor $(\mathrm{G} / \mathrm{E}$ - ratio of gauge factor of the piezoresistor to the Young's modulus of the structural layer) of metal, especially Au- and Ti-based SU-8 cantilever sensors, is better than the combination of metal or doped polysilicon piezoresistor-based cantilevers with structural layer realized with other materials. An optical image of U-shaped metal (Ti) piezoresistor-based SU-8 cantilever sensor is shown in Fig. 15. The image shows two microcantilever sensors with U-shaped integrated piezoresistors connected in a Wheatstone bridge (WSB) configuration with two on-chip resistors. The differential measurement results not only in the reduction in external noises from the 
environment like mechanical vibrations, but also in cancellation of internal noise factors like resistor mismatches and thermal drift [245].

Even though metal piezoresistor-based SU-8 cantilevers are used as an alternative for solid-state semiconductorbased design, they suffer from a few limitations. It is preferred to design cantilevers with high value of nominal resistance of the piezoresistor primarily to reduce the magnitude of current and therefore the resulting Joule heating. However, it may be noted that due to very low resistivity of metals, the maximum value of nominal resistance of metal piezoresistors cannot be increased beyond a certain limit. Thus, when biased with a dc source compared to other piezoresistive materials, metal piezoresistors carry large volumetric current that results in significant Joule heating. The Joule heating of the metal piezoresistor combined with lower thermal conductivity of SU-8 polymer matrix results not only in the difference in TCE-induced cantilever deflection, but also in an increase in Johnson noise floor and plastic deformation of the cantilever. Increasing the piezoresistor length is an option to increase the nominal resistance value. However, this adversely affects the electrical sensitivity of the device as a major portion of the resistor may be placed on the unstressed region of the cantilever. Other option is to design serpentine-shaped metal piezoresistors and biasing it with low dc voltage. Apart from the aforementioned factors, electro-migration is also closely related to the high magnitude of current density and, more importantly, the miniaturized size of the piezoresistor leading to instability in its resistance value [87]. Adhesion issue of metal with polymer is another issue that can lead to device failure. Designs such as the sensor reported in Ref. [231], where researchers have implemented titanium metal piezoresistor that does not require any adhesive layer.

In summary, although metal piezoresistors depict appreciable value of $\mathrm{G} / \mathrm{E}$ ratio, they suffer from limitations such as Joule heating-induced inaccuracies, instability of resistance value due to electro-migration, and adhesion issues with SU-8 polymer.

\subsubsection{Cantilevers with Polysilicon Piezoresistors}

An alternative piezoresistive material to metal piezoresistor is doped polysilicon. In polysilicon piezoresistor-based SU-8 cantilever sensors, a thin film of polysilicon is used as the piezoresistor material. Even though doped polysilicon piezoresistors along with SU-8 polymeric structural platforms have been demonstrated to have better performance (G/E) than metal-based piezoresistors, realization of such sensors is limited mainly due to the following reasons: (1) vulnerability of SU-8 polymers to high-temperature deposition processes such as low-pressure and plasma-enhanced

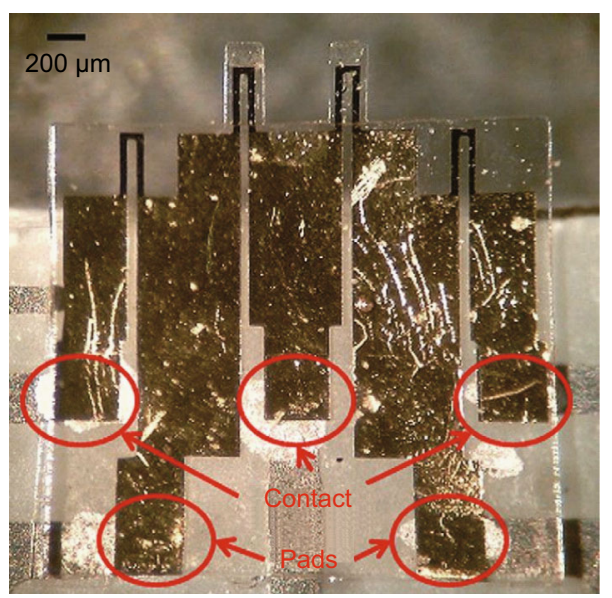

Fig. 15 Optical image of U-shaped titanium piezoresistor-based SU8 cantilever sensors operated in differential mode with passive resistors embedded in WSB configuration. Adopted from Ref. [231]. Copyright (2012) Elsevier B.V.

chemical vapor deposition (CVD) to realize polysilicon piezoresistors, and (2) reduction in electrical sensitivity due to higher stiffness of sensor structure with an integrated polysilicon piezoresistor. Limitations due to cantilever stiffness can be overcome by careful design and dimensional optimization of sensors [246].

Electrical properties of polysilicon are a strong function of its grain size, characteristics of grain boundaries, crystal orientation, doping type, and concentration [247]. More importantly, variation in the impurity concentration and process parameters can be used to tailor the electrical properties of polysilicon, especially the magnitude of the piezoresistive coefficients and the temperature coefficient of resistance (TCR) [248, 249]. Even though polysilicon has lower gauge factor compared to monocrystalline siliconbased piezoresistor, controllability over its TCR, lower transverse piezoresistive coefficients which become critical to realize surface stress-based sensors, and piezoresistive coefficients prove critical to overcome thermal drift in cantilever sensors. Polysilicon piezoresistors are realized with a low-temperature deposition technique known as hotwire chemical vapor deposition (HWCVD) [230]. Polysilicon piezoresistor is deposited atop the SU-8 structural layer and encapsulated by a thin coating of SU-8 isolation layer. The thin SU-8 layer atop the piezoresistor element acts as both the isolation and immobilization layers for target-receptor interactions. Optical images of the polysilicon piezoresistorbased U-shaped SU-8 cantilevers are shown in Fig. 16.

Despite various advantages, the performance of doped polysilicon-based SU-8 cantilevers is curtailed by the increased stiffness of composite cantilever structure when polysilicon piezoresistor is incorporated within. This is mainly due to the relatively higher Young's modulus of polysilicon piezoresistor compared to SU-8 polymer [246]. 

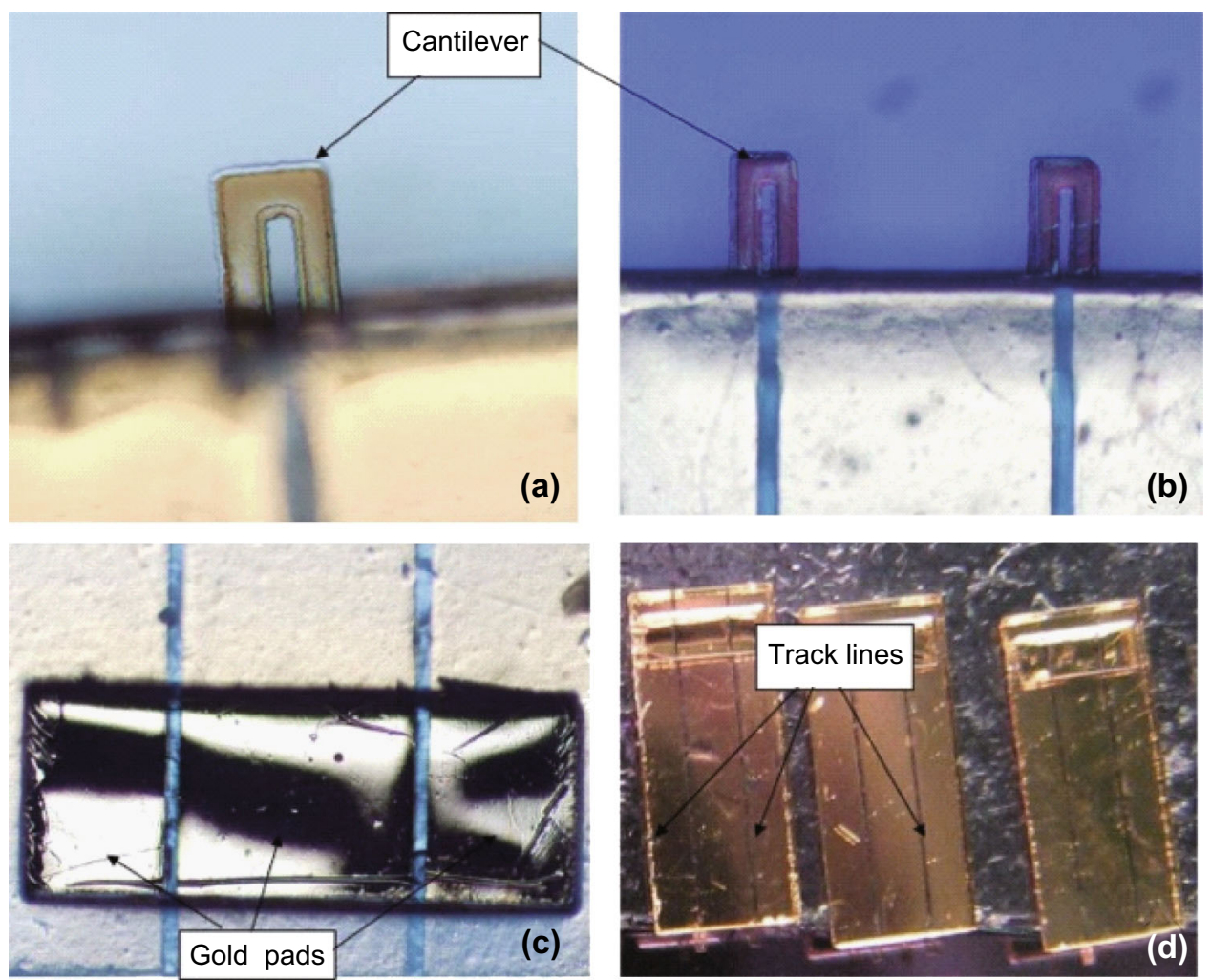

Fig. 16 Optical images of a a U-shaped polysilicon piezoresistor-based SU-8 cantilever sensor, b two U-shaped cantilever sensors, $\mathbf{c}$ gold pads and track lines, and d complete die. Adopted from Ref. [230]. Copyright (2009) IEEE

A potential solution is to reduce the thickness of the piezoresistor, however at the cost of increased electrical noise.

\subsection{Complete SU-8 Polymeric Cantilevers}

In complete SU-8 polymeric cantilevers, all the constituent layers of the device are realized using SU-8 polymers. Here, rather than metal or doped polysilicon, conductive polymers are used as the piezoresistive material. In its native state, polymer matrix behaves as an electrical insulator. However, polymers are made conductive by a controlled addition of conducting nanoparticles known as conductive fillers. Treatise encompasses various examples of conductive fillers, which are physically dispersed in the polymer matrix to realize conductive polymers like carbon black (CB) [250], silver nanoparticles [251], copper [252], multi-walled carbon nanotubes (MWCNTs) [253], diamondoids [254], single-walled carbon nanotubes (SWCNTs) [254], and gold nanoparticles [254]. The degree of electrical conductivity of polymers added with conductive fillers is determined by the density of conductive nanoparticles and their distance in the polymer matrix. The dominant mechanism of electrical conduction is electron tunneling between the nanoparticles through the polymer film boundary [255]. In-depth specifics of the electric conduction mechanism and the factors that govern the electrical conductivity in conductive polymers are detailed in [256-259]. A typical example of variation in electrical resistivity of $\mathrm{CB}$ SU-8 composite as a function of $\mathrm{CB}$ doping in SU-8 matrix is shown in Fig. 17.

Complete SU-8 polymeric cantilevers overcome the limitations of increased stiffness of hetero-SU-8 polymeric cantilevers due to the integration of metal/polysilicon piezoresistors with higher Young's modulus in the SU-8 cantilever stack. The conductive SU-8 polymer layer is spin-coated on the cantilever structural layer and then encapsulated with an isolation layer. The conductivity of doped composite SU-8 polymer depends mainly on the loading of conductive nanoparticles, dispersion and alignment of nanoparticles in the SU-8 polymer matrix, and the percolation limits. When cantilever undergoes deflection, the conductivity of CB-doped SU-8 piezoresistor changes due to distortions in the conductive network of dispersed nanoparticles in the polymer matrix. The optical image of a CB-doped SU-8-based piezoresistive cantilever sensor array is shown in Fig. 18. The higher gauge factor of CBdoped SU-8 and lower Young's modulus of SU-8 structural layer result in $\mathrm{G} / \mathrm{E}$ close to 4 . In recent times, CB-doped SU-8 polymeric cantilever has been demonstrated to have better electrical sensitivity than optics-based designs [233]. 


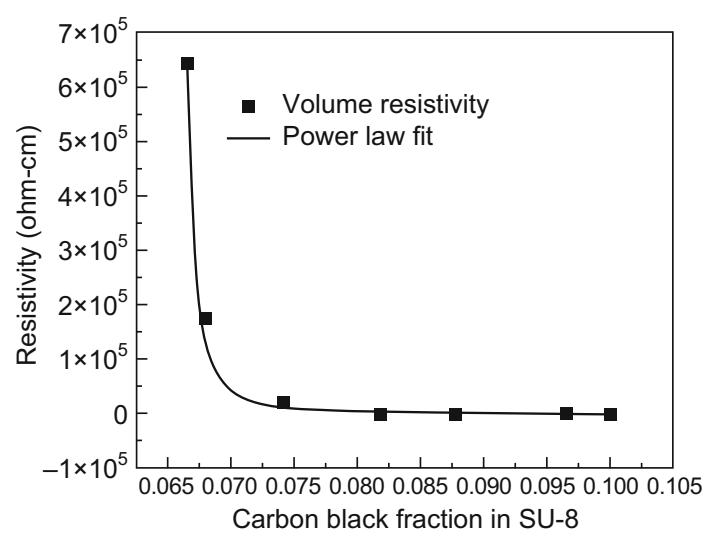

Fig. 17 Variation in electrical resistivity of CB SU-8 composite as a function of CB doping. Adopted from Ref. [192]. Copyright (2009) Elsevier Masson SAS

\section{Fabrication Details of Piezoresistive SU-8 Polymeric Cantilevers}

In this section, we elucidate the fabrication details of SU-8 piezoresistive cantilever sensors with metal, doped polysilicon, and CB-doped SU-8 polymer as the piezoresistor element. Unlike solid-state semiconductor piezoresistive sensors, which are predominantly realized by bulk micro-machining and require costly equipment like ion implantation machine and stringent clean room facilities, fabrication of SU-8 cantilevers includes steps like spin coating, deposition, and etching, which are relatively costeffective in terms of both material and amenities required. In the subsequent sections, we detail the fabrication steps required to realize both hetero- and complete piezoresistive SU-8 polymeric cantilever sensors.
A generic fabrication process flow used to realize metal/doped polysilicon/CB-doped SU-8 piezoresistorbased SU-8 polymeric cantilever sensors is shown in Fig. 19. The substrate wafer used as a base to realize the cantilevers is either an $n$ - or $p$-type SCS wafer as shown in Fig. 19a. Post-realization of the SU-8 cantilevers, the base SCS wafer is separated from the cantilever structures and reused again. A thin sacrificial layer of $\mathrm{Cr} / \mathrm{Au} / \mathrm{Cr}$ in the case of metal piezoresistors, and $\mathrm{SiO}_{2}$ in the case of doped polysilicon and CB SU-8 piezoresistors, is deposited atop the SCS wafer as shown in Fig. 19b. Subsequently, in the next step, a relatively thin layer of SU-8 (thickness $\approx 2 \mu \mathrm{m}$ ) is spin-coated and patterned as depicted in Fig. 19c. This thin SU-8 layer serves as the isolation layer and protects the piezoresistor. Thickness of the spin-coated isolation layer plays a critical role in tailoring the distance between the mid-plane of the piezoresistor and the neutral axis of the cantilever stack, and therefore the electrical sensitivity. In the following step, a metal layer (with thickness $<1 \mu \mathrm{m}$ ) is deposited atop the thin SU-8 isolation layer and patterned with standard photolithographic process to define the contact pads as depicted in Fig. 19d. Then, a thin layer of piezoresistor (metal by sputtering/doped polysilicon by HWCVD/CB SU-8 by spin coating) is deposited and photolithographically patterned to define the piezoresistor element (as shown in Fig. 19e). Subsequently, a thick layer of SU-8 layer (thickness $=3-5 \mu \mathrm{m})$ is spin-coated and patterned to form the structural layer of the cantilever sensor (as depicted in Fig. 19f). To maximize electrical sensitivity, spin-coated SU-8 structural layer thickness is chosen higher than that of the SU-8 isolation layer. In the following step, a SU-8 polymer variant with high viscosity is spin-coated. This thick film of SU-8 (thickness $=350-500 \mu \mathrm{m}$ ) is patterned

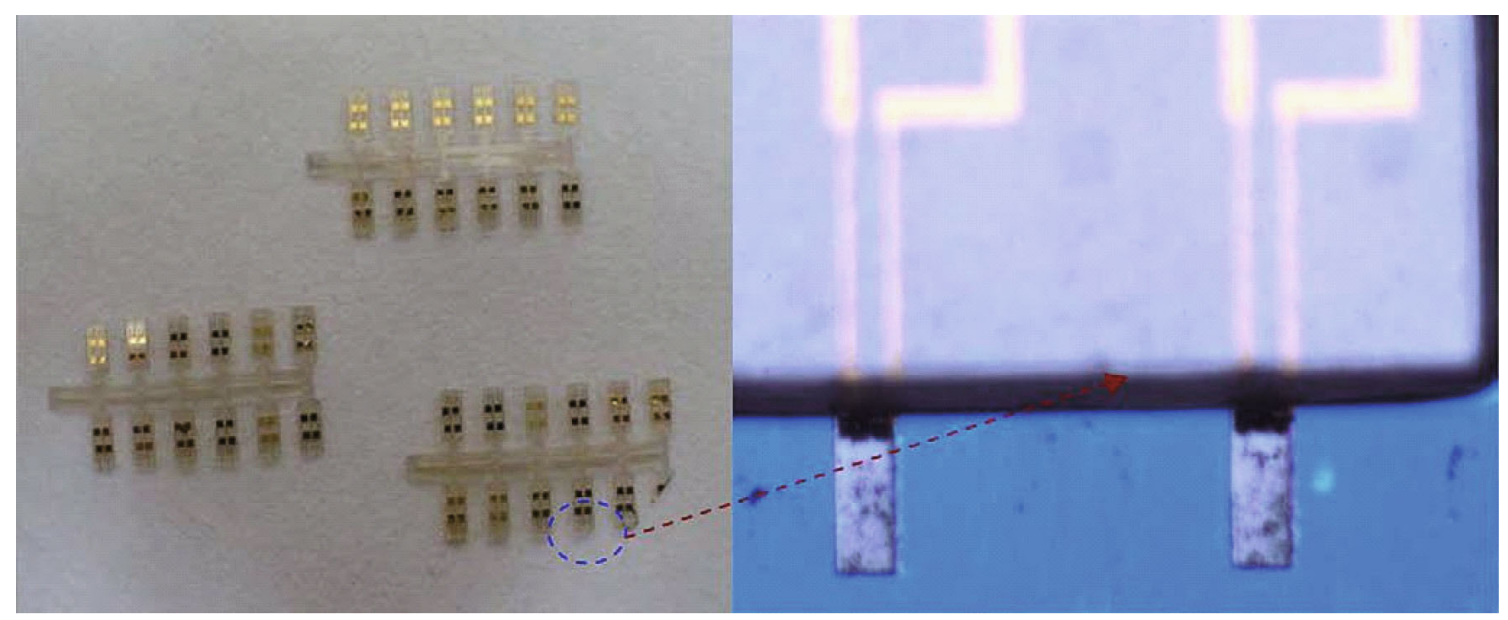

Fig. 18 Optical image of CB-doped SU-8 piezoresistor-based SU-8 cantilever sensor arrays with a zoom-in image of a pair of cantilevers. Adopted from Ref. [192]. Copyright (2009) Elsevier Masson SAS 


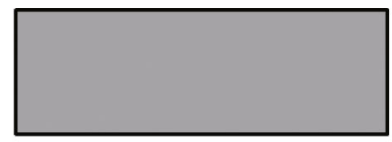

(a) Silicon wafer

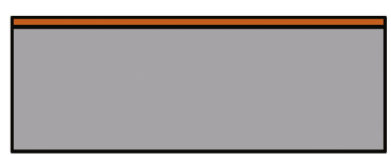

(b) Deposition of sacrificial layer

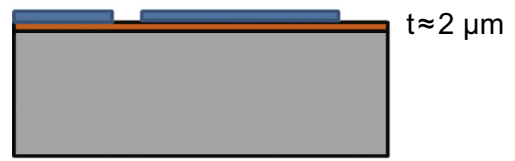

(c) Spin coating and patterning of isolation layer

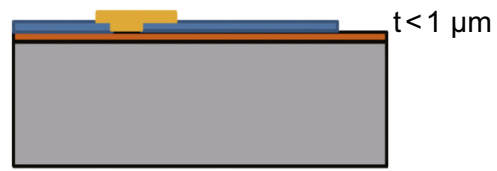

(d) Deposition and patterning of contact pads

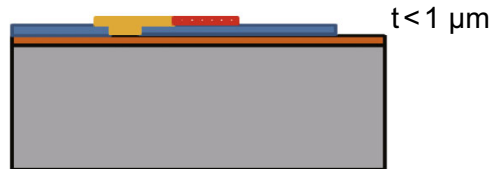

(e) Deposition/spin coating and patterning of piezoresistor

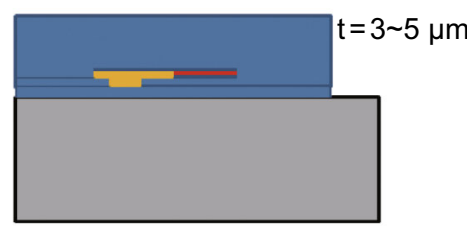

(f) Spin coating of structural layer

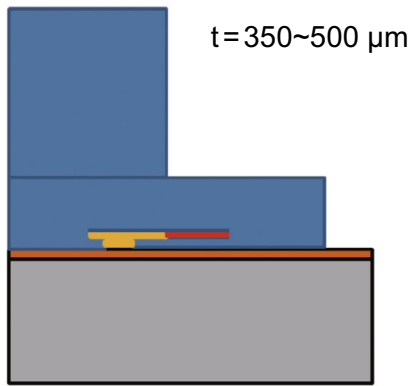

(g) Definition of cantilever base

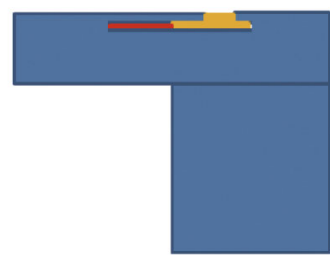

$\square \mathrm{Si}$

$\mathrm{SiO}_{2}$

SU-8

$\square \mathrm{Au}$

(h) Cantilever release

Fig. 19 Generic fabrication process steps to realize metal/doped polysilicon/CB SU-8 piezoresistor-based SU-8 polymeric micro-cantilever sensor

by a photolithographic process to realize the cantilever base as shown in Fig. 19g. Finally, the cantilever structure is released by etching the sacrificial layer using wet etching. More specifics of fabrication sequences and process parameters for realizing metal piezoresistor SU-8 sensors are detailed in Ref. [87, 231], whereas doped polysilicon and CB SU-8-based cantilever sensors are reported in Ref. [230, 260] and [217, 218, 233], respectively. For comprehensive details regarding the soft bake, exposure time, post-exposure bake, and processing of SU-8 thin film, readers are encouraged to refer the literature [261-265]. A summary of the piezoresistor materials and their corresponding fabrication techniques along with their features is summarized in Table 8.

Various issues related to the fabrication of metal, doped polysilicon, and CB SU-8-based SU-8 cantilever sensors.

Challenges to realize metal piezoresistor-based SU-8 cantilever sensors include the following: (1) Cantilever release using $\mathrm{Cr} / \mathrm{Au} / \mathrm{Cr}$ sacrificial layer with wet etching process results in complexities. In the case of $\mathrm{Cr} / \mathrm{Au} / \mathrm{Cr}$ sacrificial layer, the first layer of $\mathrm{Cr}$ acts as an adhesive layer for $\mathrm{Au}$, whereas the subsequent $\mathrm{Au}-\mathrm{Cr}$ combination forms a galvanic cell which promotes faster etching [266].
However, the wet release of cantilever suffers from limitation due to the stiction [260] and lower etch rates of wet etchants. A potential solution of this problem was reported by Haefliger et al. [267], who demonstrated an innovative dry release technique with thin fluorocarbon film (an antistiction and hydrophobic coating) as the sacrificial layer. (2) Adhesion-related issues of metal and SU-8 polymer structure. (3) Deposition of metal on SU-8 results in residual stress-induced cantilever bending that leads to device failure [268].

Challenges to realize doped polysilicon piezoresistorbased SU-8 cantilever sensors include adhesion of polysilicon to SU-8, increase in the stiffness of cantilever stack due to higher Young's modulus of polysilicon piezoresistor, and difficulty in controlling the process parameters of deposited polysilicon.

Challenges to realize doped SU-8 piezoresistor-based SU-8 cantilever sensors are given below: (1) Poor dispersion of conductive nanoparticles in the SU-8 polymer matrix results in reduced conductivity and control over the electrical resistivity of conductive polymer. The dispersion of conductive nanoparticles is improved by using a nanothinner as demonstrated by Seena et al. [192] who used a 
Table 8 Various piezoresistor materials and their respective features used to realize SU-8 piezoresistive cantilever sensors

\begin{tabular}{|c|c|c|c|c|c|}
\hline Piezoresistor & $\begin{array}{l}G / \\
E \text { ratio }\end{array}$ & $\begin{array}{l}\text { Nominal } \\
\text { resistance }\end{array}$ & $\begin{array}{l}\text { Fabrication steps to realize } \\
\text { the piezoresistor }\end{array}$ & Issues/features & References \\
\hline Metal & 0.4 & $\begin{array}{l}500 \Omega- \\
1.5 \mathrm{k} \Omega\end{array}$ & $\begin{array}{l}\text { Sputtering/thermal } \\
\text { evaporation }\end{array}$ & $\begin{array}{l}\text { Higher rate of joule heating } \\
\text { Plastic deformation of the cantilever } \\
\text { Reduced SNR } \\
\text { Electro-migration effect in resistors } \\
\text { Adhesion of metal with SU-8 }\end{array}$ & {$[68,87,226,229,231]$} \\
\hline Polysilicon & 4.0 & $100-200 \mathrm{k} \Omega$ & HWCVD & $\begin{array}{l}\text { High dependence of electrical properties of } \\
\text { poly-Si on process parameters } \\
\text { Higher stiffness compared to metal } \\
\text { piezoresistor } \\
\text { Adhesion of poly-Si with SU-8 }\end{array}$ & {$[217,230,260]$} \\
\hline CB SU-8 & 4.0 & $185-550 \mathrm{k} \Omega$ & Spin coating & $\begin{array}{l}\text { Higher gauge factor, low-temperature process } \\
\text { Lower residual stress } \\
\text { Dependence of mechanical properties on } \mathrm{CB} \\
\text { loading } \\
\text { Electrical resistivity variation due to } \mathrm{CB} \\
\text { dispersion issues }\end{array}$ & {$[67,192,233,250]$} \\
\hline
\end{tabular}

nano-thinner 2000 for improving the dispersion of $\mathrm{CB}$ in SU-8 2002. (2) The mechanical characteristics like Young's modulus of polymer with low concentration of doping ( $E_{\mathrm{CB}-\mathrm{SU}-8}$ approximately equals to $5 \mathrm{GPa}$ ) remain mostly unaltered [250]. More recently, it was shown that the CB-filled SU-8 matrix had increased by $30-40 \%$ for $\mathrm{CB}$ doping of $8 \mathrm{vol} \%$ [67]. (3) Variation in photosensitivity of SU-8 due to physical dispersion of nanoparticles directly affects the curing times and hence the quality of microfabrication.

Compared to metal and doped polysilicon-based piezoresistors, the spin-coated CB-doped piezoresistor overcomes the limitations of higher-temperature deposition techniques. In addition, since (conductive) SU-8 itself is used as the piezoresistor, the limitation of residual stress generated due to two dissimilar materials, which are found between metal-SU-8 and polysilicon-SU-8 cantilever platforms, is overcome. However, tight control over the process parameters becomes essential, especially to realize SU- 8 as the piezoresistor element. Furthermore, since the polymer matrix absorbs water from its surroundings SU-8 is susceptible to humidity [269-272]. The absorption of humidity results in variations in the resonant frequency of SU-8 polymeric cantilevers, which affects the mechanical stability of the sensor [273]. However, humidity-related drifts and resist aging-related issues can be reduced by process optimization [66, 274]. Despite the aforementioned issues, SU-8 polymer-based piezoresistive cantilever sensors have been used for various chemical and biological sensing applications through careful design and process optimization.

\section{Applications}

Piezoresistive SU-8 cantilever platform sensing technology combined with the advances in recognition techniques has been used for various chemical and biological sensing applications, as summarized in Table 9.

Typical biological sensing applications include usage as a sensing and investigation tool in the field of biomedical engineering, especially genomics and proteomics. Recently, detection of biochemical entities has been also reported using SU-8 piezoresistive cantilevers. SU-8-based piezoresistive cantilever sensors capable of sensing surface stress in the range of few $\mathrm{mN} \mathrm{m}^{-1}$, which is typical in the case of interaction of biochemicals on a gold surface, have been demonstrated by Thaysen et al. [87]. A specific example of biochemical sensing application is the detection of antigens like myoglobin (a cardiac disease marker). Myoglobin is a potential indicator of heart attacks in human, and its detection in human blood above a certain threshold could result in the early detection of heart attack and its prevention. Kale et al. [230] reported doped polysilicon-based SU-8 cantilevers, which exhibited sensitivity in the range of $\mathrm{mN} \mathrm{m}^{-1}$, are capable of detecting myoglobin and anti-myoglobin interactions. Apart from detection of biochemicals, detection and investigation of human DNA was also demonstrated with surface stress detection sensitivity of a few $\mathrm{mN} \mathrm{m}^{-1}$ using Au piezoresistor SU-8 cantilever sensors [229].

Detection of explosives like 2, 4, 6-trinitrotoluene (TNT), pentaerythritol tetranitrate (PETN), and hexahydro1,3,5-triazine (RDX) becomes critical for homeland 
Table 9 Typical chemical and biological sensing applications of piezoresistive SU-8 polymeric cantilever sensors

\begin{tabular}{lll}
\hline References & Authors & Application \\
\hline$[87]$ & Thaysen et al. & Biochemical sensing \\
{$[230]$} & Kale et al. & Antigen-antibody (myoglobin) \\
{$[192]$} & Seena et al. & Explosive detection \\
{$[233]$} & Patil et al. & Explosive detection (TNT, RDX, and PETN) \\
{$[232]$} & Reddy et al. & Carbon monoxide (CO) \\
{$[67]$} & Seena et al. & Explosive detection (TNT) \\
{$[229]$} & Johansson et al. & DNA hybridization \\
{$[227]$} & Patil et al. & Humidity and moisture detection \\
{$[68]$} & Johansson et al. & Mercaptohexanol \\
{$[226]$} & Johansson et al. & Mercaptohexanol \\
\hline
\end{tabular}

security mainly tackling chemical warfare. Compared to conventional explosive detection schemes like mass spectroscopy and ion mobility spectrometry (IMS), piezoresistive SU-8 cantilever sensors have advantages of compactness, faster response, better sensitivity, low sample volume, especially for detecting explosive in vapor phase, apart from the added benefits of MEMS technology. Typically, detection of nitro aromatic explosives like TNT, RDX, PETN is performed by immobilizing 4-mercaptobenzoic acid (4-MBA) or 6-mercaptonicotonic acid (6MNA) receptors on Au surface using thiol immobilization protocol. When exposed to TNT molecules, such receptor molecules form hydrogen bonds with TNT, resulting in the change in surface stress. Piezoresistive SU-8 cantilever sensors have been demonstrated to detect TNT down to parts-per-billion [67, 192] and parts-per-trillion [233] concentration in vapor phase with excellent selectivity. In addition, detection of chemicals like mercaptohexanol has been also reported in the literature [68, 226].

In addition, piezoresistive SU-8 cantilever sensors have been used as artificial nose for environment monitoring applications such as detection of gases like carbon monoxide (CO) and moisture. Detection of gases like $\mathrm{CO}$ becomes essential due to its toxic nature and possible health hazards. Similarly, detection of moisture becomes important in fields like food storage and processing to prevent food spoilage. Piezoresistive SU-8 cantilevers coated with $\mathrm{Fe}$ (III) porphyrin have been demonstrated to detect $\mathrm{CO}$ gas with high specificity and sensitivity down to ppm [232]. Similarly, SU-8 cantilevers coated with polyaniline (PANI) nano-fibers showed good sensitivity toward moisture [227].

\section{Challenges and Future Perspectives}

In the last decade, piezoresistive SU-8 cantilevers have been extensively explored as sensing platforms for detecting chemical and biological analytes. However, the transition of piezoresistive SU-8 cantilever sensors from a proof of concept to a potential replacement of conventional diagnostics techniques is limited by various challenges.

When used as a sensing tool, a SU-8 cantilever is functionalized with receptors for detecting a specific entity or analyte in a test sample. However, the test sample is a mixture of different entities with varying concentration. Typically, other entities are present in much higher concentration than the target molecules. Thus, the probability of non-specific interactions on the sensor surface is higher, which results in a significant biological noise floor. Moreover, specificity of such sensors becomes critical in determining the desired signal baseline. Premise is primarily influenced by the immobilization protocol adopted that determines the immobilization surface and target-receptor conjugate. Other sources that contribute to biological noise floor include the presence of more than one conjugate pair for the receptor molecules, non-uniform immobilization of receptors, and negligence in immobilization surface preparation. Non-specific interactions can be reduced by considering an immobilization material that is chemically different from SU- 8 and by tight control over immobilization technique.

Piezoresistive SU-8 cantilever sensors with Au immobilization layer depict better performance metrics (electrical sensitivity and specificity) compared to sensors with SU-8 as the immobilization surface. However, incorporating $\mathrm{Au}$ immobilization layer in the cantilever stack increases the net TCE difference in the multilayer structure, thereby enhancing TCE-induced thermal drift in the sensor terminal characteristics. TCE-induced cantilever deflection becomes a serious problem, especially when metal piezoresistors and bias voltage more than $1 \mathrm{~V}$ are used. The aforementioned factors combined with low thermal conductivity of SU-8 polymers result in sensor failure due to plastic deformation of cantilever structure. Possible solutions to overcome thermal drift include direct immobilization of SU-8 surface, lower bias voltage, and complete polymeric cantilevers. However, for maintaining 
high degree of specificity and sensitivity, thickness and coverage of $\mathrm{Au}$ immobilization layer can be carefully optimized to minimize TCE-induced deflection.

A possible solution to avoid failure due to joules heating-induced plastic deformation of the cantilever is to adopt complete SU-8 polymeric cantilevers with conductive SU-8 as the piezoresistive element. However, controlling the electrical resistivity of conductive nanoparticles-dispersed SU-8 polymer matrix still remains a challenging task. Better controllability over the dispersion of nanoparticles can be obtained by tight control over process parameters and developing better percolation models to understand the phenomenon of electric conductivity in nanoparticles-dispersed polymer matrix.

The performance of piezoresistive SU- 8 cantilever sensors is also influenced by external factors like humidity and temperature. When operated in controlled environment along with careful design for temperature compensation, the impact of temperature on sensor performance can be nullified. However, susceptibility of SU-8 polymers to humidity is a major issue. This problem becomes critical in SU-8based chemical and biological sensors, since the operational environment in such sensors is predominantly liquid or vapor. Absorption of water or moisture changes the mass of SU-8 matrix and therefore directly affects the mechanical stability of the sensor. Vulnerability of SU-8 sensors to moisture can be reduced by optimizing the baking time of SU-8 polymers. Apart from the influence of external factors, SU-8 material and processing-related challenges like aging of SU-8 resist over a period of time, cracks in SU-8 films during processing, non-uniform exposure-induced dimensional inaccuracy of high-aspect-ratio structures, and delamination of SU-8 film from the substrate due to difference in TCE fabrication also induce failure.

Aging of SU-8 polymeric cantilevers is a cumulative effect of environmental factors like temperature, humidity, light with time. Aging of SU-8 polymer has an adverse impact not only on sensor reliability in terms of measurement, but also on sensor durability or life time. Aging over a period of time to humidity and temperature becomes more critical in the case of chemical and biological sensor due to continuous/cyclic exposure to moisture and temperature variation. However, the literature encompasses examples where researchers have performed extensive research to reduce the vulnerability of SU-8 polymeric cantilever to aging by optimization of process parameter (hard bake temperature) [274], solvent content [261], and exposure time [261]. It has been reported that by optimizing process parameters, SU-8 polymeric cantilevers can be used for months (approximately 200 days) without large deviation in initial deflection (with an error within $1^{\circ}$ ) [274].

Despite the aforementioned issues, compared to conventional solid-state semiconductor piezoresistive sensors,
SU-8 polymer-based sensors have advantages in terms of reduced material and fabrication cost. In addition to high performance-to-cost ratio, SU-8 polymers have the advantage of biocompatibility, thus making them a preferred choice in chemical and biological sensing applications. Solutions to existing problems and further advancements in piezoresistive SU-8 cantilever sensors into a universal sensing tool would require close collaboration of researchers from science, engineering, and medicine streams.

\section{Conclusions}

Piezoresistive SU-8 polymeric cantilever sensors emerged as one of the potential replacements for solid-state semiconductor-based designs mainly due to their high performance-to-cost ratio. The research and development of SU8 polymer-based sensors has been a vibrant field. Continuous endeavor of researchers in developing piezoresistive SU-8 polymeric cantilever sensors has made cantilever platform a universal sensing tool for chemical and biological sensing applications. In this article, we have summarized the developments in piezoresistive SU-8 cantilever sensors and critically analyzed their performance considering the material selection, design, and fabrication aspects, and their interdependence. A brief insight into various theories of surface stress generation is detailed. Composite piezoresistive SU-8 micro-cantilever sensors have been classified as hetero- and completely polymeric cantilever. Specifics related to material selection, design, and fabrication of the aforementioned types of SU-8 polymeric cantilevers along with their performances are elucidated in detail. In addition, a critical comparison of the performance of piezoresistive SU-8 cantilever variants with their solid-state semiconductor counterparts using analytical models is also made. Finally, we cited existing challenges and various applications of piezoresistive SU-8 cantilever sensors as a chemical and biological sensing platform.

Open Access This article is distributed under the terms of the Creative Commons Attribution 4.0 International License (http://crea tivecommons.org/licenses/by/4.0/), which permits unrestricted use, distribution, and reproduction in any medium, provided you give appropriate credit to the original author(s) and the source, provide a link to the Creative Commons license, and indicate if changes were made.

\section{References}

1. Z. Zhu, An overview of carbon nanotubes and graphene for biosensing applications. Nano-Micro Lett. 9(3), 25 (2017). https://doi.org/10.1007/s40820-017-0128-6 
2. D. Thuau, C. Ayela, E. Lemaire, S. Heinrich, P. Poulin, I. Dufour, Advanced thermo-mechanical characterization of organic materials by piezoresistive organic resonators. Mater. Horiz. 2(1), 106-112 (2015). https://doi.org/10.1039/ $\mathrm{C} 4 \mathrm{MH} 00165 \mathrm{~F}$

3. J. Zhang, X. Yang, H. Deng, K. Qiao, U. Farooq et al., Lowdimensional halide perovskites and their advanced optoelectronic applications. Nano-Micro Lett. 9(3), 36 (2017). https:// doi.org/10.1007/s40820-017-0137-5

4. Z. Wen, Q. Shen, X. Sun, Nanogenerators for self-powered gas sensing. Nano-Micro Lett. 9(4), 45 (2017). https://doi.org/10. 1007/s40820-017-0146-4

5. S. Stassi, E. Fantino, R. Calmo, A. Chiappone, M. Gillono et al., Polymeric 3D printed functional microcantilevers for biosensing applications. ACS Appl. Mater. Interfaces 9(22), 19193-19201 (2017). https://doi.org/10.1021/acsami.7b04030

6. A. Wang, C. Wang, L. Fu, W. Wong-Ng, Y. Lan, Recent advances of graphitic carbon nitride-based structures and applications in catalyst, sensing, imaging, and LEDs. NanoMicro Lett. 9(4), 47 (2017). https://doi.org/10.1007/s40820-017$0148-2$

7. R. Kumar, O. Al-Dossary, G. Kumar, A. Umar, Zinc oxide nanostructures for $\mathrm{NO}_{2}$ gas-sensor applications: a review. NanoMicro Lett. 7(2), 97-120 (2015). https://doi.org/10.1007/ s40820-014-0023-3

8. J. Yin, V.J. Santos, J.D. Posner, Bioinspired flexible microfluidic shear force sensor skin. Sens. Actuator A-Phys. 264, 289-297 (2017). https://doi.org/10.1016/j.sna.2017.08.001

9. A. Sirelkhatim, S. Mahmud, A. Seeni, N.H.M. Kaus, L.C. Ann, S.K.M. Bakhori, H. Hasan, D. Mohamad, Review on zinc oxide nanoparticles: antibacterial activity and toxicity mechanism. Nano-Micro Lett. 7(3), 219-242 (2015). https://doi.org/10.1007/ s40820-015-0040-x

10. W. He, G. Li, S. Zhang, Y. Wei, J. Wang, Q. Li, X. Zhang, Polypyrrole/silver coaxial nanowire aero-sponges for temperature-independent stress sensing and stress-triggered Joule heating. ACS Nano 9(4), 4244-4251 (2015). https://doi.org/10.1021/ acsnano. 5 b00626

11. P. Singh, S.K. Pandey, J. Singh, S. Srivastava, S. Sachan, S.K. Singh, Biomedical perspective of electrochemical nanobiosensor. Nano-Micro Lett. 8(3), 193-203 (2016). https://doi.org/10. 1007/s40820-015-0077-x

12. J.L. Arlett, E.B. Myers, M.L. Roukes, Comparative advantages of mechanical biosensors. Nat. Nanotechnol. 6(4), 203-215 (2011). https://doi.org/10.1038/nnano.2011.44

13. L.A. Pinnaduwage, T. Thundat, A. Gehl, S.D. Wilson, D.L. Hedden, R.T. Lareau, Deposition characteristics of uncoated silicon micro-cantilever surfaces for explosive and common non-explosive vapors. Ultramicroscopy 100(3-4), 211-216 (2004). https://doi.org/10.1016/j.ultramic.2003.11.006

14. M. Alvarez, A. Calle, J. Tamayo, L.M. Lechuga, A. Abad, A. Montoya, Development of nanomechanical biosensors for detection of pesticides DDT. Biosens. Bioelectron. 18(5), 649-653 (2003). https://doi.org/10.1016/S0956-5663(03)000356

15. H.J. Pandya, W. Chen, L.A. Goodell, D.J. Foran, J.P. Desai, Mechanical phenotyping of breast cancer using MEMS: a method to demarcate benign and cancerous breast tissue. Lab Chip 14(23), 4523-4532 (2014). https://doi.org/10.1039/ C4LC00594E

16. R. Raiteri, G. Nelles, H.J. Butt, W. Knoll, P. Skladal, Sensing of biological substances based on the bending of microfabricated cantilevers. Sens. Actuator B-Chem. 61(1-3), 213-217 (1999). https://doi.org/10.1016/S0925-4005(99)00260-9

17. S. Cherian, R.K. Gupta, B.C. Mullin, T. Thundat, Detection of heavy metal ions using protein-functionalized microcantilever sensors. Biosens. Bioelectron. 19(5), 411-416 (2003). https:// doi.org/10.1016/S0956-5663(03)00226-4

18. J. Pei, F. Tain, T. Thundat, Glucose biosensors based on the microcantilever. Anal. Chem. 26(2), 292-297 (2004). https:// doi.org/10.1021/ac035048k

19. M. Calleja, M. Nordstom, M. Alvarez, J. Tamayo, L.M. Lechuga, A. Boisen, Highly sensitive polymer-based cantileversensors for DNA detection. Ultramicroscopy 105(1), 215-222 (2005). https://doi.org/10.1016/j.ultramic.2005.06.039

20. J. Zhang, H.P. Lang, F. Huber, A. Bietsch, W. Grange et al., Rapid and label-free nanomechanical detection of biomarker transcripts in human RNA. Nat. Nanotechnol. 1(3), 214-220 (2006). https://doi.org/10.1038/nnano.2006.134

21. Y. Arntz, J.D. Seeling, H.P. Lang, J. Zhang, P. Hunziker, J.P. Ramseyer, E. Meyer, M. Hegner, C.H. Gerber, Label-free protein assay based on a nanomechanical cantilever array. Nanotechnology 14(1), 86-90 (2003). https://doi.org/10.1088/09574484/14/1/319

22. N. Bajwa, C.J. Maldonado, T. Thundat, A. Passian, Piezoresistive measurement of swine H1N1 hemagglutinin peptide binding with microcantilever arrays. AIP Adv. 4(3), 037118 (2014). https://doi.org/10.1063/1.4869636

23. H.P. Lang, M.K. Baller, R. Berger, C. Gerber, J.K. Gimzewski et al., An artificial nose based on a micromechanical cantilever array. Anal. Chim. Acta 393(1), 59-65 (1999). https://doi.org/ 10.1016/S0003-2670(99)00283-4

24. S. Xu, R. Mutharasan, Rapid and sensitive detection of giardia lamblia using a piezoelectric cantilever biosensor in finished and source waters. Environ. Sci. Technol. 44(5), 1736-1741 (2010). https://doi.org/10.1021/es9033843

25. L.S. Haung, Y. Pheanpanitporn, Y.K. Yen, K.F. Chang, L.Y. Lin, D.M. Lai, Detection of the antiepileptic drug phenytoin using a single free-standing piezoresistive cantilever for therapeutic drug monitoring. Biosens. Bioelectron. 59, 233-238 (2014). https://doi.org/10.1016/j.bios.2014.03.047

26. J. Arcamone, G. Rius, G. Abadal, J. Teva, N. Barniol, F.P. Murano, Micro/nanomechanical resonators for distributed mass sensing with capacitive detection. Microelectron. Eng. 83(4), 1216-1220 (2006). https://doi.org/10.1016/j.mee.2006.01.177

27. R. Lopez, J.M. Aguirregabiria, M. Tijero, M. Arroyo, J. Elizalde, J. Berganzo, K. Mayora, F.J. Blanco, A new SU-8 process to integrate buried waveguides and sealed microchannels for a Lab-on-a-Chip. Sens. Actuator B-Chem. 114(1), 542-551 (2006). https://doi.org/10.1016/j.snb.2005.05.011

28. J.A. Harley, T.W. Kenny, 1/f noise considerations for the design and process optimization of piezoresistive cantilevers. J. Microelectromech. Syst. 9(2), 226-235 (2000). https://doi.org/10. $1109 / 84.846703$

29. S.M. Yang, T.I. Yin, C. Chang, A biosensor chip by CMOS process for surface stress measurement in bioanalyte. Sens. Actuator B-Chem. 123(2), 707-714 (2007). https://doi.org/10. 1016/j.snb.2006.10.008

30. Y. Yang, Y. Chen, P. Xu, X. Li, Quad-cantilever microsensors with a low cost single -sided micro-machining technique for trace chemical vapor detection. Microelectron. Eng. 87(11), 2317-2322 (2010). https://doi.org/10.1016/j.mee.2010.03.010

31. H.J. Pandya, H.T. Kim, R. Roy, J.P. Desai, MEMS based low cost piezoresistive microcantilever force sensor and sensor module. Mater. Sci. Semicond. Process. 19, 163-173 (2014). https://doi.org/10.1016/j.mssp.2013.12.016

32. R. Yang, X. Huang, Z. Wang, Y. Zhou, L. Liu, A chemisorptionbased microcantilever chemical sensor for the detection of trimethylamine. Sens. Actuator B-Chem. 145(1), 474-479 (2010). https://doi.org/10.1016/j.snb.2009.12.050

33. R.E. Fernandez, S. Stolyarova, A. Chadha, E. Bhattacharya, Y. Nemirovsky, MEMS composite porous silicon/polysilicon 
cantilever sensor for enhanced triglycerides biosensing. IEEE Sens. J. 9(12), 1660-1666 (2009). https://doi.org/10.1109/JSEN. 2009.2030643

34. Y. Zhou, Z. Wang, C. Wang, W. Ruan, L. Liu, Design, fabrication and characterization of a two-step released silicon dioxide piezoresistive microcantilever immunosensor. J. Micromech. Microeng. 19(6), 065026 (2009). https://doi.org/10.1088/0960$1317 / 19 / 6 / 065026$

35. A. Loui, F.T. Goericke, T.V. Ratto, J. Lee, B.R. Hart, W.P. King, The effect of piezoresistive microcantilever geometry on the cantilever sensitivity during surface stress chemical sensing. Sens. Actuator A-Phys. 147(2), 516-521 (2008). https://doi.org/ 10.1016/j.sna.2008.06.016

36. Y. Kim, J.Y. Cha, H. Ham, H. Huh, D.S. So, I. Kang, Preparation of piezoresistive nano smart hybrid material based on graphene. Curr. Appl. Phys. 11(1), 350-352 (2011). https://doi. org/10.1016/j.cap.2010.11.022

37. R. Lakhmi, H. Debeda, I. Dufour, C. Lucat, Force sensors based on screen-printed cantilevers. IEEE Sens. J. 10(6), 1133-1137 (2010). https://doi.org/10.1109/JSEN.2010.2040387

38. P. Alpuim, V. Chu, J.P. Conde, Piezoresistive sensors on plastic substrates using doped microcrystalline silicon. IEEE Sens. J. 2(4), 336-341 (2002). https://doi.org/10.1109/JSEN.2002. 804037

39. R. Katragadda, Z. Wang, W. Khalid, Y. Li, Y. Xu, Parylene cantilevers integrated with polycrystalline silicon piezoresistors for surface stress sensing. Appl. Phys. Lett. 91(8), 083505 (2007). https://doi.org/10.1063/1.2772189

40. K.R. Buchapudi, X. Huang, X. Ji, H.F. Yang, T. Thundat, Microcantilever biosensors for chemicals and bioorganisms. Analyst 136(8), 1539-1556 (2011). https://doi.org/10.1039/ c0an01007c

41. K.M. Goeders, J.S. Colton, L.A. Bottomley, Microcantilevers: sensing chemical interactions via mechanical motion. Chem. Rev. 108(2), 522-542 (2008). https://doi.org/10.1021/cr0681041

42. A. Boisen, S. Dohn, S.S. Keller, S. Schmid, M. Tenje, Cantilever-like micromechanical sensors. Rep. Prog. Phys. 74(3), 036101 (2011). https://doi.org/10.1088/0034-4885/74/3/036101

43. S. Sang, Y. Zhao, W. Zhang, P. Li, J. Hu, G. Li, Surface stressbased biosensors. Biosens. Bioelectron. 51, 124-135 (2014). https://doi.org/10.1016/j.bios.2013.07.033

44. M. Calleja, P.M. Kosaka, A.S. Paulo, J. Tamayo, Challenges for nanomechanical sensors in biological detection. Nanoscale 4(16), 4925-4938 (2012). https://doi.org/10.1039/c2nr31102j

45. D.W. Lee, X. Li, Integrated microcantilevers for high-resolution sensing and probing. Meas. Sci. Technol. 23(2), 022001 (2012). https://doi.org/10.1088/0957-0233/23/2/022001

46. J. Bausells, Piezoresistive cantilevers for nanomechanical sensing. Microelectron. Eng. 145, 9-20 (2015). https://doi.org/ 10.1016/j.mee.2015.02.010

47. H.F. Ji, B.D. Armon, Approaches to increasing surface stress for improving signal-to-noise ratio of microcantilever sensors. Anal. Chem. 82(5), 1634-1642 (2010). https://doi.org/10.1021/ ac901955d

48. A. Sassolas, L.J. Blum, B.D.L. Bouvier, Immobilization strategies to develop enzymatic biosensors. Biotechnol. Adv. 30(3), 489-511 (2012). https://doi.org/10.1016/j.biotechadv.2011.09. 003

49. P. Zucca, E. Sanjust, Inorganic materials as supports for covalent enzyme immobilization: methods and mechanisms. Molecules 19(9), 14139-14194 (2014). https://doi.org/10.3390/ molecules190914139

50. J.C. Love, L.A. Estroff, J.K. Kriebel, R.G. Nuzzo, G.M. Whitesides, Self-assembled monolayers of thiolates on metals as a form of nanotechnology. Chem. Rev. 105(4), 1103-1169 (2005). https://doi.org/10.1021/cr0300789
51. B.J. Kim, E. Meng, Review of polymer MEMS micromachining. J. Micromech. Microeng. 26(1), 013001 (2015). https://doi.org/ $10.1088 / 0960-1317 / 26 / 1 / 013001$

52. C. Liu, Recent developments in polymer MEMS. Adv. Mater. 19(22), 3783-3790 (2007). https://doi.org/10.1002/adma. 200701709

53. M. Nordstrom, S. Keller, M. Lillemose, A. Johansson, S. Dohn, D. Haefliger, G. Blagoi, M.H. Jakobsen, A. Boisen, SU-8 cantilevers for bio/chemical Sensing; fabrication, characterisation and development of novel read-out methods. Sensors 8(3), 1595-1612 (2008). https://doi.org/10.3390/s8031595

54. V. Seena, P. Ray, P. Kovur, M. Kandpal, V.R. Rao, Polymer MEMS sensors, in Advanced biomaterials and biodevices, ed. by A. Tiwari, A.N. Nordin (Wiley, Hoboken, 2014). https://doi. org/10.1002/9781118774052.ch4

55. H.S. Wasisto, S. Merzsch, E. Uhde, A. Waag, E. Peiner, Handheld personal airborne nanoparticle detector based on microelectromechanical silicon resonant cantilever. Microelectron. Eng. 145, 96-103 (2015). https://doi.org/10.1016/j.mee. 2015.03.037

56. H.S. Wasisto, S. Merzsch, E. Uhde, A. Waag, E. Peiner, Partially integrated cantilever-based airborne nanoparticle detector for continuous carbon aerosol mass concentration monitoring. J. Sens. 4(1), 111-123 (2015). https://doi.org/10.5194/jsss-4111-2015

57. H.S. Wasisto, Q. Zhang, S. Merzsch, A. Waag, E. Peiner, A phase-locked loop frequency tracking system for portable microelectromechanical piezoresistive cantilever mass sensors. Microsyst. Technol. 20(4-5), 559-569 (2014). https://doi.org/ 10.1007/s00542-013-1991-9

58. H.S. Wasisto, S. Merzsch, A. Waag, E. Uhde, T. Salthammer, E. Peiner, Airborne engineered nanoparticle mass sensor based on a silicon resonant cantilever. Sens. Actuator B-Chem. 180, 77-89 (2013). https://doi.org/10.1016/j.snb.2012.04.003

59. H.S. Wasisto, S. Merzsch, A. Waag, E. Uhde, T. Salthammer, E. Peiner, Evaluation of photoresist-based nanoparticle removal method for recycling silicon cantilever mass sensors. Sens. Actuator A-Phys. 202, 90-99 (2013). https://doi.org/10.1016/j. sna.2012.12.016

60. H.S. Wasisto, K. Huang, S. Merzsch, A. Stranz, A. Waag, E. Peiner, Finite element modeling and experimental proof of NEMS-based silicon pillar resonators for nanoparticle mass sensing applications. Microsyst. Technol. 20(4-5), 571-584 (2014). https://doi.org/10.1007/s00542-013-1992-8

61. S. Merzsch, F. Steib, H.S. Wasisto, A. Stranz, P. Hinze, T. Weimann, A. Waag, Production of vertical nanowire resonators by cryogenic-ICP-DRIE. Microsyst. Technol. 20(4-5), 759-767 (2014). https://doi.org/10.1007/s00542-013-2032-4

62. H.S. Wasisto, S. Merzsch, A. Stranz, A. Waag, E. Uhde, T. Salthammer, E. Peiner, Femtogram aerosol nanoparticle mass sensing utilising vertical silicon nanowire resonators. Micro Nano Lett. 8(10), 554-558 (2013). https://doi.org/10.1049/mnl. 2013.0208

63. H.S. Wasisto, S. Merzsch, A. Stranz, A. Waag, E. Uhde, T. Salthammer, E. Peiner, Silicon resonant nanopillar sensors for airborne titanium dioxide engineered nanoparticle mass detection. Sens. Actuator B-Chem. 189, 146-156 (2013). https://doi. org/10.1016/j.snb.2013.02.053

64. H.S. Wasisto, S. Merzsch, A. Stranz, A. Waag, E. Uhde, T. Salthammer, E. Peiner, Silicon nanowire resonators: aerosol nanoparticle mass sensing in the workplace. IEEE Nanotechnol. Mag. 7(2), 18-23 (2013). https://doi.org/10.1109/MNANO. 2013.2260462

65. H.S. Wasisto, S. Merzsch, F. Steib, A. Waag, E. Peiner, Vertical silicon nanowire array-patterned microcantilever resonators for enhanced detection of cigarette smoke aerosols. Micro Nano 
Lett. 9(10), 676-679 (2014). https://doi.org/10.1049/mnl.2014. 0249

66. S. Keller, D. Haefliger, A. Boisen, Fabrication of thin SU-8 cantilevers: initial bending, release and time-stability. J. Micromech. Microeng. 20(4), 045024 (2010). https://doi.org/10. 1088/0960-1317/20/4/045024

67. V. Seena, A. Fernandes, P. Pant, S. Mukherji, V.R. Rao, Polymer nanocomposite nanomechanical cantilever sensors: material characterization, device development and application in explosive vapour detection. Nanotechnology 22(29), 295501 (2011). https://doi.org/10.1088/0957-4484/22/29/295501

68. A. Johansson, M. Calleja, P.A. Rasmussen, A. Boisen, SU-8 cantilever sensor system with integrated readout. Sens. Actuator A-Phys. 123-124, 111-115 (2005). https://doi.org/10.1016/j.sna. 2005.03.025

69. A. Boisen, T. Thundat, Design \& fabrication of cantilever array biosensors. Mater. Today 12, 32-38 (2009). https://doi.org/10. 1016/S1369-7021(09)70249-4

70. J.C. Doll, B.L. Pruitt, Piezoresistor Design and Applications (Springer, New York, 2013). https://doi.org/10.1007/978-14614-8517-9

71. N.A. Gilda, S. Nag, S. Patil, M.S. Baghini, D.K. Sharma, V.R. Rao, Current excitation method for $\Delta$ Delta $\mathrm{R}$ measurement in piezo-resistive sensors with a 0.3 -ppm resolution. IEEE Trans. Instrum. Meas. 61(3), 767-774 (2012). https://doi.org/10.1109/ TIM.2011.2172118

72. K.F. Anderson, The new current loop: an instrumentation and measurement circuit topology. IEEE Trans. Instrum. Meas. 46(5), 1061-1067 (1997). https://doi.org/10.1109/19.676711

73. Z. Wang, R. Yue, R. Zhang, L. Liu, Design and optimization of laminated piezoresistive microcantilever sensors. Sens. Actuator A-Phys. 120(2), 325-336 (2005). https://doi.org/10.1016/j.sna. 2004.12.006

74. J. Chaste, A. Eichler, J. Moser, G. Ceballos, R. Rurali, A. Bachtold, A nanomechanical mass sensor with yoctogram resolution. Nat. Nanotechnol. 7(5), 301-304 (2012). https://doi.org/ 10.1038/nnano.2012.42

75. J. Tamayo, A.D.L. Humphris, A.M. Malloy, M.J. Miles, Chemical sensors and biosensors in liquid environment based on microcantilevers with amplified quality factor. Ultramicroscopy 86(1), 167-173 (2001). https://doi.org/10.1016/S03043991(00)00082-6

76. G. Dubourg, I. Dufour, C. Pellet, C. Ayela, Optimization of the performances of SU-8 organic microcantilever resonators by tuning the viscoelastic properties of the polymer. Sens. Actuator B-Chem. 169, 320-326 (2012). https://doi.org/10.1016/j.snb. 2012.04.088

77. S. Schmid, P. Senn, C. Hierold, Electrostatically actuated nonconductive polymer microresonators in gaseous and aqueous environment. Sens. Actuator A-Phys. 145-146, 442-448 (2008). https://doi.org/10.1016/j.sna.2008.01.010

78. K.W. Wee, G.Y. Kang, J. Park, J.Y. Kang, D.S. Yoon, J.H. Park, T.S. Kim, Novel electrical detection of label-free disease marker proteins using piezoresistive self-sensing microcantilever. Biosens. Bioelectron. 20(10), 1932-1938 (2005). https://doi.org/10. 1016/j.bios.2004.09.023

79. D. Lee, S. Kim, N. Jung, T. Thundat, S. Jeon, Effect of gold patterning on the bending profile and frequency response of a microcantilever. J. Appl. Phys. 106(2), 024310 (2009). https:// doi.org/10.1063/1.3177326

80. J. Tamayo, D. Ramos, J. Mertens, M. Calleja, Effect of the adsorbate stiffness on the resonance response of microcantilever sensors. Appl. Phys. Lett. 89(22), 224104 (2006). https://doi.org/ 10.1063/1.2388925

81. D. Ramos, M.A. Hernandez, E.G. Santos, H.D. Tong, C.V. Rijn, M. Calleja, J. Tamayo, Arrays of dual nanomechanical resonators for selective biological detection. Anal. Chem. 81(6), 2274-2279 (2009). https://doi.org/10.1021/ac8024152

82. G.G. Stoney, The tension of metallic film deposited by electrolysis. Proc. R. Soc. A-Math. Phys. Eng. 82(553), 172-175 (1909). https://doi.org/10.1098/rspa.1909.0021

83. J.E. Sader, Surface stress induced deflections of cantilever plates with applications to the atomic force microscope: rectangular plates. J. Appl. Phys. 89(5), 2911-2921 (2001). https://doi.org/ 10.1063/1.1342018

84. M. Godin, C.V. Tabard, P. Grutter, P. Williams, Quantitative surface stress measurements using a microcantilever. Appl. Phys. Lett. 79(4), 551 (2001). https://doi.org/10.1063/1.1387262

85. J. Tamayo, J.J. Ruz, V. Pini, P. Kosaka, M. Calleja, Quantification of the surface stress in microcantilever biosensors: revisiting Stoney's equation. Nanotechnology 23(47), 475702 (2012). https://doi.org/10.1088/0957-4484/23/47/475702

86. J. Zang, F. Liu, Theory of bending of Si nanocantilevers induced by molecular adsorption: a modified Stoney formula for the calibration of nanomechanochemical sensors. Nanotechnology 18(40), 405501 (2007). https://doi.org/10.1088/0957-4484/18/ 40/405501

87. J. Thaysen, A.D. Yalcinkaya, P. Vettiger, A. Menon, J. Thaysen, Polymer-based stress sensor with integrated readout. J. Phys. D-Appl. Phys. 35(21), 2698-2703 (2002). https://doi.org/10. 1088/0022-3727/35/21/302

88. J. Fritz, M.K. Baller, H.P. Lang, H. Routhuizen, P. Vettiger, E. Meyer, H.J. Guntherodt, C. Gerber, J.K. Gimzewski, Translating biomolecular recognition into nanomechanics. Science 288(5464), 316-318 (2000). https://doi.org/10.1126/science. 288.5464.316

89. M.Z. Ansari, C. Cho, U. Gerald, Stepped piezoresistive microcantilever designs for biosensors. J. Phys. D-Appl. Phys. 45(21), 215401 (2012). https://doi.org/10.1088/0022-3727/45/21/ 215401

90. R. Bashir, A. Gupta, G.W. Neudeck, M. McElfresh, R. Gomez, On the design of piezoresistive silicon cantilevers with stress concentration regions for scanning probe microscopy applications. J. Micromech. Microeng. 10(4), 483-491 (2000). https:// doi.org/10.1088/0960-1317/10/4/301

91. K.A.A. Wahid, H.W. Lee, M.A. Shazni, I.A. Azid, Investigation on the effect of different design of SCR on the change of resistance in piezoresistive micro cantilever. Microsyst. Technol. 20(6), 1079-1083 (2014). https://doi.org/10.1007/s00542013-1784-1

92. M.Z. Ansari, C. Cho, W. Choi, M. Lee, S. Lee, J. Kim, Improving sensitivity of piezoresistive microcantilever biosensors using stress concentration region designs. J. Phys. D-Appl. Phys. 46(50), 505501 (2013). https://doi.org/10.1088/0022$3727 / 46 / 50 / 505501$

93. J.W. Gibbs, The scientific papers of J. Willard Gibbs, vol. 1 (Green and Company, Longmans, 1906), p. 55

94. G. Wu, H. Ji, K. Hansen, T. Thundat, R. Datar, R. Cote, M.F. Hagan, A.K. Chakraborty, A. Majumdar, Origin of nanomechanical cantilever motion generated from biomolecular interactions. Proc. Natl. Acad. Sci. USA 98(4), 1560-1564 (2001). https://doi.org/10.1073/pnas.98.4.1560

95. R. McKendry, J. Zhang, Y. Arntz, T. Strunz, M. Hegner et al., Multiple label-free biodetection and quantitative DNA-binding assays on a nanomechanical cantilever array. Proc. Natl. Acad. Sci. USA 99(15), 9783-9788 (2002). https://doi.org/10.1073/ pnas. 152330199

96. M. Watari, J. Galbraith, H.P. Lang, M. Sousa, M. Hegner, C. Gerber, M.A. Horton, R.A. McKendry, Investigating the molecular mechanisms of in-plane mechanochemistry on cantilever arrays. J. Am. Chem. Soc. 129(3), 601-609 (2007). https://doi.org/10.1021/ja065222x 
97. J.C. Stachowiak, M. Yue, K. Castelino, A. Chakraborty, A. Majumdar, Chemomechanics of surface stresses induced by DNA hybridization. Langmuir 22(1), 263-268 (2006). https:// doi.org/10.1021/la0521645

98. J. Mertens, C. Rogero, M. Calleja, D. Ramos, J.M.G. Angel, C. Briones, J. Tamayo, Label-free detection of DNA hybridization based on hydration-induced tension in nucleic acid films. Nat. Nanotechnol. 3(5), 301-307 (2008). https://doi.org/10.1038/ nnano.2008.91

99. M. Godin, T.C. Vincent, Y. Miyahara, T. Monga, P.J. Williams, L.Y. Beaulieu, R.B. Lennox, P. Grutter, Cantilever-based sensing: the origin of surface stress and optimization strategies. Nanotechnology 21(7), 075501 (2010). https://doi.org/10.1088/ 0957-4484/21/7/075501

100. T. Yang, X. Li, Y. Chen, D.W. Lee, G. Zuo, Adsorption induced surface-stress sensing signal originating from both vertical interface effects and intermolecular lateral interactions. Analyst 136(24), 5261-5269 (2011). https://doi.org/10.1039/c1an15695k

101. M. Joshi, R. Pinto, V.R. Rao, S. Mukherji, Silanization and antibody immobilization on SU-8. Appl. Surf. Sci. 253(6), 3127-3132 (2007). https://doi.org/10.1016/j.apsusc.2006.07.017

102. A. Deepu, V.V.R. Sai, S. Mukherji, Simple surface modification techniques for immobilization of biomolecules on SU-8. J. Mater. Sci.-Mater. Med. 20(1), 25-28 (2009). https://doi.org/ 10.1007/s10856-008-3471-9

103. S.L. Tao, C.P. Ketul, J.J. Norman, T.A. Desai, Surface modification of SU-8 for enhanced biofunctionality and nonfouling properties. Langmuir 24(6), 2631-2636 (2008). https://doi.org/ 10.1021/la703066z

104. N. Iranpoor, P. Salehi, Ceric ammonium nitrate: a mild and efficient reagent for conversion of epoxides to $\beta$-nitrato alcohols. Tetrahedron 51(3), 909-912 (1995). https://doi.org/10. 1016/0040-4020(94)00979-5

105. Y. Wang, J.H. Pai, H.H. Lai, C.E. Sims, M. Bachman, G.P. Li, N.L. Allbritton, Surface graft polymerization of SU-8 for bioMEMS applications. J. Micromech. Microeng. 17(7), 1371-1380 (2007). https://doi.org/10.1088/0960-1317/17/7/020

106. R. Marie, S. Schmid, A. Johansson, L. Ejsing, M. Nordström, D. Häfliger, C.B. Christensen, A. Boisen, M. Dufva, Immobilisation of DNA to polymerised SU-8 photoresist. Biosens. Bioelectron. 21(7), 1327-1332 (2006). https://doi.org/10.1016/j. bios.2005.03.004

107. A.A. Meyer-Plath, K. Schröder, B. Finke, A. Ohl, Current trends in biomaterial surface functionalization-nitrogen-containing plasma assisted processes with enhanced selectivity. Vacuum 71(3), 391-406 (2003). https://doi.org/10.1016/S0042207X(02)00766-2

108. Z. Gao, D.B. Henthorn, C.S. Kim, Surface modification of SU-8 by photografting of functional polymers for lab-on-a-chip applications, in IEEE Conference on Sensors (2007), pp. 121-123. https://doi.org/10.1109/ICSENS.2007.355733

109. M. Joshi, N. Kale, R. Lal, V.R. Rao, S. Mukherji, A novel dry method for surface modification of SU-8 for immobilization of biomolecules in bio-MEMS. Biosens. Bioelectron. 22(11), 2429-2435 (2007). https://doi.org/10.1016/j.bios.2006.08.045

110. G. Blagoi, S. Keller, A. Johansson, A. Boisen, M. Dufva, Functionalization of SU-8 photoresist surfaces with IgG proteins. Appl. Surf. Sci. 255(5), 2896-2902 (2008). https://doi.org/ 10.1016/j.apsusc.2008.08.089

111. C. Cao, S.W. Birtwell, J. Høgberg, A. Wolff, H. Morgan, D.D. Bang, Surface modification of photoresist SU8 for low autofluorescence and bioanalytical applications, in 15th International Conference on Miniaturized Systems for Chemistry and Life Sciences (Seattle, Washington, USA, 2011), pp. 1161-1163. (http://eprints.soton.ac.uk/id/eprint/356607
112. R. Raiteri, M. Grattarola, H.J. Butt, P. Skládal, P, Micromechanical cantilever-based biosensors. Sens. Actuator B-Chem. 79(2), 115-126 (2001). https://doi.org/10.1016/S09254005(01)00856-5

113. W. Ruan, Y. Li, Z. Tan, L. Liu, K. Jiang, Z. Wang, In situ synthesized carbon nanotube networks on a microcantilever for sensitive detection of explosive vapors. Sens. Actuator B-Chem. 176, 141-148 (2013). https://doi.org/10.1016/j.snb.2012.10.026

114. G. Binning, C. Quate, C. Gerber, Atomic force microscope. Phys. Rev. Lett. 56(9), 930-933 (1986). https://doi.org/10.1103/ PhysRevLett.56.930

115. T. Thundat, R.J. Warmack, D.P. Allison, L.A. Bottomley, A.J. Lourenco, T.L. Ferrell, Atomic force microscopy of deoxyribonucleic acid strands adsorbed on mica: the effect of humidity on apparent width and image contrast. J. Vac. Sci. Technol. A 10, 630-635 (1992). https://doi.org/10.1116/1.577700

116. T. Thundat, D.P. Allison, R.J. Warmack, T.L. Ferrell, Imaging isolated strands of DNA molecules by atomic force microscopy. Ultramicroscopy 42-44, 1101-1106 (1992). https://doi.org/10. 1016/0304-3991(92)90409-D

117. L.A. Bottomley, J.N. Haseltine, D.P. Allison, R.J. Warmack, T. Thundat et al., Scanning tunneling microscopy of DNA: the chemical modification of gold surfaces for immobilization of DNA. J. Vac. Sci. Technol. A 10, 591-595 (1992). https://doi. org/10.1116/1.577735

118. D.P. Allison, L.A. Bottomley, T. Thundat, G.M. Brown, R.P. Woychik, J.J. Schrick, K. Bruce Jacobson, R.J. Warmack, Immobilization of DNA for scanning probe microscopy. Proc. Natl. Acad. Sci. USA 89(21), 10129-10133 (1992). https://doi. org/10.1073/pnas.89.21.10129

119. T. Thundat, D.P. Allison, R.J. Warmack, M.J. Doktycz, K. Bruce Jacobson, G.M. Brown, Atomic force microscopy of single-and double-stranded deoxyribonucleic acid. J. Vac. Sci. Technol. A 11(4), 824-828 (1993). https://doi.org/10.1116/1. 578312

120. J.K. Gimzewski, Ch. Gerber, E. Meyer, R.R. Schlittler, Observation of a chemical reaction using a micromechanical sensor. Chem. Phys. Lett. 217(5-6), 589-594 (1994). https://doi.org/10. 1016/0009-2614(93)E1419-H

121. J.R. Barnes, R.J. Stephenson, C.N. Woodburn, S.J. O'shea, M.E. Welland, T. Rayment, J.K. Gimzewski, Ch. Gerber, A femtojoule calorimeter using micromechanical sensors. Rev. Sci. Instrum. 65(12), 3793-3798 (1994). https://doi.org/10.1063/1. 1144509

122. T. Thundat, R.J. Warmack, G.Y. Chen, D.P. Allison, Thermal and ambient-induced deflections of scanning force microscope cantilevers. Appl. Phys. Lett. 64(21), 2894-2896 (1994). https:// doi.org/10.1063/1.111407

123. T. Thundat, E.A. Wachter, S.L. Sharp, R.J. Warmack, Detection of mercury vapor using resonating microcantilevers. Appl. Phys. Lett. 66(13), 1695-1697 (1995). https://doi.org/10.1063/1. 113896

124. R. Raiteri, H.J. Butt, Measuring electrochemically induced surface stress with an atomic force microscope. J. Phys. Chem. 99(43), 15728-15732 (1995). https://doi.org/10.1021/ j100043a008

125. H.J. Butt, A sensitive method to measure changes in the surface stress of solids. J. Colloid Interface Sci. 180(1), 251-260 (1996). https://doi.org/10.1006/jcis.1996.0297

126. G. Binnig, C. Gerber, E. Stoll, T.R. Albrecht, C.F. Quate, Atomic resolution with atomic force microscope. Surf. Sci. 189-190, 1-6 (1987). https://doi.org/10.1016/S00396028(87)80407-7

127. G.Y. Chen, T. Thundat, E.A. Wachter, R.J. Warmack, Adsorption-induced surface stress and its effects on resonance 
frequency of microcantilevers. J. Appl. Phys. 77(8), 3618-3622 (1995). https://doi.org/10.1063/1.359562

128. M. Tortonese, H. Yamada, R.C. Barrett, C.F. Quate, Atomic force microscopy using a piezoresistive cantilever, in Solid-State Sensors and Actuators, Digest of Technical Papers, TRANSDUCERS'91 (1991), pp. 448-451. https://doi.org/10.1109/SEN SOR.1991.148908

129. S.J. Kim, T. Ono, M. Esashi, Capacitive resonant mass sensor with frequency demodulation detection based on resonant circuit. Appl. Phys. Lett. 88, 053116 (2006). https://doi.org/10. $1063 / 1.2171650$

130. J.H. Lee, K.S. Hwang, J. Park, K.H. Yoon, D.S. Yoon, T.S. Kim, Immunoassay of prostate-specific antigen (PSA) using resonant frequency shift of piezoelectric nanomechanical microcantilever. Biosens. Bioelectron. 20(10), 2157-2162 (2005). https:// doi.org/10.1016/j.bios.2004.09.024

131. D.V. Scheible, A. Erbe, R.H. Blick, Tunable coupled nanomechanical resonators for single-electron transport. New J. Phys. 4(1), 86 (2002). https://doi.org/10.1088/1367-2630/4/1/386

132. M. Nordström, D.A. Zauner, M. Calleja, J. Hübner, A. Boisen, Integrated optical readout for miniaturization of cantileverbased sensor system. Appl. Phys. Lett. 91(10), 103512 (2007). https://doi.org/10.1063/1.2779851

133. R. Berger, H.P. Lang, C. Gerber, J.K. Gimzewski, J.H. Fabian, L. Scandella, E. Meyer, H.J. Güntherodt, Micromechanical thermogravimetry. Chem. Phys. Lett. 294(4), 363-369 (1998). https://doi.org/10.1016/S0009-2614(98)00817-3

134. H. Jensenius, J. Thaysen, A.A. Rasmussen, L.H. Veje, O. Hansen, A. Boisen, A microcantilever-based alcohol vapor sensor-application and response model. Appl. Phys. Lett. 76(18), 2615-2617 (2000). https://doi.org/10.1063/1.126426

135. A. Boisen, J. Thaysen, H. Jensenius, O. Hansen, Environmental sensors based on micromachined cantilevers with integrated read-out. Ultramicroscopy 82(1), 11-16 (2000). https://doi.org/ 10.1016/S0304-3991(99)00148-5

136. A.G. Hansen, M.W. Mortensen, J.E.T. Andersen, J. Ulstrup, A. Kühle, J. Garnæs, A. Boisen, Stress formation during selfassembly of alkanethiols on differently pre-treated gold surfaces. Probe Microscopy 2(2), 139-149 (2001)

137. G. Villanueva, J.A. Plaza, J. Montserrat, F.P. Murano, J. Bausells, Crystalline silicon cantilevers for piezoresistive detection of biomolecular forces. Microelectron. Eng. 86(5-6), 1120-1123 (2008). https://doi.org/10.1016/j.mee.2008.01.082

138. J.C. Doll, S.J. Park, B.L. Pruitt, Design optimization of piezoresistive cantilevers for force sensing in air and water. J. Appl. Phys. 106(6), 064310 (2009). https://doi.org/10.1063/1. 3224965

139. S.J. Park, J.C. Doll, B.L. Pruitt, Piezoresistive cantilever performance-part I: analytical model for sensitivity. J. Microelectromech. Syst. 19(1), 137-148 (2010). https://doi.org/10. 1109/JMEMS.2009.2036581

140. S.J. Park, J.C. Doll, A. Rastegar, B.L. Pruitt, Piezoresistive cantilever performance-part II: optimization. J. Microelectromech. Syst. 19(1), 149-161 (2010). https://doi.org/10.1109/ JMEMS.2009.2036582

141. G. Tosolini, G. Villanueva, F.P. Murano, J. Bausells, Silicon microcantilevers with MOSFET detection. Microelectron. Eng. 87(5), 1245-1247 (2010). https://doi.org/10.1016/j.mee.2009. 11.125

142. B. Komati, J. Agnus, C. Clévy, P. Lutz, Prototyping of a highly performant and integrated piezoresistive force sensor for microscale applications. J. Micromech. Microeng. 24(3), 035018 (2014). https://doi.org/10.1088/0960-1317/24/3/035018

143. S.J. Hyun, H.S. Kim, Y.J. Kim, H.I. Jung, Mechanical detection of liposomes using piezoresistive cantilever. Sens. Actuator
B-Chem. 117(2), 415-419 (2006). https://doi.org/10.1016/j.snb. 2005.11.054

144. P.A. Rasmussen, J. Thaysen, O. Hansen, S.C. Eriksen, A. Boisen, Optimised cantilever biosensor with piezoresistive read-out. Ultramicroscopy 97(1), 371-376 (2003). https://doi.org/10. 1016/S0304-3991(03)00063-9

145. A. Venkatasubramanian, J.H. Lee, V. Stavila, A. Robinson, M.D. Allendorf, P.J. Hesketh, MOF@ MEMS: design optimization for high sensitivity chemical detection. Sens. Actuator B-Chem. 168, 256-262 (2012). https://doi.org/10.1016/j.snb. 2012.04.019

146. C.P. Cheney, B. Srijanto, D.L. Hedden, A. Gehl, T.L. Ferrell, J. Schultz, E.A. Engleman, W.J. McBride, S. O'Connor, In vivo wireless ethanol vapor detection in the Wistar rat. Sens. Actuator B-Chem. 138(1), 264-269 (2009). https://doi.org/10.1016/j. snb.2009.01.052

147. M.Z. Ansari, C. Cho, A conduction-convection model for selfheating in piezoresistive microcantilever biosensors. Sens. Actuator A-Phys. 175, 19-27 (2012). https://doi.org/10.1016/j. sna.2011.12.014

148. G. Zuo, X. Li, P. Li, T. Yang, Y. Wang, Z. Cheng, S. Feng, Detection of trace organophosphorus vapor with a self-assembled bilayer functionalized $\mathrm{SiO}_{2}$ microcantilever piezoresistive sensor. Anal. Chim. Acta 580(2), 123-127 (2006). https://doi. org/10.1016/j.aca.2006.07.071

149. S.M. Yang, T.I. Yin, Design and analysis of piezoresistive microcantilever for surface stress measurement in biochemical sensor. Sens. Actuator B-Chem. 120(2), 736-744 (2007). https:// doi.org/10.1016/j.snb.2006.03.053

150. S.M. Yang, C. Chang, T.I. Yin, P.L. Kuo, DNA hybridization measurement by self-sensing piezoresistive microcantilevers in CMOS biosensor. Sens. Actuator B-Chem. 130(2), 674-681 (2008). https://doi.org/10.1016/j.snb.2007.10.072

151. C.W. Huang, H.T. Hsueh, Y.J. Huang, H.H. Liao, H.H. Tsai, Y.Z. Juang, T.H. Lin, S.S. Lu, C.T. Lin, A fully integrated wireless CMOS microcantilever lab chip for detection of DNA from Hepatitis B virus (HBV). Sens. Actuator B-Chem. 181, 867-873 (2013). https://doi.org/10.1016/j.snb.2013.02.061

152. Y. Chen, P. Xu, M. Liu, X. Li, Bio/chemical detection in liquid with self-sensing Pr-Oxi-Lever (piezo-resistive $\mathrm{SiO}_{2}$ cantilever) sensors. Microelectron. Eng. 87(12), 2468-2474 (2010). https:// doi.org/10.1016/j.mee.2010.05.001

153. M.Z. Ansari, C. Cho, On self-heating in piezoresistive microcantilevers with short piezoresistor. J. Phys. D-Appl. Phys. 44(28), 285402 (2011). https://doi.org/10.1088/0022-3727/44/ 28/285402

154. R. Pechmann, J.M. Kohler, W. Fritzsche, A. Schaper, T.M. Jovin, The Novolever: a new cantilever for scanning force microscopy microfabricated from polymeric materials. Rev. Sci. Instrum. 65(12), 3702-3706 (1994). https://doi.org/10.1063/1. 1144495

155. T.J. Yao, X. Yang, Y.C. Tai, Br F3 dry release technology for large freestanding parylene microstructures and electrostatic actuators. Sens. Actuator A-Phys. 97-98, 771-775 (2002). https://doi.org/10.1016/S0924-4247(02)00019-5

156. A.W. McFarland, J.S. Colton, Chemical sensing with micromolded plastic microcantilevers. J. Microelectromech. Syst. 14(6), 1375-1385 (2005). https://doi.org/10.1109/JMEMS.2005. 851853

157. L.P. Lee, S.A. Berger, D. Liepmann, B.L. Pruitt, High aspect ratio polymer microstructures and cantilevers for bioMEMS using low energy ion beam and photolithography. Sens. Actuator A-Phys. 71(1), 144-149 (1998). https://doi.org/10.1016/ S0924-4247(98)00177-0 
158. M. Calleja, J. Tamayo, M. Nordstrom, A. Boisen, Low-noise polymeric nanomechanical biosensors. Appl. Phys. Lett. 88(11), 113901 (2006). https://doi.org/10.1063/1.2187437

159. X.R. Zhang, X. Xu, Development of a biosensor based on laserfabricated polymer microcantilevers. Appl. Phys. Lett. 85(12), 2423-2425 (2004). https://doi.org/10.1063/1.1791731

160. A. Gaitas, Y.B. Gianchandani, An experimental study of the contact mode AFM scanning capability of polyimide cantilever probes. Ultramicroscopy 106(8), 874-880 (2006). https://doi. org/10.1016/j.ultramic.2005.12.021

161. A. Greve, S. Keller, A.L. Vig, A. Kristensen, D. Larsson et al., Thermoplastic microcantilevers fabricated by nanoimprint lithography. J. Micromech. Microeng. 20(1), 015009 (2010). https://doi.org/10.1088/0960-1317/20/1/015009

162. A.W. McFarland, M.A. Poggi, L.A. Bottomley, J.S. Colton, Injection moulding of high aspect ratio micron-scale thickness polymeric microcantilevers. Nanotechnology 15(11), 1628-1632 (2004). https://doi.org/10.1088/0957-4484/15/11/ 044

163. G. Firpo, E. Angeli, L. Repetto, U. Valbusa, Permeability thickness dependence of polydimethylsiloxane (PDMS) membranes. J. Membr. Sci. 481, 1-8 (2015). https://doi.org/10.1016/ j.memsci.2014.12.043

164. R. Zhu, T. Hoshi, Y. Chishima, Y. Muroga, T. Hagiwara, S. Yano, T. Sawaguchi, Microstructure and mechanical properties of polypropylene/poly (methyl methacrylate) nanocomposite prepared using supercritical carbon dioxide. Macromolecules 44(15), 6103-6112 (2011). https://doi.org/10.1021/ma2001965

165. P.J. Chen, D.C. Rodger, M.S. Humayun, Y.C. Tai, Floating-disk parylene microvalves for self-pressure-regulating flow controls. J. Microelectromech. Syst. 17(6), 1352-1361 (2008). https://doi. org/10.1109/JMEMS.2008.2004947

166. Y.S. Suzuki, Y.C. Tai, Micromachined high-aspect-ratio parylene spring and its application to low-frequency accelerometers. J. Microelectromech. Syst. 15(5), 1364-1370 (2006). https://doi.org/10.1109/JMEMS.2006.879706

167. J. Xie, J. Shih, Q. Lin, B. Yang, Y.C. Tai, Surface micromachined electrostatically actuated micro peristaltic pump. Lab Chip 4(5), 495-501 (2004). https://doi.org/10.1039/b403906h

168. A.A. Gómez, E. Tomas, Air-coupled piezoelectric transducers with active polypropylene foam matching layers. Sensors 13(5), 5996-6013 (2013). https://doi.org/10.3390/s130505996

169. J. Hillenbrand, G.M. Sessler, DC-Biased piezoelectret film transducers for airborne ultrasound. Ferroelectrics 472(1), 77-89 (2014). https://doi.org/10.1080/00150193.2014.964598

170. C.E. Garner, S.B. Gabriel, Y.S. Kuo, Directed ion beam sputter etching of polytetrafluoroethylene (Teflon) using an argon ion source. Thin Solid Films 95(4), 351-362 (1982). https://doi.org/ 10.1016/0040-6090(82)90041-4

171. E. Sahlin, A.T. Beisler, S.J. Woltman, S.G. Weber, Fabrication of microchannel structures in fluorinated ethylene propylene. Anal. Chem. 74(17), 4566-4569 (2002). https://doi.org/10.1021/ ac025622c

172. K.Y. Kwon, X. Bi, W. Li, Droplet backside exposure for making slanted SU-8 microneedles, in 35th Annual International Conference of the IEEE Engineering in Medicine and Biology Society (EMBC) (2013), pp. 767-770 https://doi.org/10.1109/ EMBC.2013.6609613

173. P.C. Wang, S.J. Paik, S. Chen, S. Rajaraman, S.H. Kim, M.G. Allen, Fabrication and characterization of polymer hollow microneedle array using UV lithography into micromolds. J. Microelectromech. Syst. 22(5), 1041-1053 (2013). https://doi. org/10.1109/JMEMS.2013.2262587

174. M.W. Royal, N.M. Jokerst, R.B. Fair, Droplet-based sensing: optical microresonator sensors embedded in digital electrowetting microfluidics systems. IEEE Sens. J. 13(12), 4733-4742 (2013). https://doi.org/10.1109/JSEN.2013.2273828

175. M. Hopcroft, T. Kramer, G. Kim, K. Takashima, Y. Higo, D. Moore, J. Brugger, Micromechanical testing of SU-8 cantilevers. Fatigue Fract. Eng. Mater. Struct. 28(8), 735-742 (2005). https://doi.org/10.1111/j.1460-2695.2005.00873.x

176. P. Liu, L. Liu, K. Jiang, S. Fan, Carbon- nanotube-film microheater on a polyethylene terephthalate substrate and its application in thermochromic displays. Small 7(6), 732-736 (2011). https://doi.org/10.1002/smll.201001662

177. J. Kim, X. Xu, Excimer laser fabrication of polymer microfluidic devices. J. Laser Appl. 15(4), 255-260 (2003). https://doi. org/10.2351/1.1585085

178. R. Kilaru, Z.Ç. Butler, D.P. Butler, I.E. Gönenli, NiCr MEMS tactile sensors embedded in polyimide toward smart skin. J. Microelectromech. Syst. 22(2), 349-355 (2013). https://doi. org/10.1109/JMEMS.2012.2222867

179. J. Engel, J. Chen, C. Liu, Development of polyimide flexible tactile sensor skin. J. Micromech. Microeng. 13(3), 359-366 (2003). https://doi.org/10.1088/0960-1317/13/3/302

180. K.S. Choi, D.S. Kim, H.J. Yang, M.S. Ryu, S.P. Chang, A highly sensitive humidity sensor with a novel hole array structure using a polyimide sensing layer. RSC Adv. 4(61), 32075-32080 (2014). https://doi.org/10.1039/C4RA02692F

181. S. Metz, A. Bertsch, D. Bertrand, P. Renaud, Flexible polyimide probes with microelectrodes and embedded microfluidic channels for simultaneous drug delivery and multi-channel monitoring of bioelectric activity. Biosens. Bioelectron. 19(10), 1309-1318 (2004). https://doi.org/10.1016/j.bios.2003.11.021

182. M. Dan, Johansen, Investigation of Topas ${ }^{\circledR}$ for Use in Optical Components (Master's thesis, Technical University of Denmark, DTU, Denmark, 2005)

183. R.K. Jena, C.Y. Yue, Cyclic olefin copolymer based microfluidic devices for biochip applications: ultraviolet surface grafting using 2-methacryloyloxyethyl phosphorylcholine. Biomicrofluidics 6(1), 012822 (2012). https://doi.org/10.1063/1.3682098

184. N. Klejwa, R.G. Hennessy, J.W. Chen, R.T. Howe, A reel-toreel compatible printed accelerometer, in 16th International Solid-State Sensors, Actuators and Microsystems Conference (2011), pp. 699-702. https://doi.org/10.1109/TRANSDUCERS. 2011.5969203

185. T. Thorsen, S.J. Maerkl, S.R. Quake, Microfluidic large-scale integration. Science 298(5593), 580-584 (2002). https://doi.org/ 10.1126/science. 1076996

186. M. Khoo, C. Liu, Micro magnetic silicone elastomer membrane actuator. Sens. Actuator A-Phys. 89(3), 259-266 (2001). https:// doi.org/10.1016/S0924-4247(00)00559-8

187. K. Hosokawa, K. Hanada, R. Maeda, A polydimethylsiloxane (PDMS) deformable diffraction grating for monitoring of local pressure in microfluidic devices. J. Micromech. Microeng. 12(1), 1-6 (2001). https://doi.org/10.1088/0960-1317/12/1/301

188. N. Sundararajan, M.S. Pio, L.P. Lee, A.A. Berlin, Three-dimensional hydrodynamic focusing in polydimethylsiloxane (PDMS) microchannels. J. Microelectromech. Syst. 13(4), 559-567 (2004). https://doi.org/10.1109/JMEMS.2004.832196

189. G.B. Lee, S.H. Chen, G.R. Huang, W.C. Sung, Y.H. Lin, Microfabricated plastic chips by hot embossing methods and their applications for DNA separation and detection. Sens. Actuator B-Chem. 75(1), 142-148 (2001). https://doi.org/10. 1016/S0925-4005(00)00745-0

190. H. Becker, U. Heim, Hot embossing as a method for the fabrication of polymer high aspect ratio structures. Sens. Actuator A-Phys. 83(1), 130-135 (2000). https://doi.org/10.1016/S09244247(00)00296-X

191. L.J. Heyderman, H. Schift, C. David, J. Gobrecht, T. Schweizer, Flow behaviour of thin polymer films used for hot embossing 
lithography. Microelectron. Eng. 54(3), 229-245 (2000). https:// doi.org/10.1016/S0167-9317(00)00414-7

192. V. Seena, A. Rajorya, P. Pant, S. Mukherji, V.R. Rao, Polymer microcantilever biochemical sensors with integrated polymer composites for electrical detection. Solid State Sci. 11(9), 1606-1611 (2009). https://doi.org/10.1016/j.solidstatesciences. 2009.06.009

193. R. Mathew, A.R. Sankar, Design of a triangular platform piezoresistive affinity microcantilever sensor for biochemical sensing applications. J. Phys. D-Appl. Phys. 48(20), 205402 (2015). https://doi.org/10.1088/0022-3727/48/20/205402

194. M. Joshi, P.S. Gandhi, R. Lal, V.R. Rao, S. Mukherji, Modelling, simulation and design guidelines for piezoresistive affinity cantilevers. J. Microelectromech. Syst. 20(3), 774-784 (2011). https://doi.org/10.1109/JMEMS.2011.2140353

195. P. Ray, S. Pandey, V.R. Rao, Development of graphene nanoplatelet embedded polymer microcantilever for vapour phase explosive detection applications. J. Appl. Phys. 116(12), 124902 (2014). https://doi.org/10.1063/1.4896255

196. J.D. Adams, B.W. Erickson, J. Grossenbacher, J. Brugger, A. Nievergelt, G.E. Fantner, Harnessing the damping properties of materials for high-speed atomic force microscopy. Nat. Nanotechnol. 11(2), 147-151 (2016). https://doi.org/10.1038/nnano. 2015.254

197. N. Mishra, B. Krishna, R. Singh, K. Das, Evaluation of effective elastic, piezoelectric, and dielectric properties of SU8/ZnO nanocomposite for vertically integrated nanogenerators using finite element method. J. Nanomater. 2017, 1924651 (2017). https://doi.org/10.1155/2017/1924651

198. M. Vinchurkar, A. Joshi, V.R. Rao, Carbon black nanocomposite piezoresistive microcantilevers with reduced percolation threshold, in 2015 IEEE International Conference on Electron Devices and Solid-State Circuits (EDSSC) (2015), pp. 689-692. https://doi.org/10.1109/EDSSC.2015.7285210

199. Y.C. Lim, A.Z. Kouzani, A. Kaynak, X.J. Dai, G. Littlefair, W. Duan, A protocol for improving fabrication yield of thin SU-8 microcantilevers for use in an aptasensor. Microsyst. Technol. 21(2), 371-380 (2015). https://doi.org/10.1007/s00542-0132019-1

200. Z. Mao, K. Yoshida, J.W. Kim, Study on the fabrication of a SU-8 cantilever vertically-allocated in a closed fluidic microchannel. Microsyst. Technol. 1-11 (2017). https://doi.org/ 10.1007/s00542-017-3611-6

201. C.D. Gerardo, E. Cretu, R. Rohling, Fabrication of circuits on flexible substrates using conductive SU-8 for sensing applications. Sensors 17(6), 1420 (2017). https://doi.org/10.3390/ s17061420

202. C. Ge, E. Cretu, MEMS transducers low-cost fabrication using SU-8 in a sacrificial layer-free process. J. Micromech. Microeng. 27(4), 045002 (2017). https://doi.org/10.1088/1361-6439/aa5dfb

203. T.R. Naik, S. Pandey, V. Palaparthy, R. Shelar, V.R. Rao, M. Ravikanth, Vapor-phase self-assembled monolayer on SU-8 cantilever for explosive sensing, in Nanoelectronics Conference (INEC) (2016), pp. 1-2. https://doi.org/10.1109/INEC.2016. 7589293

204. M. Bisen, M.Z. Ansari, Phenomenological modelling sensitivity of SU8/CB nanocomposite conducting polymer microcantilever biosensor. Mater. Today 4(9), 10395-10399 (2017). https://doi. org/10.1016/j.matpr.2017.06.387

205. G. Sapra, P. Sharma, Design and analysis of MEMS MWCNT/ epoxy strain sensor using COMSOL. Pramana-J. Phys. 89(1), 10 (2017). https://doi.org/10.1007/s12043-017-1398-8

206. K.G. Girija, I. Tushir, R.K. Vatsa, A. Topkar, Design, simulation and fabrication of piezoresistive microcantilevers using standard multi user MEMS process. ISSS J. Micro Smart Syst. 6(1), 83-89 (2017). https://doi.org/10.1007/s41683-017-0008-9
207. G. Sapra, M. Sharma, P. Sharma, S. Prasad, Design of MEMS based MWCNT/epoxy strain sensor using ANSYS, in 2nd International Conference on Recent Advances in Engineering \& Computational Sciences (RAECS) (2015), pp.1-3. https://doi. org/10.1109/RAECS.2015.7453383

208. A. Toor, H. So, A.P. Pisano, Dielectric properties of ligandmodified gold nanoparticle/SU-8 photopolymer based nanocomposites. Appl. Surf. Sci. 414, 373-379 (2017). https:// doi.org/10.1016/j.apsusc.2017.04.096

209. N. Tiwary, M. Vinchurkar, M. Patel, R. Nathawat, S. Pandey, V.R. Rao, Fabrication, characterization and application of $\mathrm{ZnO}$ nanostructure-based micro-preconcentrator for TNT sensing. J. Microelectromech. Syst. 25(5), 968-975 (2016). https://doi. org/10.1109/JMEMS.2016.2600631

210. S. Nayak, S.K. Behura, B.P. Singh, S. Bhattacharjee, Flexible polymer-multiwall carbon nanotubes composite developed by in situ polymerization technique. Polym. Compos. 37(9), 2860-2870 (2016). https://doi.org/10.1002/pc.23483

211. L.H. Tam, C.L. Chow, D. Lau, Moisture effect on interfacial integrity of epoxy-bonded system: a hierarchical approach. Nanotechnology 29(2), 024001 (2017). https://doi.org/10.1088/ 1361-6528/aa9537

212. N. Maheshwari, G. Chatterjee, M. Vinchurkar, G. Gupta, H. Kshirsagar, K.L. Narsimhan, V.R. Rao, Parylene-C encapsulation for polymeric cantilever stability, in Symposium on Design, Test, Integration and Packaging of MEMS/MOEMS (DTIP) (2015), pp.1-5. https://doi.org/10.1109/DTIP.2015.7161032

213. R. Mathew, A.R. Sankar, In-silico modeling and investigation of self-heating effects in composite nano cantilever biosensors with integrated piezoresistors. AIP Adv. 7, 035108 (2017). https:// doi.org/10.1063/1.4977827

214. R. Mathew, A.R. Sankar, Piezoresistive composite silicon dioxide nanocantilever surface stress sensor: design and optimization. J. Nanosci. Nanotechnol. 18(5), 3387-3397 (2018). https://doi.org/10.1166/jnn.2018.14642

215. R. Feng, R. Farris, Influence of processing conditions on the thermal and mechanical properties of SU- 8 negative photoresist coating. J. Micromech. Microeng. 13(1), 80-88 (2003). https:// doi.org/10.1088/0960-1317/13/1/312

216. J.A.V. Kan, P.G. Shao, K. Ansari, A.A. Bettiol, T. Osipowicz, F. Watt, Proton beam writing: a tool for high-aspect ratio mask production. Microsyst. Technol. 13(5-6), 431-434 (2007). https://doi.org/10.1007/s00542-006-0192-1

217. S. Keller, Fabrication of an Autonomous Surface Stress Sensor with the Polymer SU-8 (Ph. D. thesis, 2008)

218. M. Lillemose, Piezoresistive Polymer Composites for Cantilever Readout (Ph. D. thesis, 2008). http://orbit.dtu.dk/files/5253544/ Lillemose.pdf

219. N.T. Nguyen, T.Q. Truong, A fully polymeric micropump with piezoelectric actuator. Sens. Actuator B-Chem. 97(1), 137-143 (2004). https://doi.org/10.1016/S0925-4005(03)00521-5

220. V. Seidemann, S. Bütefisch, S. Büttgenbach, Fabrication and investigation of in-plane compliant SU8 structures for MEMS and their application to micro valves and micro grippers. Sens. Actuator A-Phys. 97, 457-461 (2002). https://doi.org/10.1016/ S0924-4247(01)00829-9

221. H. Lorenz, M. Laudon, P. Renaud, Mechanical characterization of a new high-aspect-ratio near UV-photoresist. Microelectron. Eng. 41, 371-374 (1998). https://doi.org/10.1016/S01679317(98)00086-0

222. H. Lorenz, M. Despont, P. Vettiger, P. Renaud, Fabrication of photoplastic high-aspect ratio microparts and micromolds using SU-8 UV resist. Microsyst. Technol. 4(3), 143-146 (1998). https://doi.org/10.1007/s005420050118 
223. R. Yang, S.A. Soper, W. Wang, Fabrication of out-of-plane refractive concave and convex microlens arrays. Proc. SPIE 5717, 134-141 (2005). https://doi.org/10.1117/12.601832

224. T. Sikanen, S. Tuomikoski, R.A. Ketola, R. Kostiainen, S. Franssila, T. Kotiaho, Characterization of SU-8 for electrokinetic microfluidic applications. Lab Chip 5(8), 888-896 (2005). https://doi.org/10.1039/b503016a

225. J.C. Doll, N. Harjee, N. Klejwa, R. Kwon, S.M. Coulthard, B. Petzold, M.B. Goodman, B.L. Pruitt, SU-8 force sensing pillar arrays for biological measurements. Lab Chip 9(10), 1449-1454 (2009). https://doi.org/10.1039/b818622g

226. A. Johansson, G. Blagoi, A. Boisen, Polymeric cantilever-based biosensors with integrated readout. Appl. Phys. Lett. 89, 173505 (2006). https://doi.org/10.1063/1.2364843

227. S.J. Patil, A. Adhikari, M.S. Baghini, V.R. Rao, An ultra-sensitive piezoresistive polymer nano-composite microcantilever platform for humidity and soil moisture detection. Sens. Actuator B-Chem. 203, 165-173 (2014). https://doi.org/10.1016/j. snb.2014.06.110

228. L. Gammelgaard, P.A. Rasmussen, M. Calleja, P. Vettigen, A. Boisen, Microfabricated photoplastic cantilever with integrated photoplastic/carbon based piezoresistive strain sensor. Appl. Phys. Lett. 88(11), 113508 (2006). https://doi.org/10.1063/1. 2186396

229. A. Johansson, O. Hansen, J. Hales, A. Boisen, Temperature effects in Au piezoresistors integrated in SU-8 cantilever chips. J. Micromech. Microeng. 16(12), 2564-2569 (2006). https://doi. org/10.1088/0960-1317/16/12/007

230. N.S. Kale, S. Nag, R. Pinto, V. Ramgopal Rao, Fabrication and characterization of polymeric microcantilever with encapsulated hotwire CVD polysilicon piezoresistor. J. Microelectromech. Syst. 18(1), 79-87 (2009). https://doi.org/10.1109/JMEMS. 2008.2008577

231. A. Shokuhfar, P. Heydari, M.R. Aliahmadi, M. Mohtashamifar, S. Ebrahimi-Nejad, M. Zahedinejad, Low-cost polymeric microcantilever sensor with titanium as piezoresistive material. Microelectron. Eng. 98, 338-342 (2012). https://doi.org/10. 1016/j.mee.2012.07.067

232. C.V.B. Reddy, M.A. Khderbad, S. Gandhi, M. Kandpal, S. Patil et al., Piezoresistive SU-8 cantilever with $\mathrm{Fe}(\mathrm{III})$ porphyrin coating for CO sensing. IEEE Trans. Nanotechnol. 11(4), 701-706 (2012). https://doi.org/10.1109/TNANO.2012.2190619

233. S.J. Patil, N. Duragkar, V.R. Rao, An ultra-sensitive piezoresistive polymer nano-composite microcantilever sensor electronic nose platform for explosive vapor detection. Sens. Actuator B-Chem. 192, 444-451 (2014). https://doi.org/10. 1016/j.snb.2013.10.111

234. M. Vinchurkar, A. Joshi, S. Pandey, V.R. Rao, Polymeric piezoresistive microcantilevers with reduced electrical variability. J. Microelectromech. Syst. 24(4), 1111-1116 (2015). https://doi.org/10.1109/JMEMS.2014.2384481

235. A. Adamia, F. Borghettia, N. Massaria, M. Decarlia, C. Collinia, D. Stoppaa, L. Lorenzellia, Design of a cantilever-based system for genomic applications. Procedia Eng. 25, 339-401 (2011). https://doi.org/10.1016/j.proeng.2011.12.099

236. K. Rajanna, S. Mohan, Studies on meandering path thin-film strain gauge. Sens. Actuators 15(3), 297-303 (1988). https://doi. org/10.1016/0250-6874(88)87018-5

237. S. Sampath, K.V. Ramanaiah, Behaviour of Bi-Sb alloy thin films as strain gauges. Thin Solid Films 137(2), 199-205 (1986). https://doi.org/10.1016/0040-6090(86)90020-9

238. J. Gouault, M. Hubin, G. Richon, B. Eudeline, 3.2 The electromechanical behaviour of a full component (dielectric and $\mathrm{Cu} /$ Ni constantan alloy) for thin film strain gauge deposited upon steel-substrate. Vacuum 27(4), 362-365 (1977). https://doi.org/ 10.1016/0042-207X(77)90024-0
239. A.G. Alonso, J. Garcia, E. Castano, I. Obieta, F.J. Gracia, Strain sensitivity and temperature influence on sputtered thin films for piezoresistive sensors. Sens. Actuator A-Phys. 37-38, 784-789 (1993). https://doi.org/10.1016/0924-4247(93)80132-Z

240. P. Kayser, J.C. Godefroy, L. Leca, High-temperature thin-film strain gauges. Sens. Actuator A-Phys. 37-38, 328-332 (1993). https://doi.org/10.1016/0924-4247(93)80055-L

241. P. Schmid, C. Zarfl, G. Balogh, U. Schmid, Gauge factor of titanium/platinum thin films up to $350 \&$ \# $\mathrm{xB}$; C. Procedia Eng. 87, 172-175 (2014). https://doi.org/10.1016/j.proeng.2014.11. 611

242. K. Rajanna, S. Mohan, Strain-sensitive property of vacuum evaporated manganese films. Thin Solid Films 172(1), 45-50 (1989). https://doi.org/10.1016/0040-6090(89)90116-8

243. H. Chiriac, M. Urse, F. Rusu, C. Hison, M. Neagu, Ni-Ag thin films as strain-sensitive materials for piezoresistive sensors. Sens. Actuator A-Phys. 76(1-3), 376-380 (1999). https://doi. org/10.1016/S0924-4247(99)00027-8

244. S.M. Mohanasundaram, R. Pratap, A. Ghosh, Tuning the sensitivity of a metal-based piezoresistive sensor using electromigration. J. Microelectromech. Syst. 21(6), 1276-1278 (2012). https://doi.org/10.1109/JMEMS.2012.2211579

245. J. Thaysen, A. Boisen, O. Hansen, S. Bouwstra, Atomic force microscopy probe with piezoresistive read-out and a highly symmetrical Wheatstone bridge arrangement. Sens. Actuator A-Phys. 83(1), 47-53 (2000). https://doi.org/10.1016/S09244247(00)00299-5

246. N.S. Kale, R.G. Rao, Design and fabrication issues in affinity cantilevers for bioMEMS applications. J. Microelectromech. Syst. 15(6), 1789-1794 (2006). https://doi.org/10.1109/JMEMS. 2006.886031

247. M. Bao, Analysis and Design Principles of MEMS Devices, $1 \mathrm{st}$ edn. (Elsevier, 2005). Chapter 6, p. 275

248. F.J. French, Polysilicon: a versatile material for microsystems. Sens. Actuator A-Phys. 99(1), 3-12 (2002). https://doi.org/10. 1016/S0924-4247(01)00876-7

249. Y. Zhou, Z. Wang, Q. Zhang, W. Ruan, L. Liu, A front-side released single crystalline silicon piezoresistive microcantilever sensor. IEEE Sens. J. 9(3), 246-254 (2009). https://doi.org/10. 1109/JSEN.2008.2012197

250. A. Katada, Y.F. Buys, Y. Tominaga, S. Asai, M. Sumita, Resistivity control in the semiconductive region for carbonblack-filled polymer composites. Colliod Polym. Sci. 283(4), 367-374 (2005). https://doi.org/10.1007/s00396-004-1149-5

251. S. Jiguet, A. Bertsch, H. Hofmann, P. Renaud, SU-8 silver photosensitive nanocomposite. Adv. Eng. Mater. 6(9), 719-724 (2004). https://doi.org/10.1002/adem.200400068

252. D.W. Marshall, Copper-based conductive polymers: a new concept in conductive resins. J. Adhes. 74(1-4), 301-315 (2000). https://doi.org/10.1080/00218460008034533

253. N. Zhang, J. Xie, M. Guers, V.K. Varadan, Chemical bonding multiwalled carbon nanotube to SU-8 via ultrasonic irradiation. Smart Mater. Struct. 12(2), 260-263 (2003). https://doi.org/10. 1088/0964-1726/12/2/314

254. H.C. Chiamori, J.W. Brown, E.V. Adhiprakasha, E.T. Hantsoo, J.B. Straalsund, N.A. Melosh, B.L. Pruitt, Suspension of nanoparticles in SU-8: processing and characterization of nanocomposite polymers. Microelectron. J. 39(2), 228-236 (2008). https://doi.org/10.1016/j.mejo.2007.05.012

255. E.K. Sichel, J.I. Gittleman, P. Sheng, Electrical properties of carbon-polymer composites. J. Electron. Mater. 11(4), 699-747 (1982). https://doi.org/10.1007/BF02672392

256. K.H. Muller, J. Herrmann, B. Raguse, G. Baxter, T. Reda, Percolation model for electron conduction in films of metal nanoparticles linked by organic molecules. Phys. Rev. B 66(7), 075417 (2002). https://doi.org/10.1103/PhysRevB.66.075417 
257. D. Toker, D. Azulay, N. Shimoni, I. Balberg, O. Millo, Tunneling and percolation in metal-insulator composite materials. Phys. Rev. B 68(4), 041403 (2003). https://doi.org/10.1103/ PhysRevB.68.041403

258. D. He, N.N. Ekere, Effect of particle size ratio on the conducting percolation threshold of granular conductive-insulating composites. J. Phys. D-Appl. Phys. 37(13), 1848-1852 (2004). https://doi.org/10.1088/0022-3727/37/13/019

259. I. Balberg, D. Azulay, D. Toker, O. Millo, Percolation and tunneling in composite materials. Int. J. Mod. Phys. B 18(15), 2091 (2004). https://doi.org/10.1142/S0217979204025336

260. J. Thaysen, Cantilever for Biochemical Sensing Integrated in a Microliquid Handling System (Ph. D. thesis, 2001). http://orbit. dtu.dk/files/4681389/Jacob_Thaysen.pdf

261. S. Keller, G. Blagoi, M. Lillemose, D. Haefliger, A. Boisen, Processing of thin SU-8 films. J. Micromech. Microeng. 18(12), 125020 (2008). https://doi.org/10.1088/0960-1317/18/12/ 125020

262. T.A. Anhoj, A.M. Jorgensen, D.A. Zauner, J. Hubner, Effect of soft bake temperature on the polymerization of SU-8 photoresist. J. Micromech. Microeng. 16(9), 1819-1824 (2006). https:// doi.org/10.1088/0960-1317/16/9/009

263. J. Zhang, K.L. Tan, G.D. Hong, L.J. Yang, H.Q. Gong, Polymerization optimization of SU-8 photoresist and its applications in microfluidic systems and MEMS. J. Micromech. Microeng. 11(1), 20-26 (2001). https://doi.org/10.1088/0960-1317/11/1/ 304

264. J. Zhang, M.B. Chan-Park, S.R. Conner, Effect of exposure dose on the replication fidelity and profile of very high aspect ratio microchannels in SU-8. Lab Chip 4(6), 646-653 (2004). https:// doi.org/10.1039/b403304c

265. M. Lillemose, M. Spieser, N.O. Christiansen, A. Christensen, A. Boisen, Intrinsically conductive polymer thin film piezoresistors. Microelectron. Eng. 85(5), 969-971 (2008). https://doi.org/10.1016/j.mee.2007.12.020

266. A.R. Sankar, S. Das, Experimental analysis of galvanic corrosion of a thin metal film in a multilayer stack for MEMS applications. Mater. Sci. Semicond. Process. 16(2), 449-453 (2013). https://doi.org/10.1016/j.mssp.2012.08.003

267. D. Haefliger, M. Nordstrom, P.A. Rasmussen, A. Boisen, Dry release of all-polymer structures. Microelectron. Eng. 78-79, 88-92 (2005). https://doi.org/10.1016/j.mee.2004.12.013

268. D. Haefliger, O. Hansen, A. Boisen, Self-positioning of polymer membranes driven by thermomechanically induced plastic deformation. Adv. Mater. 18(2), 238-241 (2006). https://doi. org/10.1002/adma.200501687

269. R.E.I. Schropp, Frontiers in HWCVD. Thin Solid Film 517(12), 3415-3419 (2009). https://doi.org/10.1016/j.tsf.2009.01.038

270. K. Wouters, R. Puers, Diffusing and swelling in SU-8: insight in material properties and processing. J. Micromech. Microeng. 20(9), 095013 (2010). https://doi.org/10.1088/0960-1317/20/9/095013

271. C. Liu, Y. Liu, M. Sokuler, D. Fell, S. Keller, A. Boisen, H. Butt, G.K. Auernhammer, E. Bonaccurso, Diffusion of water into SU-8 microcantilevers. Phys. Chem. Chem. Phys. 12(35), 10577-10583 (2010). https://doi.org/10.1039/c002478c

272. M. Tenje, S. Keller, S. Dohn, Z.J. Davis, A. Boisen, Drift study of SU8 cantilevers in liquid and gaseous environments. Ultramicroscopy 110(6), 596-598 (2010). https://doi.org/10. 1016/j.ultramic.2010.02.017

273. S. Schmid, S. Kuhne, C. Hierold, Influence of air humidity on polymeric microresonators. J. Micromech. Microeng. 19(6), 065018 (2009). https://doi.org/10.1088/0960-1317/19/6/065018

274. C. Martin, A. Llobera, G. Villanueva, A. Voigt, G. Gruetzner, J. Brugger, F. Perez-Murano, Stress and aging minimization in photoplastic AFM probes. Microelectron. Eng. 86(4), 1226-1229 (2009). https://doi.org/10.1016/j.mee.2008.12.033 